\title{
WestVirginiaUniversity
}

THE RESEARCH REPOSITORY @ WVU

Graduate Theses, Dissertations, and Problem Reports

2005

\section{Performance evaluation of dryer units used in diesel emission measurement systems}

\author{
Muhammad Nadeem Laeeq \\ West Virginia University
}

Follow this and additional works at: https://researchrepository.wvu.edu/etd

\section{Recommended Citation}

Laeeq, Muhammad Nadeem, "Performance evaluation of dryer units used in diesel emission measurement systems" (2005). Graduate Theses, Dissertations, and Problem Reports. 1634. https://researchrepository.wvu.edu/etd/1634

This Thesis is protected by copyright and/or related rights. It has been brought to you by the The Research Repository @ WVU with permission from the rights-holder(s). You are free to use this Thesis in any way that is permitted by the copyright and related rights legislation that applies to your use. For other uses you must obtain permission from the rights-holder(s) directly, unless additional rights are indicated by a Creative Commons license in the record and/ or on the work itself. This Thesis has been accepted for inclusion in WVU Graduate Theses, Dissertations, and Problem Reports collection by an authorized administrator of The Research Repository @ WVU. For more information, please contact researchrepository@mail.wvu.edu. 


\title{
Performance Evaluation of Dryer Units Used in Diesel Emission Measurement Systems
}

\author{
Muhammad Nadeem Laeeq
}

Thesis submitted to

The College of Engineering and Mineral Resources

at West Virginia University

in partial fulfillment of the requirements

for the degree of

Master of Science
in
Mechanical Engineering

Gregory Thompson, Ph.D.,Chair

Nigel N. Clark, Ph.D.

Mridul Gautam, Ph.D.

Department of Mechanical and Aerospace Engineering

\author{
Morgantown, West Virginia \\ 2005
}

Keywords: Diesel Emissions, Chiller, Dryer 


\section{Abstract \\ Performance Evaluation of Dryer Units Used in Diesel Emission Measurement Systems}

\section{Muhammad Nadeem Laeeq}

The gas dryer unit in an emission measurement system plays an important role in emission testing by removing the moisture out of the gas stream and thus reducing the dew point of the sample stream to a level which is required by the gaseous emission analyzers. Water vapor in the exhaust gas occupies considerable volume at high engine loads. In case of non-dispersive infrared (NDIR) and chemiluminescent analyzers, erroneous reporting of exhaust mass emissions could result in the presence of exhaust stream moisture due to interference effects. In addition to NDIR interference issues, an inaccurate determination of the volume displaced by water in the exhaust stream could report erroneous emission data. The current work evaluated the performance of six different types of chiller units employed in different emission measurement systems at West Virginia University. To estimate the performance of different chiller units, ambient air, dry zero air and humidified air were run through the chiller/dryer units. The pre and post chiller responses were recorded by measuring dew point temperature, dry bulb temperature and the relative humidity. Two types of hygrometers, an EdgeTech DewPrime II and Ohmic AMM 15, were utilized in the study. A performance comparison of the chiller/dryer units was accomplished by comparing the post chiller dew point, dry bulb and the relative humidity recorded for each chiller unit selected for this study. The results of this study show that all chiller units, except SEMTECH-D, when tested with dry zero air added some moisture to dry zero air, resulting in higher post chiller dew point temperatures than their pre chiller values. All chillers ran with humidified air resulted post chiller dew point temperatures ranging from 35 to $44{ }^{\circ} \mathrm{F}$, showing a close agreement to their designed specifications and requirements. 


\section{Acknowledgements}

First of all I thank to almighty God, the most Gracious and the most Merciful, who enabled me to achieve this milestone. Special tribute and thanks to my parents Sanjeeda Begum and Laeeq Ahmed, who granted me the strongest confidence and support to finish my research work. To my mother in law Tasleem Shahid, whose contributions were utmost important in convincing me to pursue for graduate studies in United States of America.

I pay my special gratitude and sincere thanks to my advisor and committee chair Dr. Gregory Thompson who provided me the chance to work for him and with him. I am obliged to him for his patience, technical guidance and moral support. His assistance has played a vital role in the accomplishment of this thesis work. He helped me whenever I needed his help throughout my academic career at West Virginia University. I also wish to thank Dr. Mridul Gautam and Dr. Nigel Clark for being my committee members and giving their precious time to review the draft of my thesis.

Many thanks to all of my friends who made my stay enjoyable at Morgantown. I would like to pay special thanks to Mr. and Mrs. Sohail Khan, Mr. and Mrs. Irfan Toor and Mr. and Mrs. Khalid Kamal for their guidance and moral support. Bundle of thanks to my friends, Faisal Chaudary, Sohail Chaudary, Tayyeb Anwar and Ali Bahu for their emotional support to finish this work.

Finally I wish to thank my wife, Uzma Nadeem for being a great wife in every aspect of my life. She provided me the emotional and moral support and boosted my confidence to finish my thesis work successfully. Love and thanks also goes to my new born son, Humayil Nadeem who has brought a new excitement and thrill to my life. 


\section{Table of Contents}

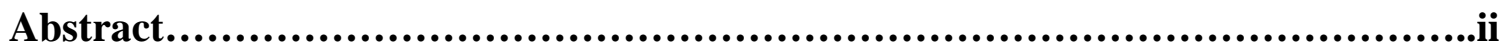

Acknowledgements...................................................................................ii

Table of Contents...................................................................................

List of Tables...........................................................................vi

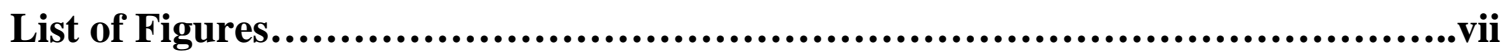

Nomenclature ...................................................................viii

1. Introduction \& Objective .......................................................

2. Review of Literature...............................................................

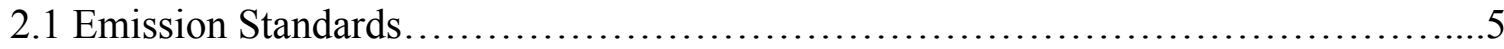

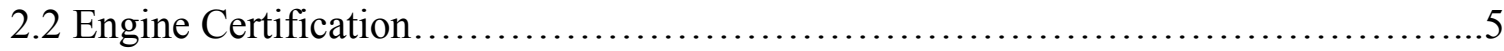

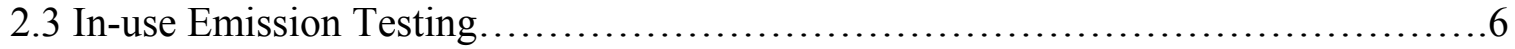

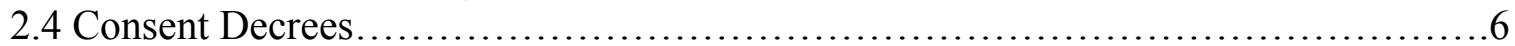

2.5 Need for Portable Emissions Measurement Systems...............................6

2.6 History of Portable and Mobile Emissions Measurement Systems..................... 7

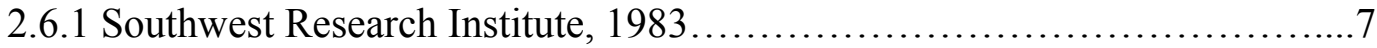

2.6.2 Michigan Technological University, $1992 \ldots \ldots \ldots \ldots \ldots \ldots \ldots \ldots \ldots \ldots \ldots \ldots$

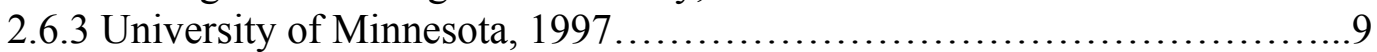

2.7 On-Board Measurement.......................................................... 9

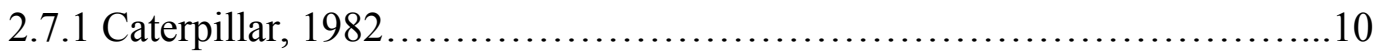

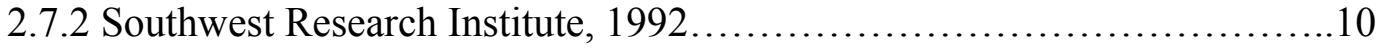

2.7.3 General Motors, 1993 ................................................. 10

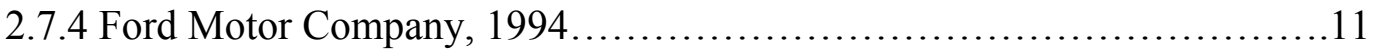

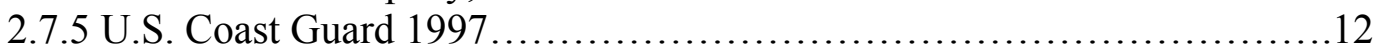

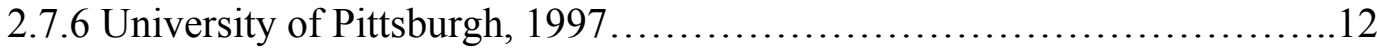

2.7.7 Flemish Institute for Technological Research, 1997 ....................13

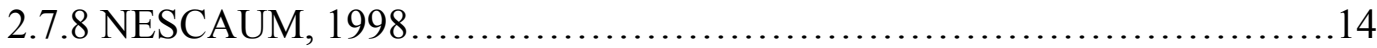

2.7.9 Ford Motor Company and WPI-Microprocessor Systems, Inc., 1999 _.......14

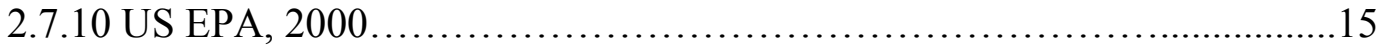

2.7.11 Honda R\&D and Nicolet Instrument Corp.2000 ........................15

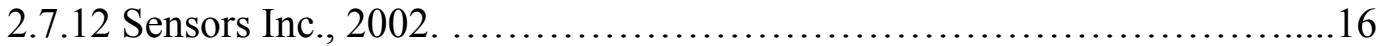

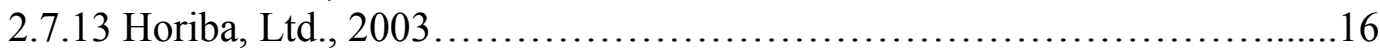

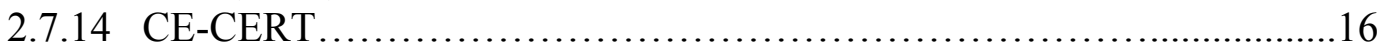

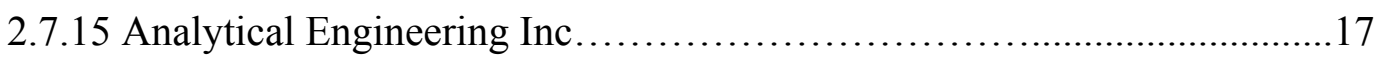

2.7.16 National Center For Environmental Research.......................... 17

3. Experimental Equipment............................................................18

3.1 Mobile Emission Measurement System Developed By West Virginia.................18

3.1.1 Exhaust Flow Measurement..............................................18

3.1.2 Emissions Sampling Box.............................................19

3.1.3 The Data Acquisition Components.....................................19

3.1.4 Engine Torque and Speed measurement...............................20

3.1.5 Ambient Temperature, Pressure and Humidity...........................20

3.2 Engine and Emissions Research Laboratory (EERC) ..............................21

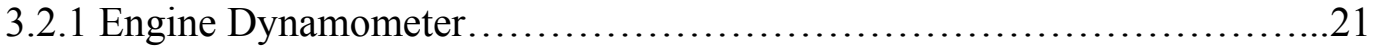

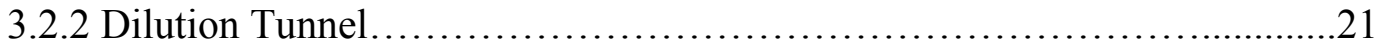




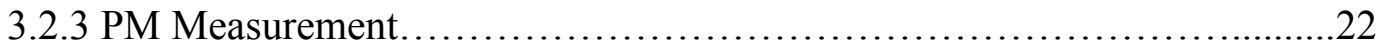

3.2.4 Air Flow and fuel Measurement.......................................23

3.2.5 Data Acquisition and Data Reduction..................................23

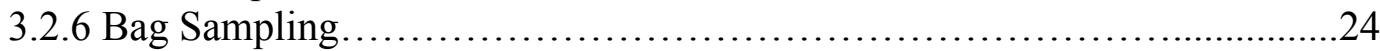

3.2.7 Gaseous Emission Analysis System...................................24

3.3 WVU Transportable Emissions Testing Laboratory .................................

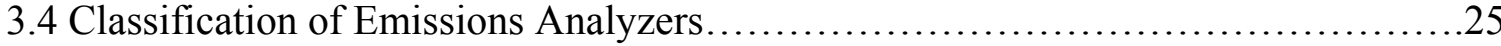

3.4.1 Garage-grade inspection and maintenance analyzers.....................26

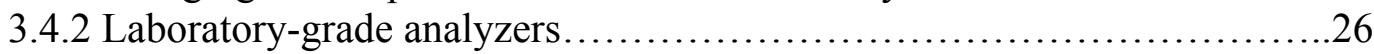

3.5 Principles of Gaseous Concentration Detector Operation..........................26

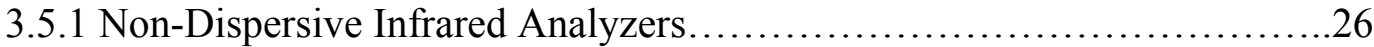

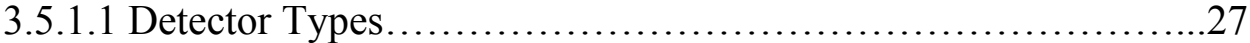

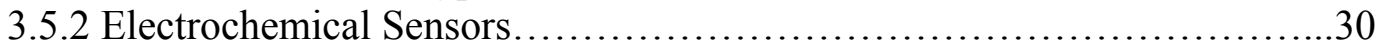

3.5.3 Electro catalytic Analyzers...............................................

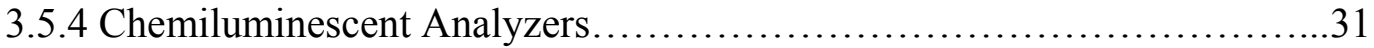

3.5.5 Heated Flame Ionization Detectors....................................32

3.5.6 Non-Dispersive Ultraviolet Photometers................................32

3.5.7 Fourier Transform Infrared Spectroscopy ..............................33

3.5.8 Miniature Gas Chromatographs.....................................33

4. Experimental Procedure \& Set Up. .................................................34

4.1 Types of Hygrometers used in the Experiment.....................................34

4.1.1 Edge Tech model 2002 dew prime, dew point hygrometer.................34

4.1.2 Automatic balance control (ABC) .....................................36

4.1.3 Ohmic, AMM-15, Portable dew-point meter............................37

4.2 Types of electric gas coolers used in the experiments......................40

4.2.1 Electric gas cooler ECP 1000/2000 .....................................40

4.2.2 Domnic Hunter CRD Refrigeration Dryer................................42

4.2.3 MEMS, Micro MEMS and, SEMTECH-D Chiller Units..................44

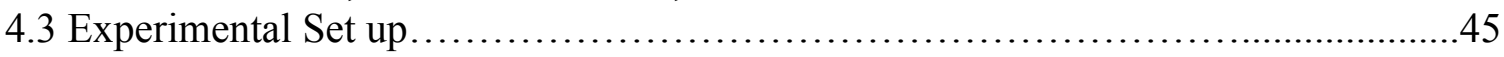

4.3.1 Test setup\#1 Instrument Calibration..................................45

4.3.2 Test setup\#2 Edge Tech Pre Chiller and Ohmic post chiller

(Domnic Hunter).............................................. .51

4.3.3 Test setup\#3\&4 Ambient Air, Dry zero air and Dry zero/bubbled air ran through chiller with Edge Tech Pre and Ohmic post chiller................57

4.3.4 Test setup\#5, 6, 7 and 8 Dry zero and Dry Zero/Bubbled air ran through chiller (ECP 1000/2000)............................................61

4.3.5 Test setup\# 9, 10.11 and 12 Dry zero and Dry zero/bubbled air ran through Mems and Micro Mems chiller units....................................65

4.3.6 Test setup\# 13 and 14 Dry zero and Dry zero/Bubbled air ran through SEMTECH-D chiller unit............................................... 70

5 Conclusions and Recommendations...........................................72

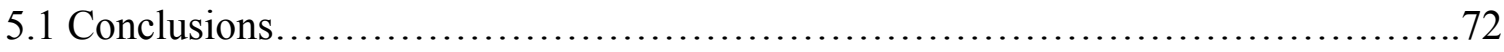

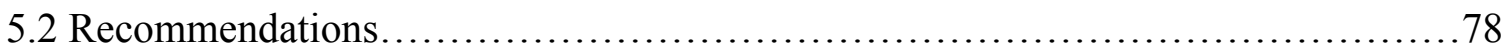

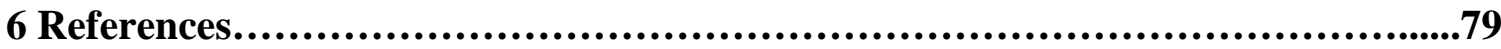




\section{List of Tables}

Table 1 EPA Emission Standard History for Heavy-Duty Diesel Engines ................4

Table 2 General Specifications of the EdgeTech DewPrime II hygrometer...............37

Table 3 Technical Data Ohmic AMM-15 Portable Dew Point meter......................39

Table 4 Technical Data ECP 1000/2000...........................................42

Table 5 Technical Specifications Domnic Hunter CRD5-100 Refrigeration Dryer.......44

Table 6 Comparison between EdgeTech DewPrime II \& Ohmic AMM-15..............47

Table 7 EdgeTech DewPrime II Pre Chiller and Ohmic AMM-15

Post Chiller (Domnic Hunter)...

Table 8 Test setup\#3 Ambient Air, Dry Zero air and Dry zero/Bubbled Air Ran

through Domnic Hunter (chiller) with Edge Tech Pre and Ohmic Post Chiller....60

Table 9 Test setup\#4 Ambient Air, Dry Zero Air and Dry Zero/Bubbled Air Ran through Domnic Hunter (Chiller) with Ohmic Pre and Edge Tech Pos Chiller....60

Table 10 Test setup\#5 Dry Zero Air Ran Through Gas Dryer ECP 1000................63

Table 11 Test setup\#6 Dry Zero/Bubbled Air Ran Through Gas Dryer ECP 1000......63

Table 12 Test setup\#7 Dry Zero Air Ran Through Gas Dryer ECP 2000..................64

Table 13 Test setup\#8 Dry Zero /Bubbled Air Ran Through Gas Dryer ECP 2000_......65

Table 14 Test setup\#9 Dry Zero Air Ran Through MEMS Chiller Unit..................68

Table 15 Test setup\#10 Dry Zero/Bubbled Air Ran Through MEMS Chiller Unit.......68

Table 16 Test setup\#11 Dry Zero Air Ran Through Micro MEMS Chiller Unit...........69

Table 17 Test setup\#12 Dry Zero/Bubbled Air Ran Through Micro MEMS

Chiller Unit............................................................69

Table 18 Test setup\#13 Dry Zero Air Ran Through SEMTECH-D Chiller Unit..........71

Table 19 Test setup\#14 Dry Zero/Bubbled Air Ran Through SEMTECH-D

Chiller Unit

Table 20 Pre and Post Dew Point, Dry Bulb and Relative Humidity Comparison with Dry zero air running through the chillers................................ 75

Table 21 Pre and Post Dew Point, Dry Bulb and Relative Humidity Comparison with Dry Zero/Bubbled Air Ran Through the Chillers........................76

Table 22 Dew Point Reduction for Dry Zero/ Bubbled Air Passing Through chiller.......77 


\section{List of Figures}

Figure 1 EdgeTech DewPrime II Dew point hygrometer............................36

Figure 2 Ohmic AMM-15, portable dew-point meter............................... 38

Figure 3 Electric gas cooler ECP 1000/2000..................................41

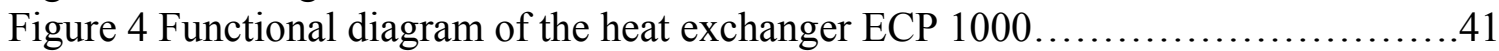

Figure 5 Domnic Hunter, CRD5-100 refrigeration dryer............................43

Figure 6 Test set up\#1 Instrument calibration.....................................46

Figure 7 Dew point comparisons between EdgeTech DewPrime II and Ohmic AMM-15 (Instrument calibration).............................48

Figure 8 Dew point comparisons between EdgeTech Dew Prime II and Ohmic AMM-15 (Instrument calibration)...............................49

Figure 9 Dew point Parity Plot between EdgeTech and Ohmic AMM-15..............50

Figure 10 Dry bulb temperature comparisons between EdgeTech DewPrime II and Ohmic AMM-15 (Instrument calibration) .............................51

Figure 11 Test set up \#2 EdgeTech DewPrime II Pre chiller and Ohmic post chiller (Domnic Hunter) ............................................53

Figure 12 Dew point comparisons between EdgeTech DewPrime II pre chiller and OhmicAMM-15 post chiller..................................55

Figure 13 Relative humidity comparisons between EdgeTech DewPrime II pre chiller and Ohmic AMM-15 post chiller................................56

Figure 14 Dry bulb temperature comparisons between EdgeTech DewPrime II pre chiller Ohmic AMM-15 post chiller...................................57

Figure 15 Test setup\#3\&4 Ambient Air, Dry zero air and Dry zero/Bubbled air ran through chiller with EdgeTech DewPrime II pre and Ohmic post chiller.........59

Figure 16 Test setup\#5 Dry zero air ran through chiller with EdgeTech Dew Prime II pre and Ohmic post chiller.................................62

Figure 17 Test setup\#6 Dry zero air and Dry zero/Bubbled air ran through chiller with Edge Tech pre and Ohmic Post Chiller...........................62

Figure 18 Test setup\#9 Dry zero air ran through Mems Chiller with EdgeTech Dew Prime II pre and Ohmic post chiller .66

Figure 19 Test setup\#10 Dry zero/Bubbled air ran through Mems chiller unit with Edge Tech pre and Ohmic post chiller.

Figure 20 Pre and post dew point comparison with dry zero/bubbled air ran through the chillers 


\section{Nomenclature}

$\begin{array}{ll}\text { AC } & \text { Alternating Current } \\ \text { CARB } & \text { California Air Resources Board } \\ \text { CFR } & \text { Code of Federal Regulations } \\ \text { CFV } & \text { Constant Volume Sampler } \\ \text { CVS } & \text { Critical Flow Veturi } \\ \mathrm{CO} & \text { Carbon Monoxide } \\ \mathrm{CO}_{2} & \text { Carbon Dioxide } \\ \text { DC } & \text { Direct Current } \\ \text { ECU } & \text { Engine Control Unit } \\ \text { ECM } & \text { Engine Control Module } \\ \text { EERC } & \text { Engine and Emission Research Center } \\ \text { EPA } & \text { Environmental Protection Agency } \\ \text { FTIR } & \text { Fourier Transform Infrared } \\ \text { FTP } & \text { Federal Test Procedures } \\ \text { GPS } & \text { Global Positioning System } \\ \mathrm{HC} & \text { Hydrocarbon } \\ \mathrm{HDDE} & \text { Heavy Duty Diesel Engine } \\ \mathrm{HFID} & \text { Heated Flame Ionization Detector } \\ \mathrm{MEMS} & \text { Mobile Emission Measurement System } \\ \mathrm{NDIR} & \text { Non-dispersive Infrared } \\ \mathrm{NMHC} & \text { Non-Methane Hydrocarbon } \\ \mathrm{NO} & \text { Nitric Oxide } \\ \mathrm{NO} & \text { Nitrogen Dioxide } \\ \mathrm{NOx} & \text { Oxides of Nitrogen } \\ \mathrm{O}_{2} & \text { Oxygen } \\ \mathrm{O}_{3} & \text { Ozone } \\ \mathrm{OREMS} & \text { On -Road Emission Measurement System } \\ \mathrm{PM} & \text { Particulate Matter } \\ \text { ppm } & \text { Parts Per Million } \\ \mathrm{Scfm} & \text { Standard Cubic Feet per Minute } \\ \text { WVU } & \text { West Virginia University } \\ & \\ & \end{array}$




\section{Introduction and Objective}

Engine dynamometer, chasis dynamometer, and in-use mobile emissions analysis systems may employ non-dispersive infrared (NDIR) analyzers for measurement of carbon dioxide $\left(\mathrm{CO}_{2}\right)$, carbon monoxide (CO), and hydrocarbon (HC). NDIR detection is a principle based on the absorption of energy at distinct wavelengths. An infrared light source provides light energy and a filter allows only a specific wavelength to pass through to a detector at the opposite end of a sample cell. Non-dispersive indicates that the light energy is not dispersed, but is absorbed proportionally to gas concentration being measured. When the gas being measured, or other gas which absorbs a similar wavelength, is not present all of the light energy passing through the filter reaches the detector. As the concentration of gas being measured increases, the amount of energy absorbed by the gas increases. Therefore, the amount of energy reaching the detector is reduced causing a change in output from the detector.

In an NDIR-based emission measurement system, the sample stream must be filtered and conditioned to an acceptable humidity level. If water condensed out on the inside of the sample cell, the walls will become contaminated with deposits, causing errors in the measurement. Also, water shows overlapping absorption spectra, causing interference with NDIR analyzers. Effects from water interference are minimized as the humidity of the sample stream is decreased.

Chemiluminescent analyzers are commonly used for the measurement of NO concentration. NO concentration is determined from the infrared energy emitted when NO is converted to $\mathrm{NO}_{2}$. An interfering molecule, such as water, can collide with the excited $\mathrm{NO}_{2}$ molecule $\left(\mathrm{NO}_{2}{ }^{*}\right)$. The colliding molecules move faster after their contact, 
but the additional energy, normally released as a photon, is dissipated during the collision. Therefore, if the water is not removed, measurements made with the chemiluminescent detector can be erroneously low.

Considering water interference issues for both NDIR and chemiluminescent analyzers, it may be necessary to install a water removal system before these analyzers for accurate determination of emission concentrations.

The objective of this work was to investigate the performance of the six different types of chiller units employed in emissions testing used for sample stream moisture removal. The performance evaluation was accomplished by measuring and then comparing pre and post chiller dew point temperature, dry bulb temperature and the relative humidity for the chiller units selected for this study. The six types of chiller units utilized for this study included Domnic Hunter CRD5-100, ECP 1000, ECP 2000, MEMS chiller unit [3], Micro MEMS chiller unit and SEMTECH-D thermoelectric chiller unit. The dew point temperature, dry bulb temperature, and the relative humidity were recorded by the use of two different types of hygrometers, an EdgeTech DewPrime II and a Ohmic AMM-15 portable dew point meter. A detailed description and specification about these instruments can be found later in experimental procedure and setup section. 


\section{Review of Literature}

\subsection{Emission Standards.}

Diesel engine emissions are currently an important air-quality issue. About onethird of the nation's NOx emissions and one-quarter of the PM emissions from mobile sources are generated from diesel engines [1]. Since 1970 the EPA has been regulating certain emissions from heavy duty diesel vehicles (HDDV) [36]. The EPA regulates the following pollutants from mobile sources:

- Total Hydrocarbons (HC)

- Oxides of nitrogen (NOx)

- Particulate matter (PM)

- Carbon monoxide (CO)

In 1974, $\mathrm{CO}$ and a combined $\mathrm{HC}+\mathrm{NO}_{\mathrm{x}}$ regulation were put into effect as well as tighter smoke standards. The $\mathrm{CO}$ limit was introduced at $40 \mathrm{~g} / \mathrm{bhp}-\mathrm{hr}$ and the $\mathrm{HC}+\mathrm{NO}_{\mathrm{x}}$ was introduced at $16 \mathrm{~g} / \mathrm{bhp}-\mathrm{hr}$. The emissions standards again tightened in 1979 with CO emission levels tightened to $25 \mathrm{~g} / \mathrm{bhp}-\mathrm{hr}$. Also in 1979, a choice of $5 \mathrm{~g} / \mathrm{bhp}-\mathrm{hr} \mathrm{HC}+\mathrm{NO}_{\mathrm{x}}$ or $\mathrm{HC}$ of $1.5 \mathrm{~g} / \mathrm{bhp}-\mathrm{hr}$ combined with a $10 \mathrm{~g} / \mathrm{bhp}-\mathrm{hr} \mathrm{HC}+\mathrm{NO}_{\mathrm{x}}$ was introduced for the first time.

In 1984 new regulations split $\mathrm{NO}_{\mathrm{x}}$ and $\mathrm{HC}$ into individual standards. In 1988 particulate matter regulations were introduced for the first time and set at $6.0 \mathrm{~g} / \mathrm{bhp}-\mathrm{hr}$. In 2004, $\mathrm{HC}$ and $\mathrm{NO}_{\mathrm{x}}$ were again recombined to be regulated as one emission. On December 21, 2000 the EPA signed emission standards for model year 2007 and later heavy-duty highway engines (the California ARB adopted virtually identical 2007 heavy-duty engine 
standards in October 2001). The rule includes two parts: (1) emission standards and (2) diesel fuel regulation.

The first part of the regulation introduces very stringent emission [1] standards, as follows:

- $\mathrm{PM}-0.01 \mathrm{~g} / \mathrm{bhp}-\mathrm{hr}$

- $\mathrm{NOx}-0.20 \mathrm{~g} / \mathrm{bhp}-\mathrm{hr}$

- $\quad \mathrm{NMHC}-0.14 \mathrm{~g} / \mathrm{bhp}-\mathrm{hr}$

The PM emission standard will take full effect in the 2007 heavy-duty engine model year. The $\mathrm{NO}_{\mathrm{x}}$ and $\mathrm{NMHC}$ standards will be phased in for diesel engines between 2007 and 2010. The phase-in would be on a percent-of-sales basis: 50\% from 2007 to 2009 and $100 \%$ in 2010 . The diesel fuel regulation limits the sulfur content in on-highway diesel fuel to $15 \mathrm{ppm}$ (wt.), down from the previous $500 \mathrm{ppm}$ [1]. History of emission regulations since 1974 is shown in Table 1.

Table 1 EPA Emission Standard History for Heavy -Duty Diesel Vehicles [36]

\begin{tabular}{|c|c|c|c|c|}
\hline Year & CO (g/bhp-hr) & NOx (g/bhp-hr) & HC (g/bhp-hr) & PM (g/bhp-hr) \\
\hline 1974 & 40 & \multicolumn{2}{|c|}{16} & - \\
\hline 1979 & 25 & \multicolumn{2}{|c|}{5} & - \\
\hline 1984 & 15.5 & 10.7 & 1.3 & - \\
\hline 1988 & 15.5 & 6 & 1.3 & 0.6 \\
\hline 1990 & 15.5 & 6 & 1.3 & 0.6 \\
\hline 1991 & 15.5 & 5 & 1.3 & 0.25 \\
\hline 1993 & 15.5 & 5 & 1.3 & 0.1 \\
\hline 1998 & 15.5 & 4 & 1.3 & 0.1 \\
\hline 2004 & 15.5 & \multicolumn{2}{|c|}{2.5} & \\
\hline 2007 & 15.5 & 0.2 & 0.14 & 0.01 \\
\hline
\end{tabular}




\subsection{Engine Certification}

The FTP (Federal Test Procedure) heavy-duty transient cycle is currently used for emission testing of heavy-duty on-road engines in the USA [CFR Title 40, Part 86.1333]. The cycle includes "motoring" segments and, therefore, requires a DC or AC electric dynamometer capable of both absorbing and supplying power.

The transient cycle consists of four phases: the first is a NYNF (New York Non Freeway) phase typical of light urban traffic with frequent stops and starts, the second is LANF (Los Angeles Non Freeway) phase typical of crowded urban traffic with few stops, the third is a LAFY (Los Angeles Freeway) phase simulating crowded expressway traffic in Los Angeles, and the fourth phase repeats the first NYNF phase. It comprises a cold start soak period, followed by idling, acceleration and deceleration phases, and a wide variety of different speeds and loads sequenced to simulate the running of the vehicle that corresponds to the engine being tested. There are few stabilized running conditions, and the average load factor is about 20 to $25 \%$ of the maximum horsepower available at a given speed. The cycle is carried out twice and the second repetition is made with a hot start after a soak period of $1200 \mathrm{~s}$ (20 min) on completion of the first cycle.

\subsection{In-use Emission Testing.}

Despite the fact that there have been advancements in capabilities of modern engine and chasis dynamometers testing, there are still differences between the laboratory and real-world or "in-use" emissions. Tunnel studies and on-road data have indicated that emissions differ significantly from those predicted by emissions models based on 
certification data [2]. The differences between engine laboratory certification and what occurred in the real-world were seen as defeat devices by the EPA.

\subsection{Consent Decrees}

In October of 1998, a settlement took place between the EPA, Department of Justice, California ARB and engine manufacturers (Caterpillar, Cummins, Detroit Diesel, Volvo, Mack Trucks/Renault and Navistar) over the issue of high NOx emissions from heavy-duty diesel engines during certain driving modes. When the engines were tested for compliance with the emissions standards, the manufacturer would cause the ECU to operate in the "urban mode," which would allow the engine to pass the certification test. However, on road, the engine would produce greater emissions than the standards because the ECU would switch the engine to the "highway mode."

Provisions of the Consent Decree included the following:

- Civil penalties for engine manufacturers and requirements to allocate funds for pollution research.

- Upgrading existing engines to lower NOx emissions.

- Certification of engines on both the transient FTP and the Supplemental SteadyState Test.

- Meeting the 2004 emission standards by October 2002, 15 months ahead of time.

\subsection{Need for Portable Emissions Measurement Systems}

An outcome of the consent decrees resulted in much effort to develop real time, in-use emission measurement systems. The benefit of having in-use emission systems over laboratory testing is comparatively shorter test duration and less expensive processes involved in engine or chassis dynamometer emission testing. In-use emission testing only 
requires portable emission measurement system. In-use emission testing only requires portable emission measurement system. An accurate measurement of pollutant concentration, engine work output, and exhaust volumetric flow rate must be accomplished by a well and properly designed portable system. In comparison to the test cell emissions measurement system, which employs high level, reliable and precision quality sensor technology, measurement accuracy of pollutant concentration, engine work output and exhaust flow rate for portable system is limited by its current portable sensor's technology. At present WVU's MEMS [3], US EPA's ROVER [4], Sensors SEMTECHD [5] and Horiba's OBS 2000 are few of the portable emissions measurement systems that have undergone extensive independent evaluations.

\subsection{History of Portable and Mobile Emissions Measurement Systems.}

Portable systems may be transported to the emissions source while mobile systems may be installed on a vehicle for in-use testing. The majority of previously developed portable and mobile emission measurement system were developed and employed for testing engines used in underground mining applications. A literature review of previously developed portable and mobile emission measurement system is given in the following section. Much of the following section has been repeated from the MEMS White Paper [3].

\subsubsection{Southwest Research Institute, 1983}

Development of a transportable system for $\mathrm{I} / \mathrm{M}$ testing of diesel engines in a mining application was carried out by Southwest Research Institute through a project from 1978 to 1983 [8]. The system included a portable dynamometer, laboratory-grade emissions analyzers, laboratory-grade emissions instruments, volumetric fuel flow meter, 
and a laminar air flow meter. The emissions measurement system consisted of NDIR analyzers for $\mathrm{CO}$ and $\mathrm{CO}_{2}$, a heated flame ionization detector (HFID) for $\mathrm{HC}$, heated chemiluminescent analyzer (CLA) for NOx, and a polar graphic analyzer for oxygen $\left(\mathrm{O}_{2}\right)$. The PM measurement system included a mini dilution tunnel. Calibration gases for these analyzers were carried along with the unit. The system itself was minimally portable, as it had calibration gases on-board the unit thus making it incapable of performing on-board emissions testing on-board vehicle emissions measurements.

\subsubsection{Michigan Technological University, 1992}

Researchers at Michigan Technological University developed an Emissions Measurement Apparatus (EMA) system to perform emissions testing on diesel engines used in underground mining [9]. The EMA was designed to measure both PM and gaseous emissions. The EMA consisted of a dilute bag sampling system, a mini-dilution tunnel for gravimetric analysis of PM, battery powered portable emissions analyzers (for off-line bag analysis), and heated sample lines to eliminate the possibility of water condensation within the sampling line. An engine dynamometer test was performed to compare the portable analyzer measurements to laboratory-grade equipment. Results showed that $\mathrm{CO}_{2}$ measurements were within $5 \%$, CO within $10 \%$, NO within $5 \%$, and PM within $7 \%$ of laboratory measurements. Being too bulky, labor intensive and incapable of recording transient engine events, the system was not suitable to be used as MEMS for on-board vehicle measurements. 


\subsubsection{University of Minnesota, 1997}

Researchers at the University of Minnesota developed the emissions-assisted maintenance procedure (EAMP) for diesel-powered mining equipment [10]. The system was designed to be more portable than the previous systems that were developed by Southwest Research Institute and Michigan Technological University. The EAMP was designed to measure emissions from vehicles on site by stalling the vehicle's torque converter or hydrostatic transmission. Thus, it could not be used on vehicles with manual transmissions. Various instruments were used to assess their portability, including NDIR, Fourier transform infrared (FTIR) spectrophotometer, and electrochemical gas sensors (EGS). EGS sensor technology was determined to be rugged and portable. Measurements made by these analyzers were within $5 \%$ of measured value for $\mathrm{NO}, \mathrm{NO}_{2}, \mathrm{CO}, \mathrm{CO}_{2}$, and $\mathrm{O}_{2}$. The main purpose of the EAMP system was to detect engine faults to determine if any engine maintenance was required. A portable gas analyzer was used to measure $\mathrm{CO}$ concentrations to establish any need for maintenance. The testing had four parts: loading the engine against the stalled torque converter, measuring the emissions while the engine operates under load, recording the generated data, and reducing that data to determine the condition of the engine.

\subsection{On-Board Measurements.}

On board emission measurement is considered as reliable method to determine emissions from a vehicle over a driving cycle. Until recently, most work in the field of on-board measurements was focused toward internal research projects of engine manufacturers. 


\subsubsection{Caterpillar, 1982}

Caterpillar developed a portable bag collection system to quantify fuel specific NOx emission levels from in-use diesel engines [11]. The system consisted of a probe, pre filter, sample line, pump, air-cooled condensing coil, and two collection bags. A twobag collection system was designed with the capability of removing water vapor before the bags. The system was powered by an on-board supply and could be operated remotely by the driver. Moreover, the collection system could fit in a "small suitcase." Engine testing showed that the portable Caterpillar bag collection system could report NOx emissions within $10 \%$ of laboratory instruments on a concentration basis.

\subsubsection{Southwest Research Institute, 1992}

Southwest Research Institute developed a portable system to measure exhaust emissions from diesel buses. The study was made to compare emissions from the buses to the emissions measured by the EPA on transient engine testing [12]. The system was designed to collect information regarding emissions without the use of a chassis dynamometer. The designed test procedure could only be performed on vehicles with automatic transmissions. An Enerac 2000E was used to measure undiluted concentrations of $\mathrm{CO}, \mathrm{NOx}, \mathrm{O}_{2}$, and $\mathrm{CO}_{2}$ from a bag sample, and a mini dilution tunnel was used for the PM measurement. Exhaust emissions concentrations measured using the Enerac 2000E were within $5 \%$ of laboratory-grade instruments. This system was based on an integrated bag approach, rather than on a continuous sampling approach.

\subsubsection{General Motors, 1993}

General Motors instrumented a 1989 gasoline-fueled 3.8-liter displacement Pontiac Bonneville SSE passenger car to measure its emissions [13]. The exhaust sample 
was taken at the outlet of the catalytic converter. The system was capable of removing water from the sample through the use of an ice-cooled trap. The 400-lbs system consisting of five 12-volt batteries, inverters, computers, and five different emissions analyzers system were housed in the trunk of the vehicle. A Horiba MEXA-311GE was used to measure $\mathrm{CO}$ and $\mathrm{CO}_{2}$. A second Horiba analyzer, a MEXA-324GE, was used to measure $\mathrm{HC}$ and $\mathrm{CO}$. A Siemens Ultramat-22P analyzer measured $\mathrm{HC}$ and $\mathrm{CO}$. Another Siemens analyzer was used to measure NO. A Draeger electrochemical analyzer recorded ambient levels of $\mathrm{CO}$ within the driver compartment. The exhaust flow measurement was made using a Kurz flow meter. Intake flow was measured using stock flow meter signals. A relationship between exhaust flow and intake flow was then developed, allowing for the inference of the exhaust flow from the intake flow. Limitations of the system included its inability to record transient events and slow data collection rate. Testing was limited to only one vehicle. However, the system generated useful data for in-use emissions measurements of spark-ignited engines.

\subsubsection{Ford Motor Company, 1994}

Ford Motor Company devised a testing apparatus to measure emissions from three different gasoline-fueled passenger vehicles. The objective of the study was to compare on-board measurements to those obtained using remote equipment [14]. An OnBoard Emissions (OBE) system, housed in an Aerostar van, consisted of an FTIR, and a dilution tunnel. Gaseous emissions measured were $\mathrm{CO}_{2}, \mathrm{CO}$, NOx, and $\mathrm{HC}$. The results of $\mathrm{OBE}$ were compared to laboratory results obtained from chassis dynamometer tests on the vehicle. Comparative data showed that measurements were within $2 \%$ for $\mathrm{CO}_{2}, 3 \%$ 
for $\mathrm{CO}, 10 \%$ for NOx, and $7 \%$ for HC. FTIR responded very slowly, making it unsuitable for an on-board testing apparatus. The Taurus wagon was instrumented with an MPSI infrared-based analyzer to monitor $\mathrm{HC}, \mathrm{CO}, \mathrm{CO}_{2}$, and $\mathrm{O}_{2}$ emissions.

An NDUV (non-dispersive ultraviolet) analyzer was used to record measurements of NO. Comparisons were made between the on-board NDUV NO measurements and laboratory equipment using a chassis dynamometer. A close relationship between the onboard device and the laboratory chemiluminescent analyzer was obtained.

\subsubsection{U.S. Coast Guard, 1997}

The United States Coast Guard devised an apparatus to measure emissions from the engines of three 82-ft U.S. Coast Guard Cutters (WPBs) as part of the 1990 Clean Air Act for non-road air pollution [15]. An Enerac 2000E analyzer was used to measure concentrations of $\mathrm{CO}, \mathrm{NO}, \mathrm{NO}_{2}, \mathrm{SO}_{2}, \mathrm{O} 2$, and $\mathrm{HC} . \mathrm{CO} 2$ concentrations were inferred from these measurements. The monitoring system included air and fuel flow measurements as well as propeller shaft speed and torque. Engine torque was measured via driveshaft mounted strain gages and transmitted through radio frequency. The emissions sample was taken at the outlet of the turbocharger due to space limitations. Emissions were successfully measured, but the system lacked portability because the apparatus was quite large and bulky.

\subsubsection{University of Pittsburgh, 1997}

The University of Pittsburgh developed an I/M system to measure emissions for natural gas-powered passenger vans at the University of Pittsburgh [16, 17]. A RG240 five-gas analyzer from OTC SPX was used to measure the undiluted gas concentrations of $\mathrm{HC}, \mathrm{CO}, \mathrm{CO}_{2}, \mathrm{NOx}$ (actually $\mathrm{NO}$ ), and $\mathrm{O}_{2}$. Engine data was also collected via third 
party diagnostic equipment. Since the system was developed for gasoline-fueled vehicles, the hydrocarbon results were biased. It was reported that the system did provide a means of measuring real world, in-use emissions from natural gas-fueled vehicles using a lightweight and portable testing apparatus. The system had several unresolved problems, including determination of mass emission rates, time alignment of signals, and analyzer (and the system) response times.

\subsubsection{Flemish Institute for Technological Research, 1997}

The Flemish Institute for Technological Research, or VITO, performed on-board emission tests with their VOEM (Vito's On-the-road Emission and Energy Measurement) system on gasoline-fueled cars and diesel-fueled buses [18]. The system used NDIRbased analyzer for $\mathrm{CO}$ and $\mathrm{CO}_{2}$, an $\mathrm{HFID}$ for $\mathrm{HC}$, and a chemiluminescent-based analyzer for NOx determination. A nitrogen-driven ejector was used to draw a portion of the tailpipe exhaust and dilute it in order to prevent water condensation. A hightemperature sampling tube carried the sample to the analyzers to prevent the loss of any heavy hydrocarbons that are associated with distance specific diesel exhaust. Emissions were reported in terms of distance-specific or mass rate by combining dilute exhaust measurements with fuel consumption, engine speed, and lambda values. Data generated by the VOEM was compared against a fixed chassis dynamometer. Results showed that gaseous emissions measurements were within $10 \%$, with the exception of $\mathrm{CO}(20 \%)$ and HC (25\%). The VOEM system was bulky, weighing approximately 500 lbs., making onboard, in-use testing difficult. 


\subsubsection{NESCAUM, 1998}

A study by the Northeast States for Coordinated Air Use Management (NESCAUM) evaluated in-use emissions from diesel-powered off-road construction vehicles [19]. The system consisted of a heated, raw exhaust sample line to transfer a portion of the raw exhaust to a mini dilution tunnel. A portion of the mixture was extracted through sampling lines to provide continuous emissions monitoring (using an MPSI five-gas portable gas analyzer) and bag (Tedlar) sampling for the off-line analysis of THC, NOx, and CO. A 70-mm filter was placed at the exit of a mini-dilution tunnel to obtain PM measurements. $\mathrm{CO}_{2}$ was used to infer fuel consumption. An analysis of the data showed that emissions measurements were unreliable, as NOx response time was slow, and the concentration levels of $\mathrm{CO}$ and $\mathrm{HC}$ were too low. An engine dynamometer test showed that results obtained with the system had an error of $27 \%$ for $\mathrm{CO}, 12 \%$ for NOx, $22 \%$ for $\mathrm{HC}, 38 \%$ for PM, and $9 \%$ for the fuel consumption calculation.

\subsubsection{Ford Motor Company and WPI-Microprocessor Systems, Inc., 1999}

Ford Motor Company and WPI-Microprocessor Systems, Inc. developed a portable system known as PREVIEW (Portable Real-time Emission Vehicular Integrated Engineering Workstation) [20]. PREVIEW was reported to be a fully integrated, capable of sampling water-laden exhaust, portable system that simultaneously measures exhaust mass emissions $\left(\mathrm{CO}, \mathrm{CO}_{2}, \mathrm{NO}\right.$ and $\left.\mathrm{HC}\right)$ and up to forty engine parameters (through the engine control module readout). FTP and Highway Fuel Economy tests were conducted in a dynamometer laboratory using laboratory-grade instrumentation. Results showed that PREVIEW obtained accurate results, with an error of $1.5 \%$ for $\mathrm{CO}_{2}, 3.4 \%$ for $\mathrm{CO}, 12.3 \%$ 
for $\mathrm{HC}$, and $0.4 \%$ for NOx. PREVIEW NOx instantaneous mass measurements showed a faster response and a faster response time than the laboratory analyzer.

\subsubsection{US EPA, 2000}

For the purpose of measuring on-road emissions from vehicles the EPA's Certification and Compliance Division (CCD) developed ROVER, which is Real-time On-road Vehicle Emissions Reporter [23]. The system includes four major components: a sampling and flow meter which is attached to the vehicle's tailpipe, an exhaust emissions analyzer unit, a scan tool which serves as a decoder for the engine's computer outputs, and records the quantity of gaseous emissions - $\mathrm{HC}, \mathrm{CO}, \mathrm{CO} 2, \mathrm{NOx}$ and $\mathrm{O} 2$ in grams/mile and smoke while a vehicle is being operated, as well as fuel economy, engine parameters, engine air/fuel ratio, road grade, and physical location, all at a user-selectable rate. ROVER played a very important role in investigation of the diesel engine defeat devices, resulting in the Consent Decrees.

\subsubsection{Honda R\&D and Nicolet Instrument Corp., 2000}

FTIR-based emissions measuring system was developed by Honda R\&D Americas, Ltd., Honda R\&D Co., Ltd., and Nicolet Instrument Corp. The system was designed for measuring the performance of light-duty gasoline powered vehicles. The system was used to measure $\mathrm{NMHC}, \mathrm{NO}_{\mathrm{x}}$ and $\mathrm{CO}$ [21]. Intake air was sampled from the front of the vehicle and exhaust sample drawn through a heated line inserted into the tailpipe was dried using a water-removal system and then passed directly into the gas cells of twin FTIR spectrometers. Vehicle acceleration and vibration are the two significant factors, which affect the system performance. 


\subsubsection{Sensors Inc., 2002}

Sensors Inc. developed an on-board system, the SEMTECH-D, for measurement of exhaust flow rate and diesel emissions including $\mathrm{HC}, \mathrm{CO}, \mathrm{CO}_{2}, \mathrm{NO}, \mathrm{NO}_{2}$, and particulate matter [5]. The SEMTECH-D systems used non-dispersive ultra violet (NDUV) spectroscopy to measure $\mathrm{NO}$ and $\mathrm{NO}_{2}$ constituents of $\mathrm{NO}_{\mathrm{x}}$ simultaneously and independently. The exhaust flow is calculated using a hot-wire anemometer. The system can be rack or cart mounted. The system requires two connections with the vehicle tested. One is to the tailpipe to draw exhaust sample and the other is to the vehicle's diagnostic connector, which provides the system access to the vehicle's data stream.

\subsubsection{Horiba, Ltd., 2003}

Horiba recently developed a system for on-road testing of vehicles called OBS$1000[6,7]$. The concentrations of gaseous emissions of $\mathrm{CO}, \mathrm{CO}_{2}$ and $\mathrm{HC}$ are measured using a heated type NDIR analyzer, MEXA-1170 HNDIR, without water extraction. NOx concentration and air-fuel ratio are measured using a $\mathrm{ZrO}_{2}$-type analyzer, MEXA-720 NOx. The system also consists of data logging software on the PC can save vehicle parameters like vehicle velocity, engine speed and other external signals as well as the outputs of the gas analyzers and the accessory signals. The software can provide timetrend profiles and integrated values for both mass emission and fuel consumption.

\subsubsection{CE-CERT}

To measure the emissions from heavy-duty diesel vehicles under actual driving conditions, CE-CERT developed an emissions laboratory within a 53-foot container trailer [22, 23]. On-board instrumentation provides real-time emissions measurement. For a testing cycle or for a particular event, additional instrumentation provides a means of 
post processing to quantify gaseous and particulate emissions expressed in grams per mile or grams per horsepower-hour.

\subsubsection{Analytical Engineering Inc.}

Analytical Engineering Inc developed Simple Portable On-Vehicle testing (SPOT) to measure of off-road diesel emissions [24]. The system provides the means to measure $\mathrm{NOx}, \mathrm{O}_{2}$ (thus calculated $\mathrm{CO}_{2}$ ), total exhaust mass flow, relative humidity, ambient temperature, engine speed, fuel consumption, estimated brake specific NOx, GPS coordinates, barometric pressure and other engine parameters. Currently USEPA is using the on-vehicle real-time brake-specific NOx emissions data collection to study the environmental impact of such emissions. For exhaust flow measurement a low-pressure area behind the nose cone is created, thus inducting outside air. The flow rate of clean outside air being inducted is measured with a hot-wire anemometer. It is reported that the induction zone is self-cleaning and no fouling occurs [25].

\subsubsection{National Center for Environmental Research}

A remote sensing method to measure emissions of motor vehicles under actual driving conditions has been developed by the National Center for Environmental Research in collaboration with Massachusetts Institute of Technology and Aerodyne Inc. [26]. Tunable Infrared Laser Differential Absorption Spectroscopy (TILDAS) are used as

remote sensors in the system. The remote sensing of emissions was demonstrated and good agreement was obtained comparing TILDAS measurement with other on-board measurement systems. $\mathrm{NO}_{2}$ emission measurement was made by (TILDAS) and results obtained exhibited close agreement in comparison to other on-board emission measurement system. 


\section{Experimental Equipment}

\subsection{Mobile Emission Measuremt System Developed by West Virginia University}

A system named Mobile Emission Measurement System was developed by WVU for the on-board measurement of in-use emissions from heavy-duty on-road vehicles [3]. In order to achieve accurate in-use brake-specific mass emissions, an on-board emission measurement system must not only be portable, but also be capable of accurately measuring several parameters in a repeatable manner with the highest level of precision. These include engine speed, engine torque, exhaust mass flow rates, and exhaust constituent concentrations. The MEMS was developed after an extensive evaluation of available technologies as they relate to these issues. The MEMS is capable of measuring in-use brake-specific emissions of $\mathrm{NOx}$ and $\mathrm{CO}_{2}$ from diesel-powered vehicles operated under real-world conditions. The three primary components that make up the MEMS system are an exhaust flow measurement apparatus, the emissions box, and the data acquisition equipment.

\subsubsection{Exhaust Flow Measurement}

Exhaust flow rate measurement is necessary to convert the emission gas concentrations to a mass measurement per time, which can then be converted to a mass measurement per distance or per work output. The MEMS utilizes an Annubar, a multiport averaging pitot tube sensor for the purpose of measuring exhaust flow. This type of device is desirable for the measurement of the pulsing exhaust flow because of its ability to determine an average upstream and downstream total pressure. This pressure drop can be related to the velocity of the exhaust gas when coupled with temperature data. With 
velocity and temperature data known, the cross-sectional area of the tube was used to determine exhaust gas flow rate.

\subsubsection{Emissions Sampling Box}

The emissions sampling box consisted of a number of components. The sample first enters the system through a stainless-steel probe located in the exhaust stream, from there it travels through a heated line and filter to a heated-head pump. The sample then passes through a $\mathrm{NO}_{2}$ to $\mathrm{NO}$ converter. The sample is then dried with a thermoelectric chiller, which lowers the dew point of the sample to an acceptable level. The analyzer used for measurement of $\mathrm{CO}_{2}$ is a Horiba BE-140 multi gas analyzer with a MEXA-120 (or Mexa-720) sensor used for determination of NOx concentration. Measurement of HC and $\mathrm{CO}$ is possible with the Horiba BE-140 analyzer, but the resolution is too coarse for accurate measurement of the concentrations found in diesel exhaust. An electrochemical cell was also utilized for an additional check of NOx levels in the exhaust. It was deemed necessary to perform two NOx measurements for quality control/quality assurance (QC/QA) purposes and to ensure that the NOx converter was performing properly.

\subsubsection{The Data Acquisition Components}

The data acquisition components of the MEMS were a computer, signal conditioning hardware, and data acquisition and control software. The MEMS data acquisition system was capable of measuring analog and digital signals from various engine sensors as well as the emissions measurement box. During testing, it was necessary to record a variety of signals from thermocouples, pressure transducers, the emissions analyzers, and numerous ECU outputs. The computer utilized for testing was a laptop with National Instruments Corp. data acquisition boards. The systems reliance on 
the ECU data is an additional strike against it for off-highway testing because the vehicles that are currently in use are often mechanically injected with no sensor feedback. However, the system was able to obtain fairly accurate measurement of diesel emissions when compared to laboratory-grade analyzers during engine and chassis-dynamometer testing. Steady-state testing revealed that the MEMS $\mathrm{CO}_{2}$ data differed from the laboratory data by $2.5 \%, \mathrm{NO}_{\mathrm{x}}$ by $11.5 \%$ (MEXA-120) and $5.7 \%$ (Electrochemical cell).

\subsubsection{Engine Speed and Torque Speed measurement}

Engine speed measurement and torque inference was made with a manufacturersupplied computer interface with the ECU that controls the fuel injection duties. A global positioning system (GPS) for vehicle speed measurement was used to assure data quality of the vehicle speed signal from engine ECU. The MEMS is capable of monitoring engine torque and speed via an ECU protocol adaptor through an RS232 or USB interface with the data acquisition system.

\subsubsection{Ambient Temperature, Pressure and Humidity}

To convert the results of a test to results taken at standard conditions per $40 \mathrm{CFR}$ 86 , ambient pressure, temperature, and humidity are recorded. The production of NOx tends to decrease with increasing humidity due to lower in-cylinder temperatures caused by the diluting effect and possibly the reduction of flame travel speed. Ambient pressure may also be used to calculate changes in altitude over a test route if high accuracy is not required. 


\subsection{Engine and Emissions Research Laboratory (EERC)}

The EERC was built to meet the specifications outlined by The CFR, Part 86, Subpart N and has been in operation since 1993. It is permanently installed on the Evansdale campus of West Virginia University. This section provides a brief detail of the various components used in the EERC for diesel emission measurement.

\subsubsection{Engine Dynamometer}

The DC dynamometer employed for testing engines is a General Electric model DYC 243, capable of absorbing up to 550 horsepower (hp) and producing $500 \mathrm{hp}$ during motoring power. Speed is measured using a digital tachometer internally installed on the dynamometer. A strain gage type load cell, attached to the dynamometer, is used to measure the torque by measuring the force placed on the moment arm of a known distance. The engine is connected to the dynamometer by a drive shaft and a rubber coupling.

\subsubsection{Dilution Tunnel}

The primary purpose of the dilution tunnel is to mix the raw diesel exhaust emissions with a larger volume of air in order to reduce the dew point temperature for preventing water vapor condensation, and try to simulate real world atmospheric dilution of exhaust. Upon mixing, the diluted exhaust temperature is lowered to $125^{\circ} \mathrm{F}$ at the PM sampling filter face. If water condensation at any point in the dilution tunnel were to occur, certain gaseous components would be lost which would alter the emissions measurement results. Also, the non-dispersive infrared analyzers would be affected by the water condensation. Dilution tunnel design requirements include a mixing orifice, 8 inches in diameter, placed 3 feet downstream of the air and raw exhaust inlets, a 
minimum tunnel diameter of 18 inches, at least 10 diameters in length to allow complete mixing and the formation of fully developed flow and the use of Critical Flow VenturiConstant Volume Sampling (CFV-CVS) flow sampling system. The Code of Federal Regulations 40, Part 86, Subpart N, states that diesel exhaust must be connected to a critical flow venturi constant volume sampler (CFV-CVS) or a positive displacement pump-constant volume sampler (PDP-CVS) in order to sample particulate emissions. Four critical flow venturies were used to control the flow in the dilution tunnel. Sample probes were located 15 feet from the entrance of the tunnel, to ensure proper mixing. One of the four venturies was rated at a flow of $400 \mathrm{scfm}$ and the remaining three were rated at a flow of $1000 \mathrm{scfm}$ each. Any multiple of flow from the venturies could be achieved in the dilution tunnel. The laboratory uses a $75 \mathrm{hp}$ electric centrifugal blower to pull the dilute exhaust.

\subsubsection{Secondary Dilution Tunnel}

The purpose of the secondary dilution tunnel is to further reduce the sample temperature by pulling a constant flow of diluted exhaust through the secondary tunnel for PM measurement. West Virginia University uses the double dilution method in their engine test cell. In the double-dilution system, the flow capacity must be sufficient to maintain the diluted exhaust stream in the primary dilution tunnel at a temperature of $375^{\circ} \mathrm{F}\left(191^{\circ} \mathrm{C}\right)$ or less at the sampling zone and prevent condensation at any point in the dilution tunnel. More importantly, the filter face temperature must be less than $125^{\circ} \mathrm{F}$. The diluted exhaust from primary dilution sample zone can be diluted for a second time for use in determining particulate emissions. 
WVU laboratory uses the double-dilution method for particulate matter sampling by drawing a proportional sample of diluted exhaust from the primary tunnel and diluting it further if required in the secondary dilution tunnel before it passes through two Pallflex 70-mm fluorocarbon coated fiberglass filters, which collect the particulate matter. A filter holder is located at the end of the secondary dilution tunnel during testing to house the primary and secondary filters. The filter holder is constructed of stainless steel to prevent reactions with the corrosive exhaust sample. Continuous PM is measured using a Tapered Element Oscillating Microbalance (TEOM), Rupprecht \& Patashnick Co., Inc. TEOM Series 1105, Diesel Particulate Mass. The TEOM measured total mass, mass concentration and mass rate. The TEOM is connected to the secondary dilution tunnel and draws a 2-lpm sample from the tunnel.

\subsubsection{Air Flow and fuel Measurement}

The engine intake flow measurement at WVU EERC is measured using a laminar flow element (LFE). The airflow of the dilution tunnel is measured using the CFV-CVS system. Butterfly valves are used to set the intake depression and exhaust backpressure of the engine. The fuel metering system at the WVU EERC is a Max Machinery 710 fuel conditioning system. This system is capable of measuring the amount of fuel consumed by the engine and conditioning the fuel through the use of temperature controllers, solenoids, and heat exchangers.

\subsubsection{Data Acquisition and Data Reduction}

The data acquisition and the data reduction software at the EERC are developed in house. The system is equipped with RTI-815 input/output boards capable of recording and scanning analog channels at $5 \mathrm{~Hz}$. The channels recorded by the system include 
engine water temperature, engine oil temperature, fuel temperature, manifold air pressure, intake air temperature, exhaust temperature and dilution tunnel pressure/temperature engine speed, load cell force. The data acquisition programs acquire the raw data (in the form of $\mathrm{ADC}$ codes) and a reduction program converted the raw data into proper engineering units.

\subsubsection{Bag Sampling}

Two types of bag sampling, a diluted or integrated bag and a background bag are taken at WVU EERC The bag samples are collected in 80-liter Tedlar bags during each emission. The background dilution air bag is analyzed and the concentration levels are used to account for the dilution air contribution to emissions levels that are recorded during a given test. The dilute bag is a sample taken from the tunnel during the test and represents an integrated concentration of the emissions present in the tunnel. The concentration of emissions in the background are later subtracted from the emissions continuously collected and the emissions from the dilute bag using the equations outlined in 40 CFR Part 86 to represent the concentration of gases emitted from the engine.

\subsubsection{Gaseous Emission Analysis System}

The gaseous emission analysis system at WVU EERC consists of heated sample probes, heated transfer lines, and a gas analysis bench. Three electrically heated stainless steel sample probes were installed 10 diameters downstream of the mixing zone origin in

the primary dilution tunnel in order to ensure fully developed turbulent duct flow. All probes faced upstream and were approximately six inches into the tunnel. Heated lines were used to transfer the gaseous pollutants from the probes to the respective analyzers. The hydrocarbon line and probe were maintained at a wall temperature of $375^{\circ} \mathrm{F} \pm 10^{\circ} \mathrm{F}$ to 
prevent condensation of higher molecular weight hydrocarbons and all other probes and lines were kept at $235^{\circ} \mathrm{F} \pm 10^{\circ} \mathrm{F}$ to avoid water condensation. The exhaust gas analysis system at WVU EERC consisted of four major components: $\mathrm{CO}_{2}$ analyzer, $\mathrm{CO}$ analyzer, NOx analyzer, and $\mathrm{HC}$ analyzer. Low and high $\mathrm{CO}$ and $\mathrm{CO}_{2}$ emissions were measured using Horiba Series Non-Dispersive Infrared (NDIR) analyzers. NOx component of the exhaust was measured by a Rosemount Model 955 heated chemiluminescent analyzer. In addition to the Model 955 the setup also included Rosemount Model 958 NOx efficiency tester to calculate the converter's $\mathrm{NO}_{2}$ to $\mathrm{NO}$ conversion efficiency. The total hydrocarbon measurements were made with a Rosemount Model 402 heated flame ionization detector (HFID).

\subsection{WVU Transportable Emissions Testing Laboratory}

The WVU Transportable laboratory [28] makes use of the same type of emissions sampling system as the WVU EERC. However, the transportable laboratory consists of a heavy-duty chassis dynamometer capable of inertia loading and loading with eddy current dynamometers. Power is transferred from the vehicle drive axles through drive shafts from the driven wheels, rather than through the tires to rollers as with most chassis dynamometers. This configuration eliminates tire slippage on the rollers as a factor in the power transferred through the load cell to the dynamometers. Hence, a source or error is eliminated.

\subsection{Classification of Emissions Analyzers}

Two types of emission analyzers used for emissions measurement from internal combustion engines can be divided between garage-grade inspection and maintenance 
analyzers and laboratory-grade analyzers. A third type of the system is developing and lies between the first two and are the in-use grade-level.

\subsubsection{Garage-grade Inspection and Maintenance Analyzers}

Garage-grade analyzers are typically small, lightweight and low-cost compared to laboratory grade analyzers. Size constraints for a system that is reasonably easy to transport and install eliminate most laboratory grade analyzers as candidates for use in the MEMS. Inspection and maintenance grade analyzers are not necessarily designed for mobile operation, but most utilize solid-state sensors that should be resistant to vibrationinduced errors. These analyzers are also sometimes used to detect malfunctioning engines. Most inspection and maintenance grade analyzers utilize NDIR techniques for measurement of $\mathrm{CO}, \mathrm{CO}_{2}$ and $\mathrm{HC}$, and electrochemical cells for $\mathrm{NO}$ and $\mathrm{O}_{2}$ if so equipped.

\subsubsection{Laboratory-grade analyzers}

Laboratory-grade analyzers are accepted worldwide as the standard for measuring emissions from engines. Furthermore, laboratory-grade analyzers were designed for stationary operation in a controlled laboratory environment.

\subsection{Principles of Gaseous Concentration Detector Operation}

The following section describes principle of operation and emission measurement detection schemes employed in various emission analyzers.

\subsubsection{Non-Dispersive Infrared Analyzers}

Non-Dispersive Infrared detection is a principle based on the absorption of energy of unique wavelengths by different gases. An infrared light source provides light energy and a filter allows only a very specific wavelength to pass through to a detector at the 
opposite end of a sample cell. When the gas being measured, or other gas which absorbs a similar wavelength, is not present all of the light energy passing through the filter reaches the detector. As the concentration of gas being measured increases, the amount of energy absorbed by the gas increases. Therefore, the amount of energy reaching the detector is reduced causing a change in output from the detector.

Some analyzers are designed so that the light waves pass alternately through a sample cell and a reference cell filled with inert gas before reaching the detector. Other analyzers contain only a sample cell before the detector, and the light source is switched off and on. Several types of detectors are used in NDIR analyzers.

\subsubsection{Detector Types:}

A solid-state photo conductive detector is often used where vibration may be of concern. This type of detector changes conductance based on the IR energy falling on it. A Luft type detector is generally capable of higher accuracy than a solid-state photo conductive detector and is often used in laboratory-grade analyzers that will not be subjected to vibration. Luft type detectors measure pressure through the use of a diaphragm with a capacitor between the moving diaphragm and a stationary object. A Luft detector may be placed between two chambers of the candidate gas, with one chamber receiving energy through a reference cell, and one receiving energy through a sample cell. Another method of detection using Luft detector is a series arrangement consisting of a sample cell followed by two sealed detection cells containing the candidate gas. A chopper wheel or pulsed light source is used to switch the light path from one cell to the other in the parallel arrangement, while the light is simply switched on and off or periodically blocked off by the chopper wheel in the series arrangement. A 
series arrangement of the two detector cells allow the first cell, which is shorter, to absorb energy closest to the ideal wavelength while the second cell absorbs energy in the fringe areas of the wavelength range. The second cell must be longer than the first because energy in the fringe wavelengths is absorbed less efficiently. The lengths of the two cells are chosen to result in zero pressure difference when all of the light energy reaches the detection cell. When some of the available energy is absorbed by gas in the sample cell, less energy is absorbed by the first detection cell than by the second detection cell. Therefore, the higher pressure in the second detection cell causes a deflection of the diaphragm. Interference from other gases that absorb light of a similar wavelength is minimized because the pressure in the second cell decreases more than the pressure in the first cell when interfering gases in the fringe wavelengths are present in the sample cell. The same arrangement of sample and detection cells may be used in conjunction with a micro flow sensor between the two detection cells. In this case, as the gas is heated or cooled, it flows between the two cells to maintain virtually constant pressure. The output of the capacitor or the micro flow sensor is then converted to gas concentration in the sample cell based on calibration with known gas concentrations [27]. A parallel detection scheme, consisting of a reference cell and a sample cell, followed by two detection cells, may also use a photoconductive detector, a Luft detector or a microflow detector. One detection cell absorbs light passing through the sample cell and another detection cell absorbs light energy passing through the reference cell. As with the series arrangement, the detection cells are sealed and contain the gas being measured. When there is no candidate gas present in the sample cell, both detection chambers receive the maximum energy given off by the light source. As the concentration of candidate gas increases in 
the sample cell more energy is absorbed by that gas, so the energy reaching the detection cell following the sample cell is reduced.

This results in a pressure differential for the Luft detector or flow of gas across a microflow sensor. If a single photoconductive detector is used in a parallel arrangement, mirrors may be used to direct the light beams passing through the sample and reference cells to a single detector. An AC signal is output from the detector due to the pulsing or blocking of the light source by a chopper. An AC signal is desirable because AC amplifiers are less prone to drift than DC amplifiers. The signal is then rectified to DC after being amplified. Sample cell length is chosen based on the expected concentration of the measured gas in the sample stream. Longer cells are used for lower concentrations and shorter cells for higher concentrations. While a longer cell will provide higher resolution, it will be less linear and will have a slower response to transient event [28].

NDIR analyzers are available for measurement of $\mathrm{CO}_{2}, \mathrm{CO}$, and $\mathrm{HC}$. Commercially available instruments vary widely in size depending on their intended use. Laboratory-grade analyzers are typically too large for use in MEMS. However, accuracy is generally sacrificed as size is decreased because the most accurate designs such as a sample and reference cell in parallel followed by a series detection cell requires the most room. Single cell analyzers incorporating a solid-state detector may be very compact and lightweight which qualifies them for use on the MEMS. The sample stream for NDIR analyzers must be filtered and conditioned to an acceptable relative humidity. If water condensed out on the inside of the sample cell the walls will become contaminated with deposits, causing errors in the measurement. Also, water interference is often observed 
with NDIR analyzers. Effects from water interference are minimized as the relative humidity of the sample stream is decreased.

\subsubsection{Electrochemical Sensors}

Electrochemical analyzers are used for gaseous emission measurements including $\mathrm{NO}, \mathrm{NO}_{2}, \mathrm{NO}_{\mathrm{x}}, \mathrm{SO}_{2}, \mathrm{CO}, \mathrm{O}_{2}$, and $\mathrm{CO}_{2}$. An electrochemical cell consists of two or more electrodes separated by an electrolyte. For a cell with two electrodes, one electrode must be porous so the gas can pass through it after diffusing through a membrane. A resistor is connected between the two electrodes and voltage drop across the resistor is proportional to gas concentration. The oxidation reaction for an $\mathrm{NO}$ at the sensing electrode of an electrochemical cell is shown below [29].

$\mathrm{NO}+2 \mathrm{H}_{2} \mathrm{O} \rightarrow \mathrm{HNO}_{3}+3 \mathrm{e}^{-}$

Notice that water is a reactant and therefore must be available in the sample stream to avoid depletion of water from the electrolyte. Electrochemical cells typically have a T90 response time of at least 5 seconds for $\mathrm{NO}$, and approximately 30-40 seconds for $\mathrm{CO}$ and $\mathrm{NO}_{2}$ [29]. Therefore, electrochemical cells are generally considered for NO measurement due to highly transient engine operation of in-use vehicles. A NOx converter would be required to obtain an $\mathrm{NO}+\mathrm{NO}_{2}$ measurement, as required for the MEMS. The sample must be filtered to avoid clogging of the membrane and the sample stream for the NO cells investigated should be between 15 and $90 \%$ relative humidity [30].

\subsubsection{Electrocatalytic Analyzers}

Oxygen concentrations can be measured by an electrocatalytic analyzer consisting of solid zirconium oxide $\left(\mathrm{ZrO}_{2}\right)$ catalytic electrolyte which allows the flow of electron through it. $\mathrm{ZrO}_{2}$ allows the transfer of $\mathrm{O}_{2}$ - ions when heated to approximately $700^{\circ} \mathrm{C}$. A 
current is generated if the electrolyte is placed between gases of two different concentrations. Concentrations of $\mathrm{NO}, \mathrm{CO}$ and $\mathrm{HC}$ can also be measured by this principle. $\mathrm{NO}$ is measured by first removing $\mathrm{O}_{2}$ from the sample and then causing the $\mathrm{NO}$ to dissociate into $\mathrm{N}_{2}$ and $\mathrm{O}_{2} . \mathrm{O}_{2}$ is removed from the sample through a $\mathrm{ZrO}_{2}$ electrolyte coated with platinum to catalyze the transfer process. Current must be supplied in this case because the oxygen is being transferred in the opposite direction of the flow that would be induced by the concentration gradient. The sample then flows into a second cavity where the $\mathrm{O}_{2}$ produced from the dissociation process is measured with a second electrocatalytic device of the same design as the first [29]. Some disadvantages of electrocatalytic sensors include the negative response to components such as $\mathrm{CO}$ and $\mathrm{HC}$ if they are oxidized at the high operating temperatures with the presence of oxygen. In fact, a similar type of sensor is used to measure $\mathrm{CO}$ and $\mathrm{HC}$ by oxidizing the component gases with a heated platinum wire. These sensors are known as catalytic oxidation sensors or pellistors. Gas concentrations are determined based on the resistance change of the wire as its temperature increases due to the combustion of candidate gas. A second platinum wire, poisoned so it does not catalyze the reaction, is used as a reference resistance. The resistance values of the two wires are compared using a Wheatstone bridge to determine the gas concentration [31].

\subsubsection{Chemiluminescent Analyzers}

Chemiluminescent analyzers are commonly used for the measurement of NO concentration. NO concentration is determined from the infrared energy emitted when $\mathrm{NO}$ is converted to $\mathrm{NO}_{2}$. The sample gas containing $\mathrm{NO}$ is reacted with excess ozone $\left(\mathrm{O}_{3}\right)$ to produce $\mathrm{NO}_{2}$. About $10 \%$ of the $\mathrm{NO}_{2}$ molecules formed are in an electronically 
excited state. Photon emissions from the conversion of excited molecules to the non excited state are directly proportional to the concentration of NO. The Chemiluminescent detection principle is governed by the following reactions,

$\mathrm{NO}+\mathrm{O}_{3} \rightarrow \mathrm{NO}_{2}{ }^{*}+\mathrm{O}_{2}$

$\mathrm{NO}_{2}{ }^{*} \rightarrow \mathrm{NO}_{2}+\mathrm{hv}$

An interfering molecule, such as water, can collide with the excited $\mathrm{NO}_{2}$ molecule $\left(\mathrm{NO}_{2}{ }^{*}\right)$. The colliding molecules move faster after their contact, but the additional energy, normally released as a photon, is dissipated during the collision. Therefore, if the water is not removed, measurements made with the chemiluminescent detector can be erroneously low. An $\mathrm{NO}_{2}$ to $\mathrm{NO}$ converter upstream of the analyzer is required for measurement of NOx [27]. Chemiluminescent analyzers may not be suitable for the MEMS due to the size required to contain an ozone generator and NOx converter.

\subsubsection{Heated Flame Ionization Detectors}

Exhaust hydrocarbon levels are measured by counting elemental carbon atoms. A regulated flow of sample gas flows through a flame that is produced by regulated flows of air and premixed hydrogen/helium fuel gas (FID fuel) [28]. The flame causes ions to be produced, which are in turn collected by polarized electrodes, causing a current flow, which is proportional to the number of carbon atoms that make up hydrocarbons in the sample stream.

\subsubsection{Non-Dispersive Ultraviolet Photometers}

Non-dispersive ultraviolet (NDUV) photometers resemble NDIR detectors in their principle of operation. The higher energy ultraviolet light being shorter in wavelength in comparison to infrared light, is capable of being measured easily and more accurately 
then infrared light energy. Also, an advantage of NDUV detectors over NDIR detectors is its ability to sample wet exhaust because water absorbs very little energy in the ultraviolet wavelength range used [29]. Two different wavelengths of ultraviolet energy are transmitted through a single sample cell. Two band-pass filters are used, one to provide energy of a wavelength absorbed by the candidate gas, and one to provide energy of a wavelength that is not absorbed by the candidate gas. The transmitted energy of each wavelength range is measured and compared to determine candidate gas concentration.

\subsubsection{Fourier Transform Infrared Spectroscopy}

Fourier transform infrared spectroscopy (FTIR) analyzers are a relatively new method of measuring emissions gases. They have capability of measuring several gases at a time. The infrared energy absorbed over a wide wavelength range, typically 5 to 25 micrometers is recorded. This data is then converted to gas concentrations with a Fourier transform [27]. Because of their large size and weight, these instruments are not suitable for use in MEMS.

\subsubsection{Miniature Gas Chromatographs}

Gas chromatographs may also be used for gaseous exhaust measurement. However, they are not suitable for on-road vehicle testing because of their slow time response and batch wise function. Their T90 response is approximately 180 seconds [29]. 


\section{Experimental Procedure and Setup}

In order to check the drying effectiveness of chiller units installed in various emission measurement systems at WVU EERC, experimental setups were devised. The measurement of dew point temperature, dry bulb temperature and relative humidity of sample stream was accomplished by the use of two different portable hygrometers, an EdgeTech hygrometer [32] and an Ohmic AMM-15 [33] portable dew-point meter. Both of these hygrometers were used to measure gas inlet and outlet conditions of the six different chiller units. An acquisition program was used to record the data to a computer from both of the hygrometers. Recorded data was analyzed and interpreted to establish a correlation between the meters. The data also provided insight into the drying characteristics of the chiller units utilized in different emission measurement systems. A detailed description of experimental arrangements, instruments to measure dew point, dry bulb temperature, relative humidity and the design and specification of chiller units used for the experiments is given below.

\subsection{Types of Hygrometers Used in the Experiment}

Two types of hygrometers, an EdgeTech DewPrime II hygrometer and an Ohmic AMM-15 portable dew-point meter, were utilized for humidity measurements during the tests. A brief description about these instruments and their theory of operation is presented below.

\subsubsection{EdgeTech DewPrime II hygrometer}

A photograph of the EdgeTech DewPrime II can be seen in the Figure 1. This instrument was used to measure the dew point temperature, dry bulb temperature and relative humidity. EdgeTech DewPrime II hygrometer uses chilled mirror technology to 
measure the dew point of the sample. It measures the gas dew point by cooling a surface over which a gas flows until a layer of dew forms on the surface, then maintaining the temperature of that surface such that the layer of the dew remains uniform. The surface is a mirror with an LED light source shining on it and reflecting to an optical sensor. Another LED light source shines directly on a second optical sensor. The system is set up so that when the mirror is dry, a positive voltage is output from a amplifier A1. This positive voltage results in positive current from amplifier A2, a voltage to current converter into the thermo-electric heater/cooler to cool the mirror surface. When the dew point is reached, a layer of dew begins to form on the mirror resulting in decreased reflectance of LED light and a positive signal at the input summing point of the amplifier A1. Since A1 is an inverting amplifier, the voltage input of A1 will reduce (possibly becomes negative) and results in a decrease in cooling current (or possibly a reversal causing heating to occur). The temperature of the mirror surface is maintained closely in this manner, and the temperature is monitored by means of a platinum resistance thermometer (PRT), embedded beneath the mirror surface. The PRT is the part of a bridge, and the bridge output, proportional to the mirror surface temperature, is amplified by an amplifier A3 and converted into a digital value approximately once per second, which is used for the display of the dew point and for analog or serial output. 


\section{Figure 1 EdgeTech DewPrime II hygrometer [32]}

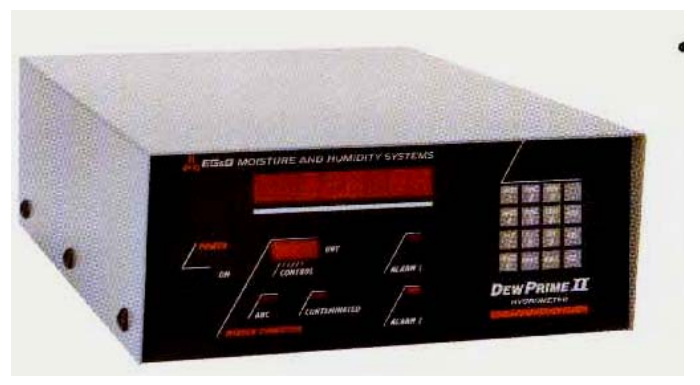

\subsubsection{Automatic Balance Control (ABC)}

At programmable intervals EdgeTech DewPrime II hygrometer can be forced into an automatic balance control cycle to compensate for the build up of contaminates on the mirror surface, which may change the optical balance of the system. When an $A B C$ is begun, the control loop is interpreted, the mirror is heated so that the dew is evaporated, and a new balance point is found that compensates for mirror contaminants. The control loop is then reconnected and after sometime normal control operation is attained.

Table 2 shows the manufacturer's specifications of EdgeTech Dew Prime II hygrometer. This instrument measures the dew/frost point ranging from $-50^{\circ} \mathrm{F}$ to $212^{\circ} \mathrm{F}$, sample temperature (dry bulb temperature) from $-58^{\circ} \mathrm{F}$ to $266^{\circ} \mathrm{F}$ and measurement range for relative humidity is from 1 to $100 \%$. The measurement accuracy for dew point and sample temperature (dry bulb temperature) are $\pm 0.36^{\circ} \mathrm{F}$ and a value of $\pm 0.5 \%$ for relative humidity. Repeatability may be defined as the variation in measurements obtained when one person measures the same unit with the same measuring equipment. EdgeTech Dew Prime II has a repeatability of $0.2^{\circ} \mathrm{F}$. The sample flow rate specified for this hygrometer ranges between 0.5 to 5 standard cubic feet per hour. The sample pressure and operating 
temperature range for this instrument lies between 0-300 PSIA and -58 to $212^{\circ} \mathrm{F}$, respectively.

Table 2 General Specifications of the EdgeTech DewPrime II Hygrometer [32]

\begin{tabular}{|c|c|c|}
\hline Parameters & Units & Values \\
\hline Dew/Frost Point Range & ${ }^{\circ} \mathrm{F}$ & -50 to 212 \\
\hline Dry Bulb Temperature Range & ${ }^{\circ} \mathrm{F}$ & -58 to 266 \\
\hline Relative Humidity Range & ${ }^{\circ} \mathrm{o}$ & 1 to 100 \\
\hline Accuracy Dew /Frost Point & ${ }^{\circ} \mathrm{F}$ & \pm 0.36 \\
\hline Accuracy Dry Bulb Temperature & ${ }^{\circ} \mathrm{F}$ & \pm 0.36 \\
\hline Accuracy Relative Humidity & ${ }^{\circ} \%$ & \pm 0.5 \\
\hline Repeatability & ${ }^{\circ} \mathrm{F}$ & 0.2 \\
\hline Operating Temperature & ${ }^{\circ} \mathrm{F}$ & -58 to 212 \\
\hline Sample Flow Rate & SCFH & 0.5 to 5.0 \\
\hline Sample Pressure & PSIA & 0 to 300 \\
\hline Auxiliary Coolant (Water) & ${ }^{\text {LPM }}$ & \\
\hline & & \\
\hline
\end{tabular}

\subsubsection{Ohmic AMM-15 Portable Dew-Point Meter}

A photograph of the Ohmic AMM-15 portable dew point meter can be seen in Figure 2. The model AMM-15 measures dew point by utilizing microprocessor circuitry to convert the voltage output of Ohmic's HC-610 precision water vapor sensor and a temperature sensor to dew/frost point temperature by the use of psychrometric equations. Assembled in a rugged hand-held Acrylonitrile Butadiene Styrene (ABS) plastic enclosure and equipped with quick disconnect tubing couplings and an internal sensor 
manifold. An orifice maintains line pressure for true pressure dew point readings. The Ohmic hygrometer only measures the dew point and dry bulb temperature. Relative humidity was calculated by the help of following set of equations.

$$
\begin{aligned}
& \mathrm{Es}=6.11 * 10.0 * *(7.5 * \mathrm{Tc} /(237.7+\mathrm{Tc})) \\
& \mathrm{E}=6.11 * 10.0 * *(7.5 * \mathrm{Tdc} /(237.7+\mathrm{Tdc})) \\
& \mathrm{RH}=(\mathrm{E} / \mathrm{Es}) * 100
\end{aligned}
$$

Where Es is the saturation vapor pressure and $\mathrm{E}$ is the actual vapor pressure calculated in millibars. Tc and Tdc represent dry bulb and dew point temperatures in degree Celsius. The dew point and dry bulb temperatures measured by the Ohmic hygrometer were converted from Fahrenheit to degree Celsius.

Finally the relative humidity was calculated by dividing Saturation vapor pressure (Es) by actual vapor pressure (E) using the formula mentioned above.

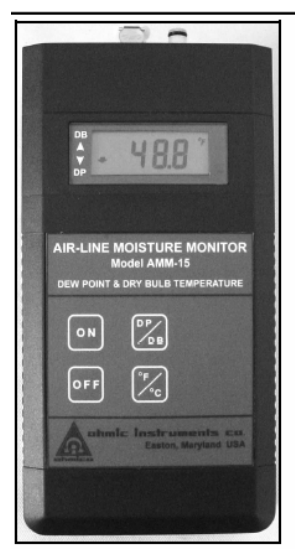

Figure 2 Ohmic AMM-15 Portable Dew-Point Meter [33] 
Table 3 shows the manufacturer's specifications of Ohmic AMM-15 portable dew point meter. This instrument measures dew/frost point ranging from $-40^{\circ} \mathrm{F}$ to $80^{\circ} \mathrm{F}$ and ambient temperature (dry bulb temperature) ranging from $0^{\circ} \mathrm{F}$ to $200^{\circ} \mathrm{F}$. The measurement accuracy for dew point is $\pm 4^{\circ} \mathrm{F}$ for a dew point ranging from -40 to $+20^{\circ} \mathrm{F}$ and shows a dew point accuracy of $\pm 2^{\circ} \mathrm{F}$ for the dew point between 20 to $80^{\circ} \mathrm{F}$. Ambient temperature (dry bulb temperature) measurement is accurate to a value of $\pm 1^{\circ} \mathrm{F}$. The Ohmic AMM-15 portable dew-point can be operated with a maximum sample inlet pressure of 175 PSIG and also its design permits to withstand a maximum sample inlet temperature of $550^{\circ} \mathrm{F}$.

Table 3 General Specifications of the Ohmic AMM-15 Portable Dew-Point Meter [33]

\begin{tabular}{|c|c|c|}
\hline Parameters & Units & Values \\
\hline Dew point Range & ${ }^{\circ} \mathrm{F}$ & -40 to 80 \\
\hline Dry Bulb Temp. Range & ${ }^{\circ} \mathrm{F}$ & 0 to 200 \\
\hline Dew point Accuracy from -40 to $+20^{\circ} \mathrm{F}$ & ${ }^{\circ} \mathrm{F}$ & \pm 4 \\
\hline Dew point Accuracy from 20 to $+80^{\circ} \mathrm{F}$ & ${ }^{\circ} \mathrm{F}$ & \pm 2 \\
\hline Dry Bulb Accuracy & ${ }^{\circ} \mathrm{F}$ & \pm 1 \\
\hline Maximum Inlet Temp. & ${ }^{\circ} \mathrm{F}$ & 550 \\
\hline Inlet Pressure & PSIG & 175 \\
\hline Sensor Response Time for63\% step change & Sec & 10 \\
\hline
\end{tabular}




\subsection{Types of Electric Gas Coolers Used in the Experiments}

In order to estimate the behavior and drying efficiency, different types of gas coolers/dryers used in the experiments include an electric gas cooler ECP 1000, ECP 2000, a refrigeration dyer CRD 5-100, MEMS chiller unit, Micro MEMS chiller unit and SEMTECH-D chiller unit.

Refrigeration dyer CRD 5-100 makes use of a refrigerant R134a which absorbs the heat from sample and dries the sample stream by removing the moisture from it. ECP 1000, ECP 2000, MEMS chiller unit, Micro MEMS chiller unit and SEMTECH-D chiller unit utilize a Peltier cooler to cool down the sample stream to a desired level. Peltier coolers consist of the Peltier element itself, and a heat sink/fan combination to cool the thermo electric cooler (TEC).

\subsubsection{Electric Gas Cooler ECP 1000/2000}

A photograph of the dryer units ECP 1000/2000 can be seen in the Figure 3. The Peltier gas sample cooler type ECP 1000/2000 are used in analyzer sample system design [34] to reduce the dew point of wet gases to a level that is stable and low. Sample gas cooling prevents subsequent condensation in the analyzer. The stability of the dew point is also extremely important as it helps to prevent water vapor cross sensitivity and volumetric error, particularly in infrared analyzers. The sample gas passes through a sampling probe to the type ECP $1000 / 2000$ cooler where it is lowered to a dew point of $5^{\circ} \mathrm{C}$. Solids are trapped in the filter of the sample probe or are trapped in a downstream fine filter. The type ECP 1000 Peltier gas sample cooler contains an ECP Jet-Stream heat exchanger made either of Duran glass, stainless steel or PolyVinyliDene Fluoride 
(PVDF) for a maximum flow of $150 \mathrm{l} / \mathrm{h}$. The ECP 2000 contains two ECP 1000 JetStream heat exchanger for cooling of two channels at $150 \mathrm{l} / \mathrm{h}$ each. Figure 4 shows functional diagram of the ECP 1000 heat exchanger. The exchanger is housed for ease of replacement in a thermally insulated cooling block. The temperature is measured with a PT 100 temperature sensor and regulated electronically by Peltier elements on a constant temperature of $5^{\circ} \mathrm{C}\left(41^{\circ} \mathrm{F}\right)$. Sample gas enters at the top and the condensate is collected at the bottom of the cooling block.

Figure 3 Electric Gas Cooler ECP 1000 and ECP 2000 [34].
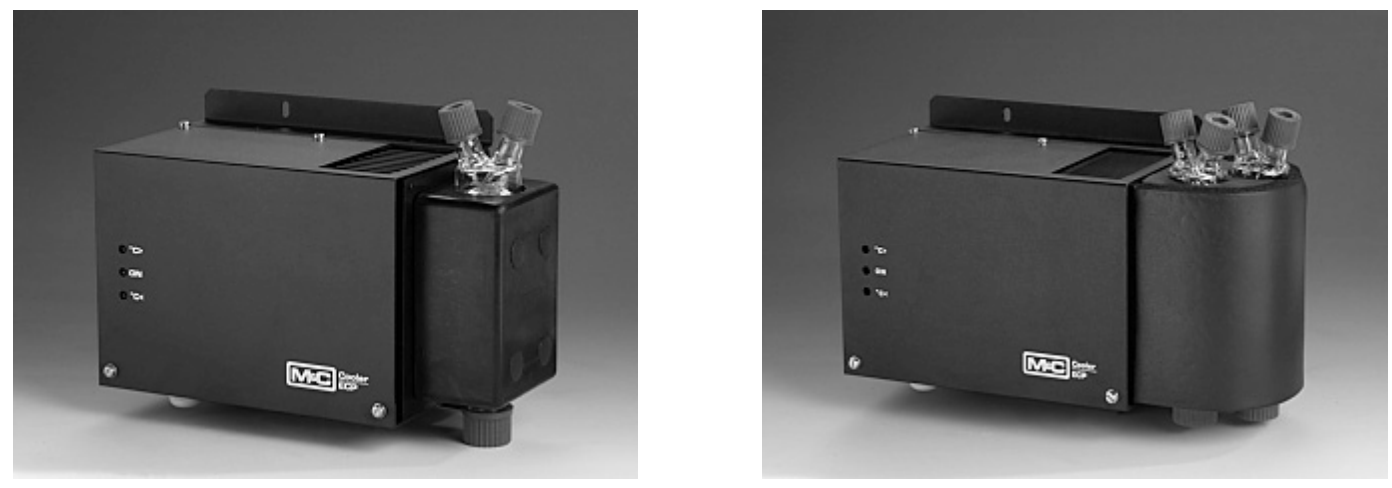

Figure 4 [34] Functional Diagram of the ECP 1000 Heat Exchanger

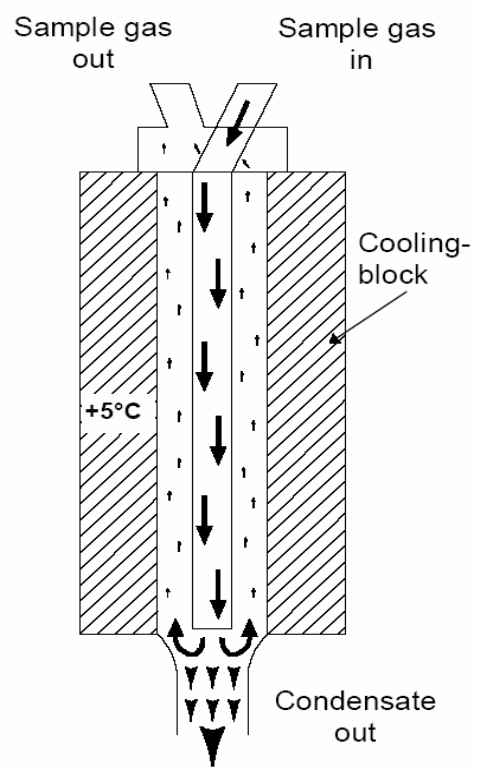




\section{General Specifications of the Gas Dryer ECP 1000/2000 [34]}

Table 4 is the manufacturer's specification for gas dryer units ECP 1000/2000. Both of the dryer units permit maximum sample inlet dew point of $176^{\circ} \mathrm{F}$. Sample outlet dew point is delivered at $41^{\circ} \mathrm{F}$ with a variation of $\pm 1.8^{\circ} \mathrm{F}$. The ECP 1000 has one heat exchanger and has a flow rate of 150 1/h. ECP 2000 has two heat exchangers for cooling of two channels at $150 \mathrm{l} / \mathrm{h}$ each. The ECP 1000/200 heat exchanger is made of stainless steel. ECP 1000/2000 is designed to be operated on a maximum sample inlet temperature of $356^{\circ} \mathrm{F}$ and can withstand a maximum pressure of 10 bar for heat exchangers.

Table 4 [34] General Specifications of the Gas Dryer ECP 1000/2000

\begin{tabular}{|c|c|c|}
\hline Electro Gas Cooler & ECP 1000 & ECP 2000 \\
\hline Sample Outlet Dew Point & \multicolumn{2}{|c|}{42.8 to $39.2^{\circ} \mathrm{F}$} \\
\hline Sample Inlet Temperature & Max. $356^{\circ} \mathrm{F}$ \\
\hline Sample Inlet Dew Point & $15016^{\circ} \mathrm{F}$ \\
\hline $\begin{array}{c}\text { Gas Flow Rate Per Heat } \\
\text { Exchanger }\end{array}$ & 1 & $1501 / \mathrm{h}$ \\
\hline No. of Heat Exchangers & \multicolumn{2}{|c|}{ Stainless steel 1.4571} \\
\hline Material of Heat Exchangers & 41 to $113^{\circ} \mathrm{F}$ & \multicolumn{2}{|c|}{41 to $122^{\circ} \mathrm{F}$} \\
\hline Ambient Temperature & \multicolumn{2}{|c|}{ Max. 10 bar } \\
\hline Inlet Pressure & \multicolumn{2}{|c|}{} \\
\hline
\end{tabular}

\subsubsection{Domnic Hunter, CRD Refrigeration Dryer}

The WVU EERC emission bench includes a gas sample dryer unit, Domnic Hunter CRD5-100 refrigeration dryer [35], for condensing the moisture in the sample stream before it enters the emission analyzers. Photographs of Domnic Hunter CRD5-100 can be seen in the Figure 5. This chiller unit is designed for compressed air applications. It removes water from compressed systems which is drained out through a float drain 
installed in the system. Domnic Hunter CD5-100 uses refrigerant R134a. The system also contains an air-to-air heat exchanger to raise the outlet air temperature and to eliminate the condensation that can occur on the chilled piping in the humid conditions.

\section{Figure 5 [35] Domnic Hunter CRD5-100 Refrigeration Dryer}
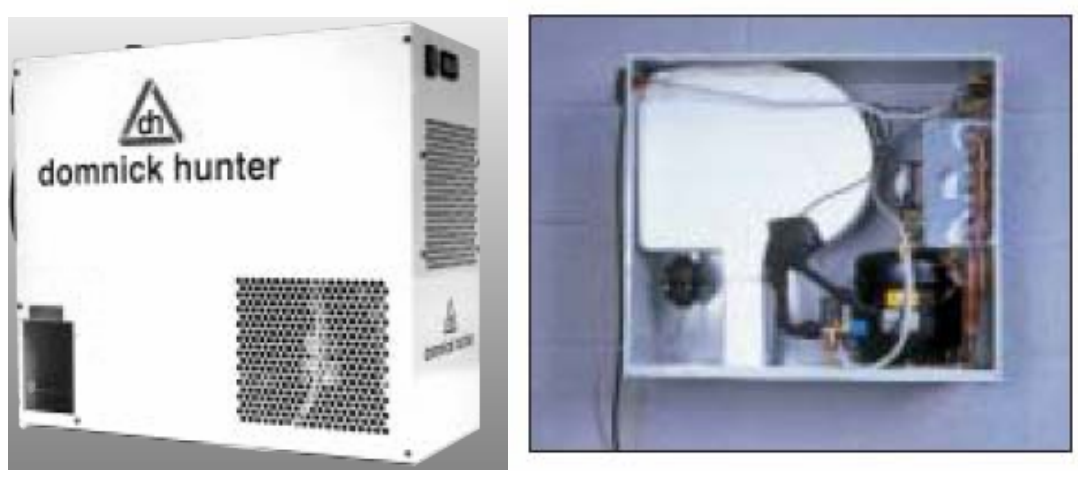

As shown in Table 5, the dried sample from Domnic Hunter CRD5-100 has an outlet dew point within the limits $33-39^{\circ} \mathrm{F}$. It can be operated with a maximum air inlet temperature of $140^{\circ} \mathrm{F}$. The ambient operating condition for this dryer unit lies between $40-122^{\circ} \mathrm{F}$ and can be operated with a maximum air inlet pressure of 16 bar.

Table 5 [35] Technical Specification Domnic Hunter CRD5-100 Refrigeration Dryer

\begin{tabular}{|c|c|c|}
\hline Parameters & Units & Values \\
\hline Air Outlet Dew Point & ${ }^{\circ} \mathrm{F}$ & 33 to 39 \\
\hline Air Inlet Temperature & ${ }^{\circ} \mathrm{F}$ & Max. 140 \\
\hline Ambient Temperature & ${ }^{\circ} \mathrm{F}$ & 40 to 122 \\
\hline Air Inlet Pressure & Bar & Max. 16 \\
\hline
\end{tabular}




\subsubsection{MEMS, Micro MEMS and SEMTECH-D Chiller Units}

The electric gas cooler used in MEMS chiller unit was a Universal Analyzers model 1080. The Universal Analyzers model 1080 is a dual-stream cooler with a total flow rate capacity of 10 LPM. This cooler is capable of drying the sample gas to a dew point of $41^{\circ} \mathrm{F}\left(5^{\circ} \mathrm{C}\right)$ at a flow rate of up to $5 \mathrm{LPM}$ per side.

The Peltier cooler used in Micro MEMS utilized a TE Technology TE-2-(127127)-1.3 mufti-stage module Peltier element. The chiller cold plate was controlled at $5^{\circ} \mathrm{C}$.

SEMTECH-D used a thermo-electric chiller to cool the sample in order to condense water and heavy hydrocarbons before entering the $\mathrm{CO} 2 / \mathrm{CO}, \mathrm{O} 2$, and $\mathrm{NO} / \mathrm{NO} 2$ analyzers. The chiller cold-plate was controlled at $4{ }^{\circ} \mathrm{C}$. 


\subsection{Experimental Setup}

Experimental setups were devised to measure dew point temperature, dry bulb temperature and the relative humidity of the sample gas utilizing EdgeTech DewPrime II hygrometer and an Ohmic AMM-15 Portable Dew-point meter. A brief detail of experimental arrangements is given as follows.

\subsubsection{Test Setup\#1 Instrument Comparison}

EdgeTech DewPrime II hygrometer and an Ohmic AMM-15 portable dew-point meter were correlated against each other using different level of humidified air. A STEC SGD 710 gas divider was used in the comparison. Calibration gases, dry nitrogen as a balance gas and dry zero air passing through a water bubbler (moist air) with a specific humidity ranging from 0.0005 to $0.017 \mathrm{lb}$ of water/lb of dry air was used as a component gas. The mixture of calibration gases from the gas divider were passed through EdgeTech DewPrime II and Ohmic AMM-15 portable dew point meters. Initially the gas divider was set to $0 \%$ moist zero air and the response of both hygrometers was recorded using a data acquisition program to record dew point temperature, dry bulb temperature and the relative humidity from both of the meters. The gas mixture concentrations were varied by setting the gas divider regulator to different percentages of moist air, ranging from 0$100 \%$ in $10 \%$ increments. After reaching the $100 \%$ position, a check on the repeatability and the accuracy of the measurement was done by following the same procedure again. From the recorded data, curves were drawn to make a comparison of two hygrometers for their accuracy and repeatability of measurements.

Figure 6 shows the schematic diagram of the first setup. Dry bottled air passing through a water bubbler and dry bottled nitrogen were connected to a gas divider STEC 
SGD 710 using quarter inch outer diameter teflon tubing and quick disconnects. The divider outlet was connected to EdgeTech DewPrime II and Ohmic AMM-15 portable dew-point meter using combination of T-joints and quick disconnects. Both EdgeTech and Ohmic hygrometers were connected to the computer through serial ports to record the response from both hygrometers.

Figure 6 Test Setup1 Instrument Comparison

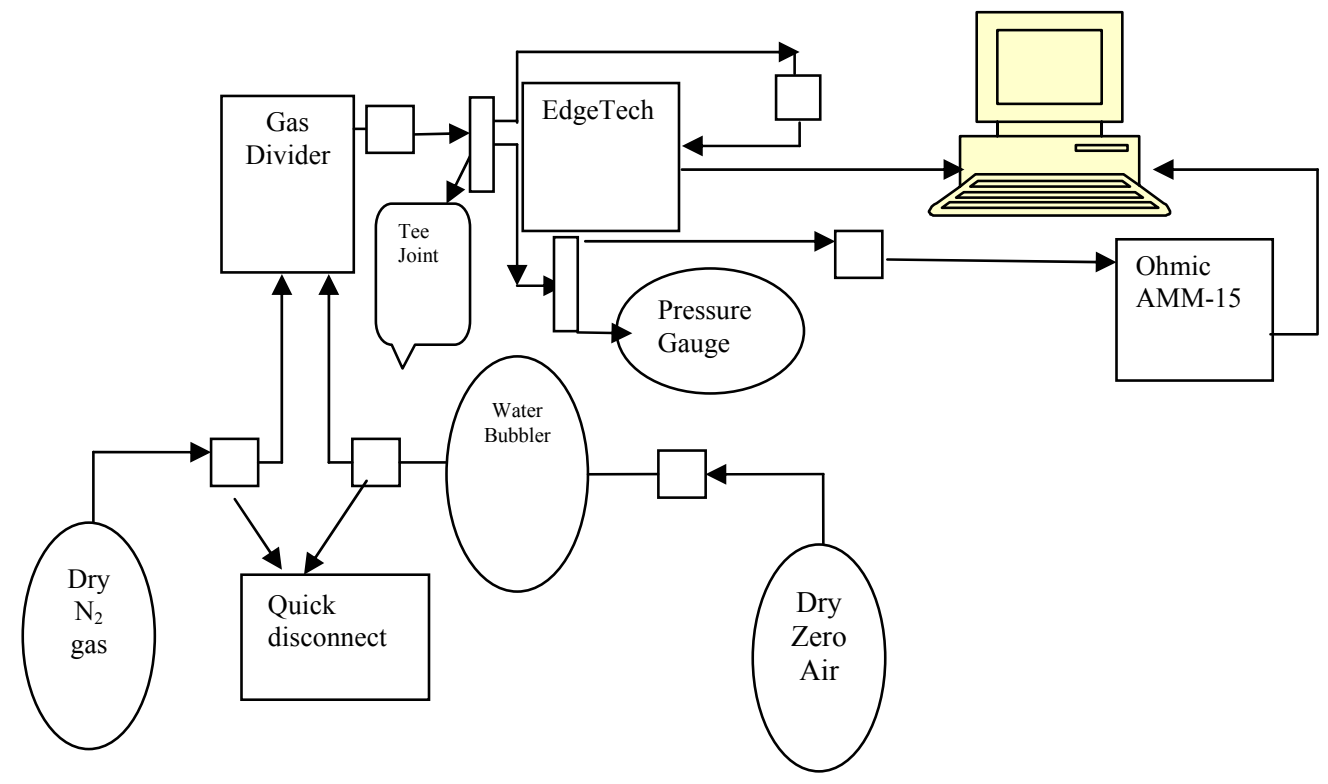

For the EdgeTech DewPrime II and Ohmic AMM-15 hygrometer comparison, it can be concluded from Table 7 that at the lower moisture concentration the dew point and the relative humidity are lower for both of the hygrometers and they keep on increasing as the moist air concentration increases. The EdgeTech and Ohmic hygrometers show greater variation between dew points and relative humidity at lower moist air concentrations as compared to the variations at higher dry bubbled air concentrations. This might be due to the fact that both hygrometers have different accuracy limits. Looking towards the accuracy limits of both of these hygrometers (Tables 2 and 3), it can 
be followed from Table 6 that both of the meters show larger difference in the values of dew point and relative humidity at lower bubbled air concentrations and this gap narrows and is within the accuracy limit of both meters with increasing bubbled air concentration and higher dew points. The difference in the dew points and relative humidity at a lower humidity level might also be due to fact that EdgeTech DewPrime II is unable to lower the chamber temperature at lower humidity levels without external coolant.

Table 6 Comparison between EdgeTech DewPrime II Hygrometer and Ohmic AMM-15 Portable Dew Point Meter

\begin{tabular}{|c|c|c|c|c|c|c|}
\hline $\begin{array}{c}\text { Dry Bubbled } \\
\text { Air } \\
\text { Concentration }\end{array}$ & $\begin{array}{c}\text { Ohmic } \\
\text { Dew Point } \\
\text { Temp. }\end{array}$ & $\begin{array}{c}\text { EdgeTech } \\
\text { Dew Point } \\
\text { Temp. }\end{array}$ & $\begin{array}{c}\text { EdgeTech } \\
\text { Dry Bulb } \\
\text { Temp. }\end{array}$ & $\begin{array}{c}\text { Ohmic } \\
\text { Dry Bulb } \\
\text { Temp. }\end{array}$ & $\begin{array}{c}\text { EdgeTech } \\
\text { Relative } \\
\text { Humidity }\end{array}$ & $\begin{array}{c}\text { Ohmic } \\
\text { Relative } \\
\text { Humidity }\end{array}$ \\
\hline$\%$ & F & F & F & F & $\%$ & $\%$ \\
\hline 0.00 & -23.00 & -6.000 & 80.00 & 82.30 & 3.250 & 1.270 \\
\hline 10.0 & 17.04 & 9.500 & 80.08 & 82.30 & 6.700 & 8.700 \\
\hline 20.0 & 30.80 & 27.00 & 80.20 & 82.30 & 14.19 & 15.49 \\
\hline 30.0 & 39.83 & 38.00 & 80.20 & 82.40 & 22.10 & 22.10 \\
\hline 40.0 & 47.26 & 46.00 & 80.40 & 82.40 & 29.88 & 29.37 \\
\hline 50.0 & 53.10 & 52.00 & 80.49 & 82.40 & 37.28 & 36.49 \\
\hline 60.0 & 58.10 & 58.00 & 80.50 & 82.48 & 46.35 & 43.62 \\
\hline 70.0 & 62.50 & 62.00 & 80.00 & 82.58 & 54.31 & 50.84 \\
\hline 80.0 & 66.30 & 66.00 & 80.30 & 82.40 & 61.85 & 58.38 \\
\hline 90.0 & 69.90 & 69.00 & 80.20 & 82.40 & 68.80 & 66.06 \\
\hline 100 & 72.92 & 72.00 & 80.20 & 82.40 & 76.18 & 73.17 \\
\hline
\end{tabular}

It is clear from Figure 7 that both of the EdgeTech and Ohmic hygrometer show a larger variation in dew points in the beginning of the experiment when dry bubbled air concentration is low compared to the variation at higher dry bubbled air concentrations. Also it is concluded from the graph that EdgeTech, in comparison to Ohmic hygrometer, 
stabilizes more quickly and maintains constant values. The reason for Ohmic hygrometer to have less steady state behavior might be due to the difference in the accuracy limit as well as the time response difference among the two meters. Also it is apparent from the Figure 7 that data measured from both of the hygrometers is also repeatable.

Figure 7 Dew Point Comparison between EdgeTech DewPrime II Hygrometer and Ohmic AMM-15 Portable Dew-point Meter

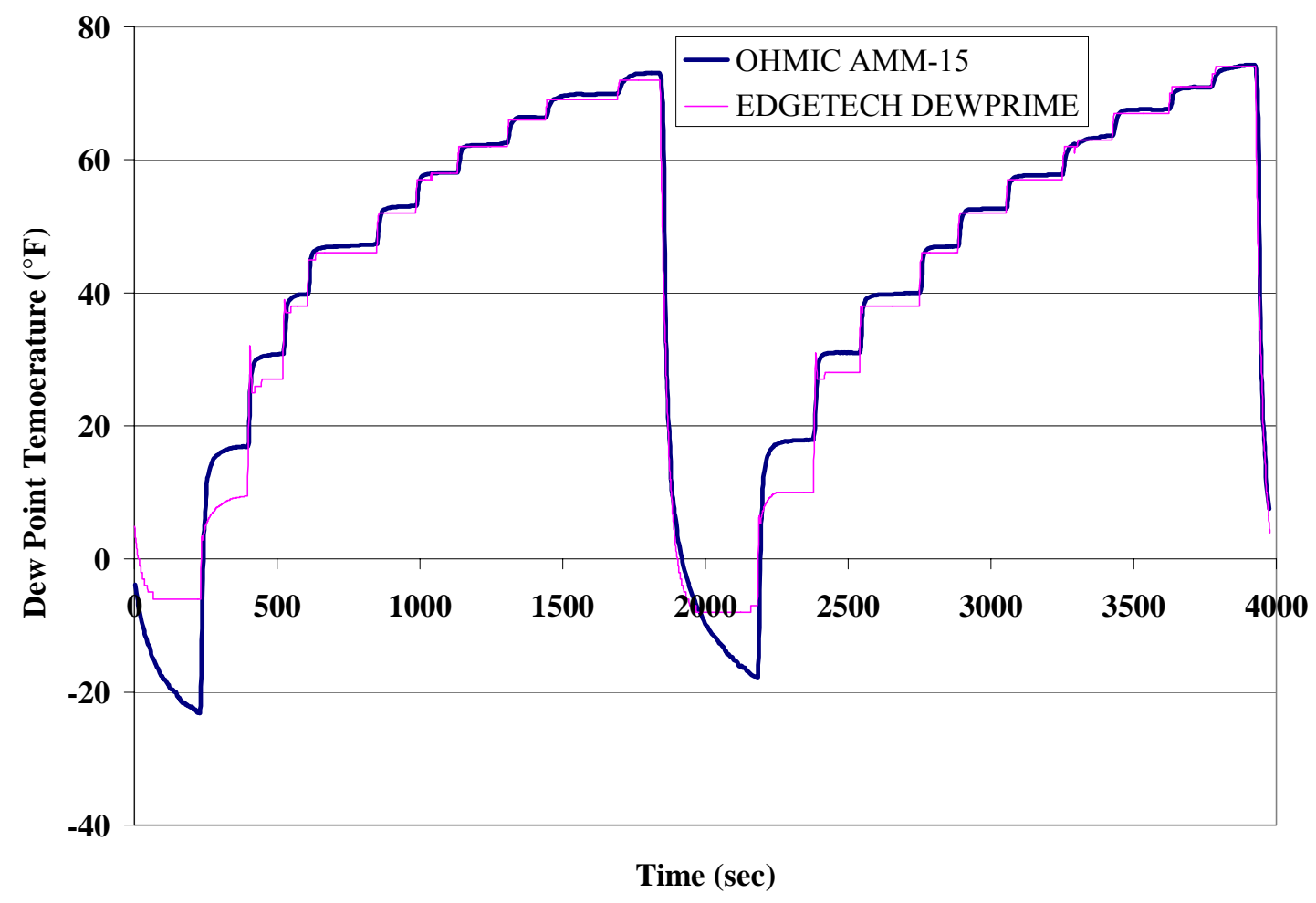

Figure 8 shows that both EdgeTech DewPrime II hygrometer and Ohmic AMM15 portable dew point meter show largest difference in dew point measurements at $0 \%$ position or dry air. The gap between the two curves narrows down as the bubbled air concentration increases. The difference in the dew point accuracy between EdgeTech and Ohmic is also due to the lack of cooling of EdgeTech's chilled mirror at lower humidity level accounts for the variation in measured dew points at both low and high humidity levels. 
Figure 8 Dew Point Comparison between EdgeTech DewPrime II hygrometer and Ohmic AMM-15 Portable Dew Point Meter

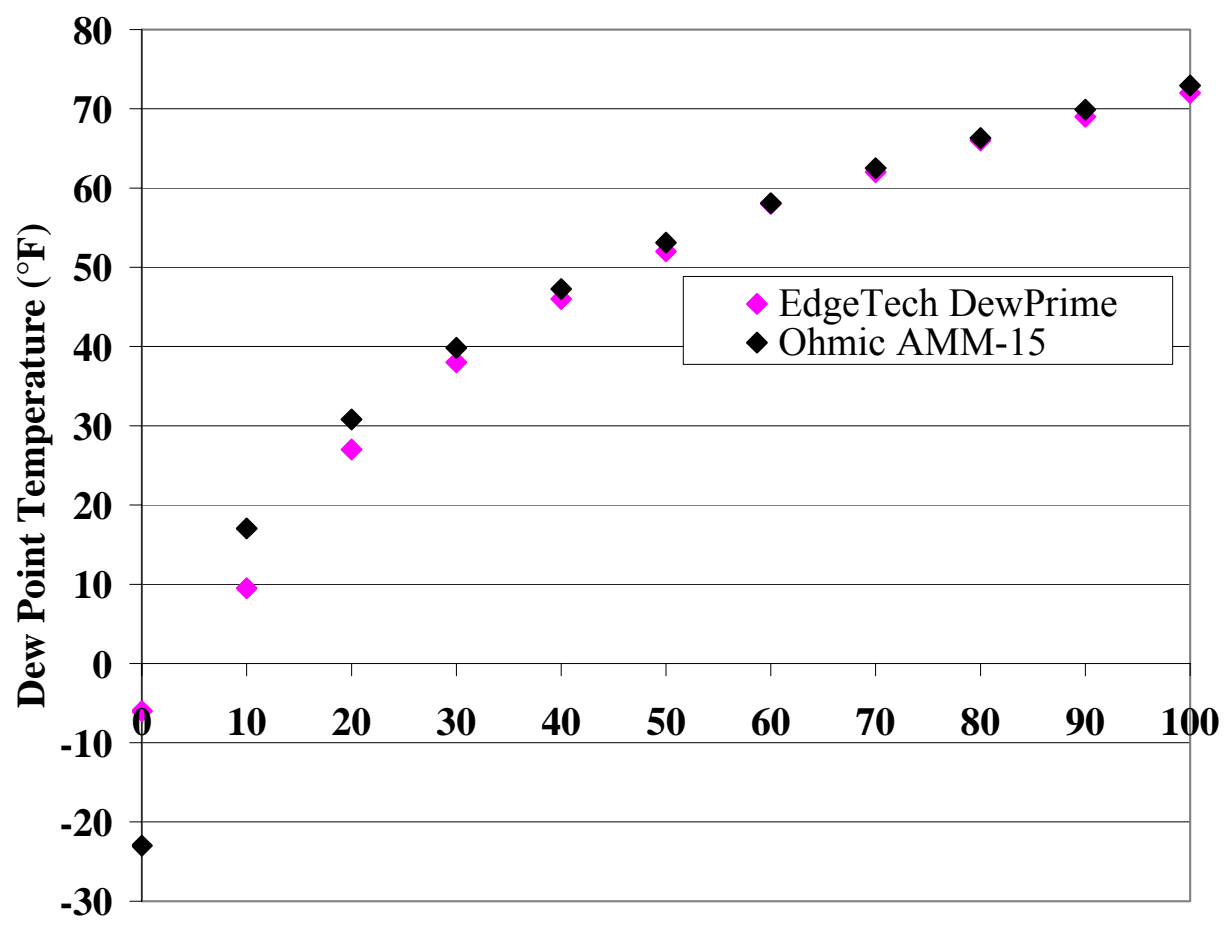

Dry Zero/Bubbled Gas Divider Position (\%)

Figure 9 is a parity plot showing a comparison of dew point measurement made by Ohmic and EdgeTech hygrometers. Experimental data shows that both hygrometers present larger error at lower moist air concentration. This error in dew point accuracy is reduced and also within the accuracy range (Table 2 and 3) for two meters with increasing moist air concentration. 
Figure 9 Dew point Parity Plot between EdgeTech and Ohmic AMM-15

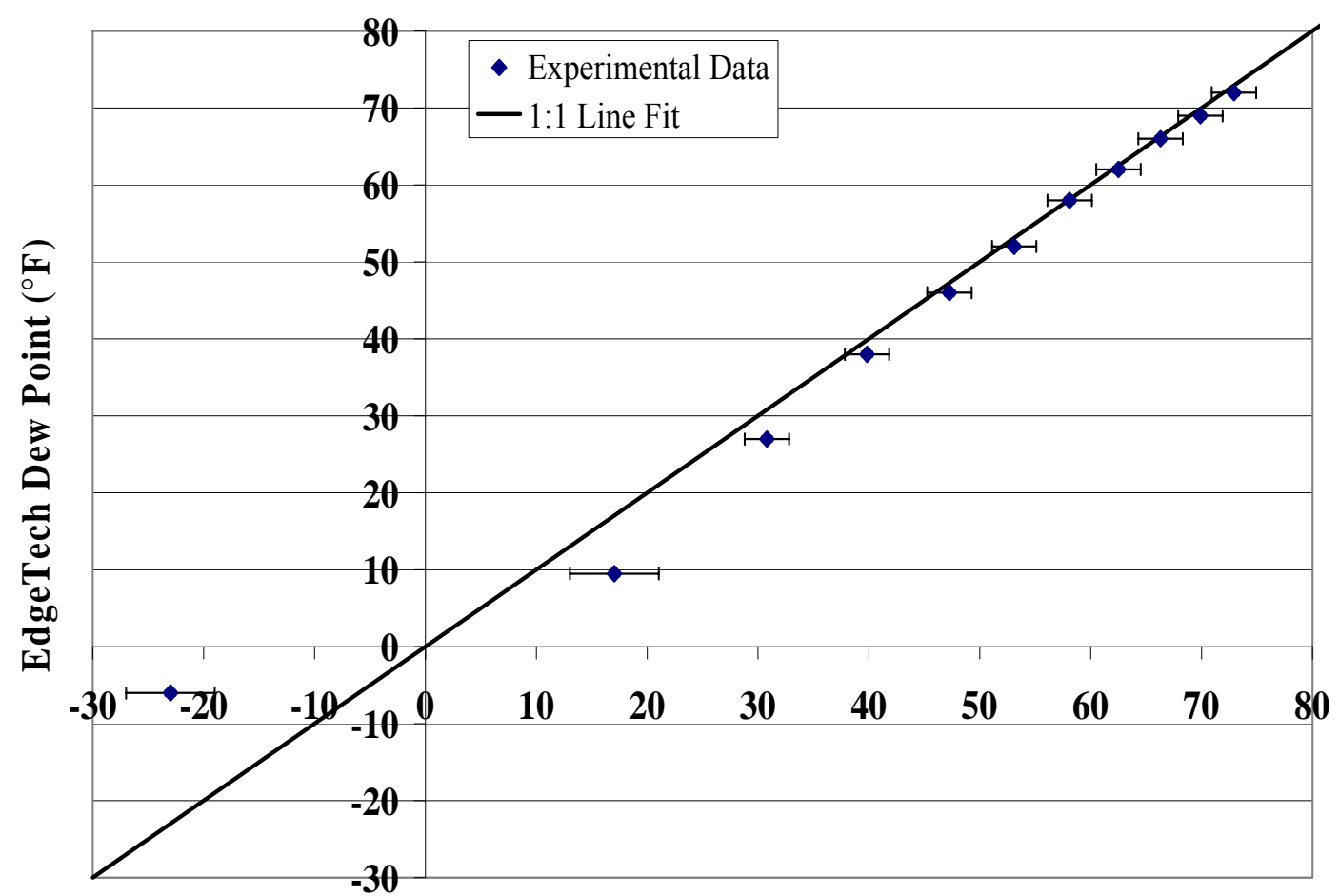

Ohmic Dew Point $\left({ }^{\circ} \mathbf{F}\right)$

It can be concluded from the Figure 10 that both of the hygrometers approximately show the steady state behavior at different dry bubbled air concentrations. Ohmic having a dry bulb accuracy of $\pm^{\circ} 1$ in comparison to Edge Tech dry bulb accuracy $\pm 0.6^{\circ} \mathrm{F}$, partially accounts for the differences in the measured values of dry bulb temperatures from both of the hygrometers. It is also speculated that ambient air temperature and or sensor location may have also caused a difference in these readings. The Ohmic AMM-15 sensor was embedded in the instrument and electrical heating from the instrument's electronics may have caused a higher reading than the EdgeTech DewPrime II hygrometer. 
Figure 10 Dry Bulb Temperature Comparison between EdgeTech DewPrime II Hygrometer and OHMIC AMM-15 Portable Dew-point Meter

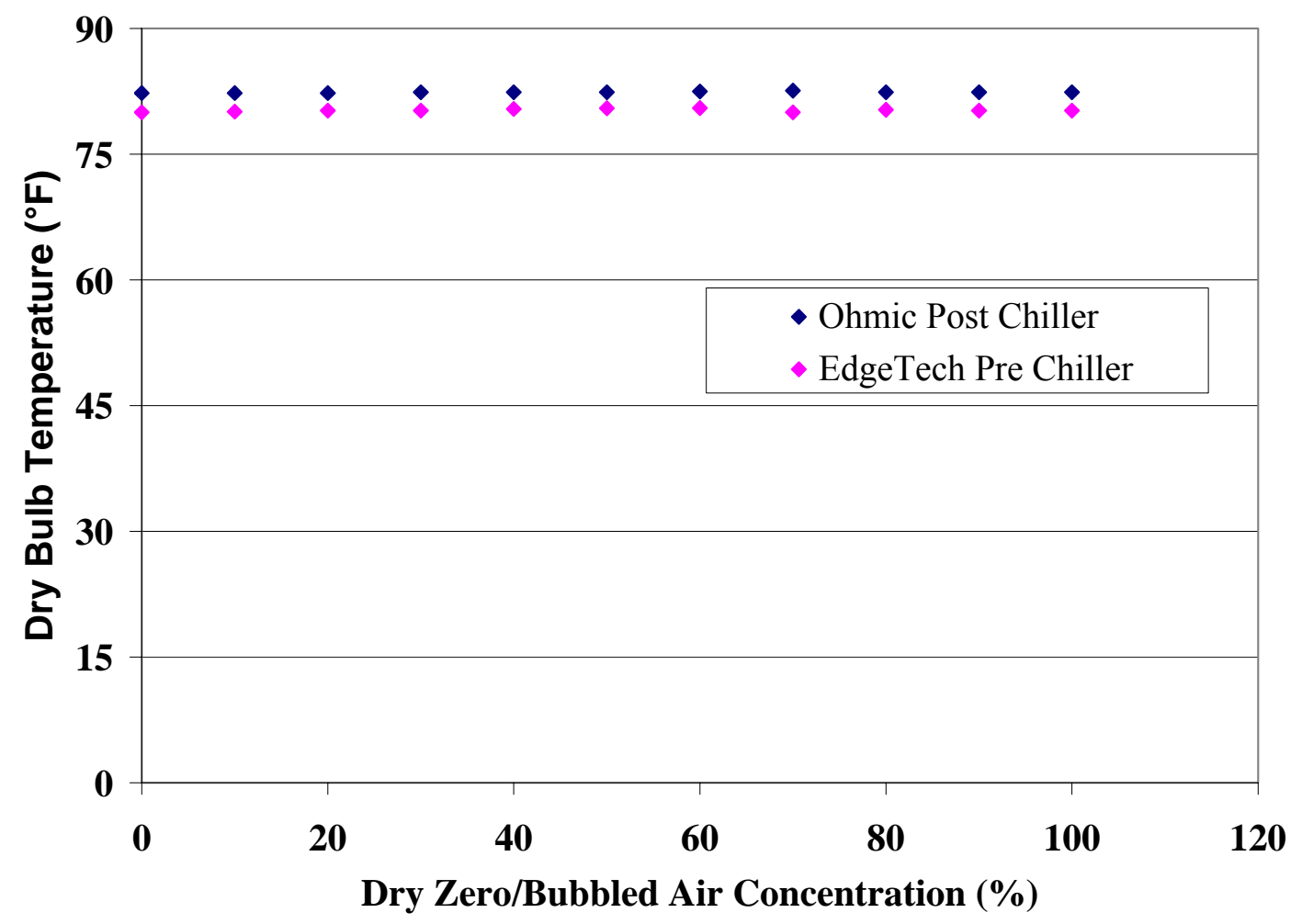

\subsubsection{Test Setup\#2 EdgeTech DewPrime II Pre Chiller and Ohmic AMM-15 Post Chiller (Domnic Hunter)}

In the second set of experiments, dry nitrogen as the balance and the dry zero air used as a component gas passing through a water bubbler, were fed through a gas divider and the mixture of the calibration gases coming out of the divider was used to flood the probe in the dilution air tunnel. The component gas pressure was set at a higher value than the balance. WVU ERL utilizes a Domnic Hunter CRD5-100, to condense moisture from the gas sample. A $\mathrm{CO} / \mathrm{CO}_{2}$ pump in the emission bench at WVU ERL was used to pull the gas sample into chiller unit. The EdgeTech hygrometer was set at the inlet and the Ohmic AMM-15 was set at the outlet of the chiller unit to record the dew point temperature, dry bulb temperature and the relative humidity, using a data acquisition program. In the beginning of the test only ambient dilution tunnel air was ran through the 
chiller for some time and data was recorded. After running the ambient air through the chiller, the gas divider regulator was set to $0 \%$ (dry zero air) and the response of the both hygrometers were recorded. The gas mixture concentrations were varied continuously by setting the gas divider regulator to different percentages of dry and moist air, ranging from $0-100 \%$ on the gas divider. After reaching the $100 \%$ gas divider position, a check on the repeatability and the accuracy of the measurement was performed by following the same procedure again. Figure 11 shows the schematic diagram of the test setup number two. Initially only ambient air was pulled by the $\mathrm{CO} / \mathrm{CO}_{2}$ pump in the emission bench and delivered it to Domnic Hunter CRD5-100 (chiller) and both EdgeTech and Ohmic hygrometers installed at pre and post chiller operation, using quarter inch outer diameter teflon tubing and quick disconnect arrangement. In the next set up dry bottled zero air passing through water bubbler and dry bottled nitrogen were connected to a gas divider STEC SGD-710 using quarter inch outer diameter teflon tubing and quick disconnect arrangement. Outlet from the gas divider was connected to flooded probe in the dilution tunnel using teflon tubing and quick disconnect arrangement. A $\mathrm{CO} / \mathrm{CO}_{2}$ pump in the emission bench at WVU EERC pulled the sample from the dilution tunnel and delivered it to Domnic Hunter CRD5-100 (chiller) and both EdgeTech and Ohmic hygrometers installed at pre and post chiller operation using quarter inch outer diameter teflon tubing and quick disconnect arrangement. Both EdgeTech and Ohmic hygrometers were connected to the computer through serial ports to record the response from both hygrometers. 
Figure 11 Test set up \#2 Edge Tech Pre Chiller and Ohmic Post Chiller (Domnic Hunter)

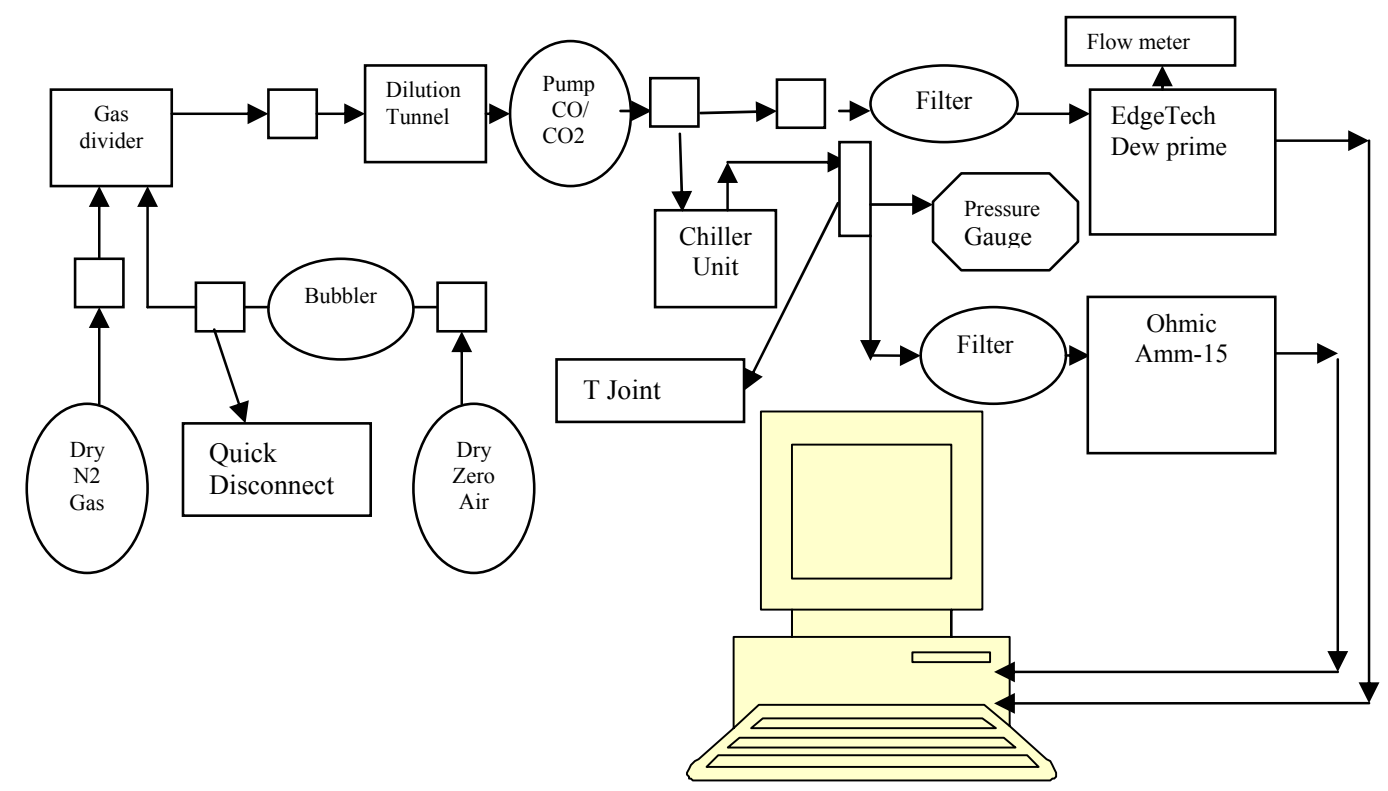

As shown in Table 7, the post chiller behavior of the Domnic Hunter seems very consistent. There are no large variations in the post chiller dew point temperature, relative humidity and dry bulb temperature at different dry zero/bubbled air concentrations. As expected the pre chiller dew point and the relative humidity show significant changes in their values with increasing zero/bubbled air concentrations. The pre and post chiller dry bulb temperatures also seem to be very consistent at different zero/bubbled air concentrations. Post chiller dry bulb temperature measured by the Ohmic hygrometer is always approximately $1^{\circ} \mathrm{F}$ higher then the pre chiller dry bulb temperature, similar to the comparison of the two instruments (Figure 10). 
Table 7 Edge Tech Pre Chiller and Ohmic Post Chiller (Domnic Hunter)

\begin{tabular}{|c|c|c|c|c|c|c|}
\hline $\begin{array}{c}\text { Dry/ bubbled } \\
\text { air } \\
\text { Concentration }\end{array}$ & $\begin{array}{c}\text { EdgeTech } \\
\text { Pre } \\
\text { Chiller } \\
\text { Dew point } \\
\text { Temp. }\end{array}$ & $\begin{array}{c}\text { Ohmic } \\
\text { Post } \\
\text { Chiller } \\
\text { Doint } \\
\text { Temp. }\end{array}$ & $\begin{array}{c}\text { EdgeTech } \\
\text { Pre } \\
\text { Chiller } \\
\text { Relative } \\
\text { Humidity }\end{array}$ & $\begin{array}{c}\text { Ohmic } \\
\text { Post } \\
\text { Chiller } \\
\text { Relative } \\
\text { Humidity }\end{array}$ & $\begin{array}{c}\text { EdgeTech } \\
\text { Pre } \\
\text { Chiller } \\
\text { Dry Bulb } \\
\text { Temp. }\end{array}$ & $\begin{array}{c}\text { Ohmic } \\
\text { Post } \\
\text { Chiller } \\
\text { Dry } \\
\text { Bulb } \\
\text { Temp. }\end{array}$ \\
\hline \% & F & F & \% & \% & F & F \\
\hline Ambient air & 53.68 & 43.44 & 35.06 & 23.19 & 84.30 & 85.24 \\
\hline 0.00 & 15.37 & 43.00 & 7.560 & 22.69 & 84.40 & 85.40 \\
\hline 10.0 & 24.52 & 42.90 & 11.17 & 22.60 & 84.40 & 85.40 \\
\hline 20.0 & 32.25 & 43.00 & 15.40 & 22.69 & 84.30 & 85.40 \\
\hline 30.0 & 37.87 & 43.16 & 19.26 & 22.68 & 84.30 & 85.60 \\
\hline 40.0 & 42.80 & 43.51 & 23.40 & 23.06 & 84.20 & 85.50 \\
\hline 50.0 & 47.74 & 43.35 & 28.22 & 23.08 & 84.20 & 85.29 \\
\hline 60.0 & 51.86 & 43.64 & 32.90 & 23.10 & 84.20 & 85.60 \\
\hline 70.0 & 54.28 & 42.85 & 35.97 & 22.41 & 84.18 & 85.60 \\
\hline 80.0 & 57.01 & 43.29 & 39.78 & 23.01 & 84.13 & 85.31 \\
\hline 90.0 & 58.18 & 42.97 & 41.55 & 22.52 & 84.08 & 85.60 \\
\hline 100 & 60.46 & 43.26 & 45.19 & 22.77 & 84.00 & 85.60 \\
\hline
\end{tabular}

As shown in Figure 12, the pre chiller dew point temperatures measured by the Edge Tech hygrometer shows a consistent increase with an increase in moist air concentrations. The post chiller behavior from the post chiller dew point measurement by Ohmic hygrometer and shown in Figure 12 is quite stable and does not present much variation. Figure 12 suggests that Domnic Hunter CRD5-100 maintains a constant post chiller dew point temperature if moisture is present in the chiller unit. That is, even though dry air was entering this chiller unit, the sample stream was being humidified 
inside the chiller unit resulting in constant post chiller dew point. Also it can be inferred that changing the pre chiller dry/bubbled air concentrations did not significantly affect the post chiller operation.

Fig. 12 Dew Point Comparison Between EdgeTech DewPrime II Pre Chiller and Ohmic AMM-15 Post Chiller

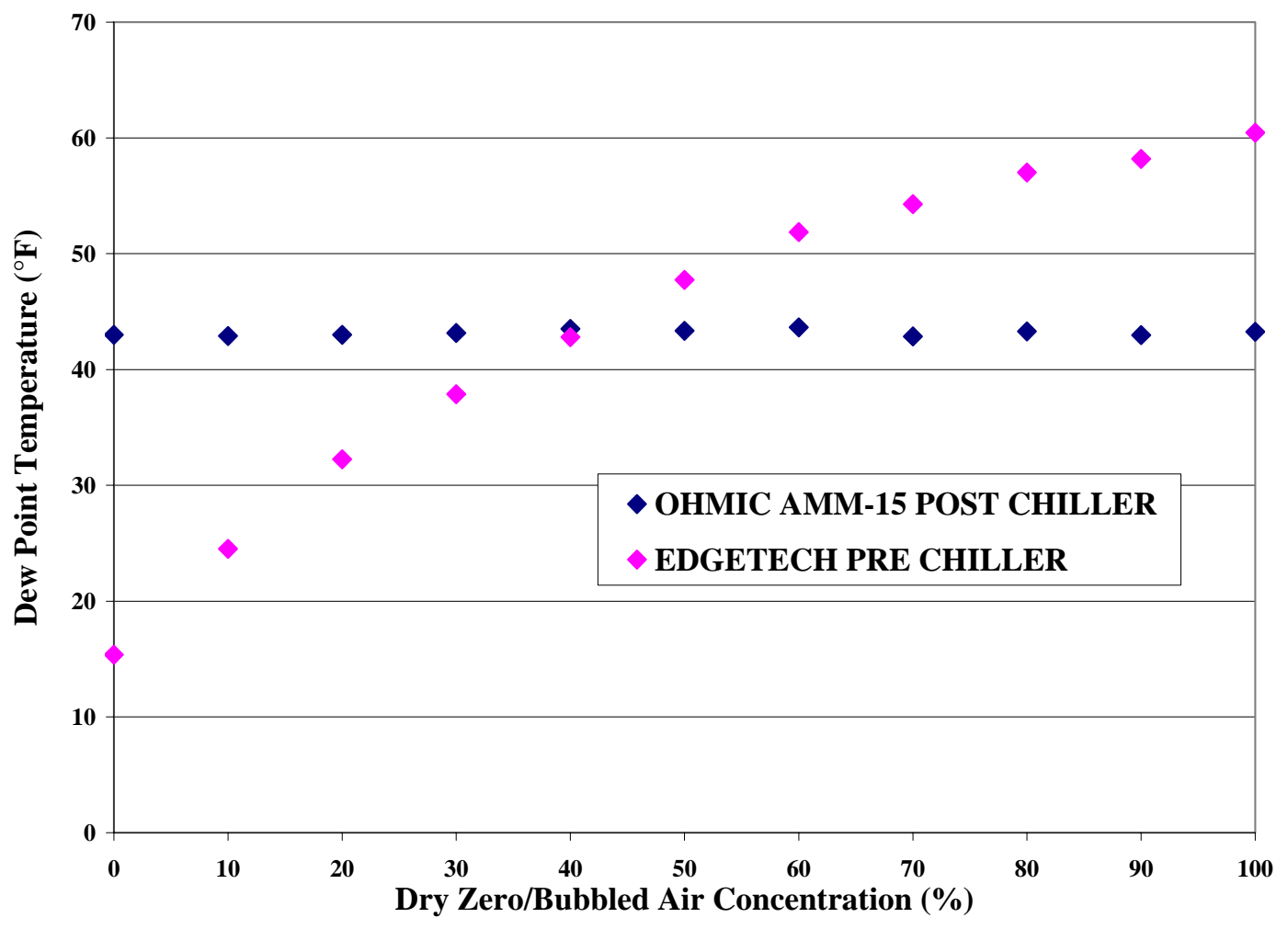

As shown in Figure 13, the pre chiller relative humidity measured by EdgeTech hygrometer at different concentrations of dry zero/bubbled air concentrations, approximately follows a straight line and shows a gradual increase in pre chiller relative humidity with an increase in dry zero/bubbled air concentration. The post chiller relative humidity measured by Ohmic AMM-15 almost follows a steady state pattern. It can be concluded from the Figure 13 that post Domnic Hunter (chiller unit) relative humidity maintains a fixed average value of $23 \%\left(43^{\circ} \mathrm{F}\right.$ dew point $)$ regardless of the pre chiller dry zero/bubbled air concentrations. 
Fig. 13 Relative Humidity Comparison Between EdgeTech DewPrime II Pre Chiller and Ohmic AMM-15 Post Chiller

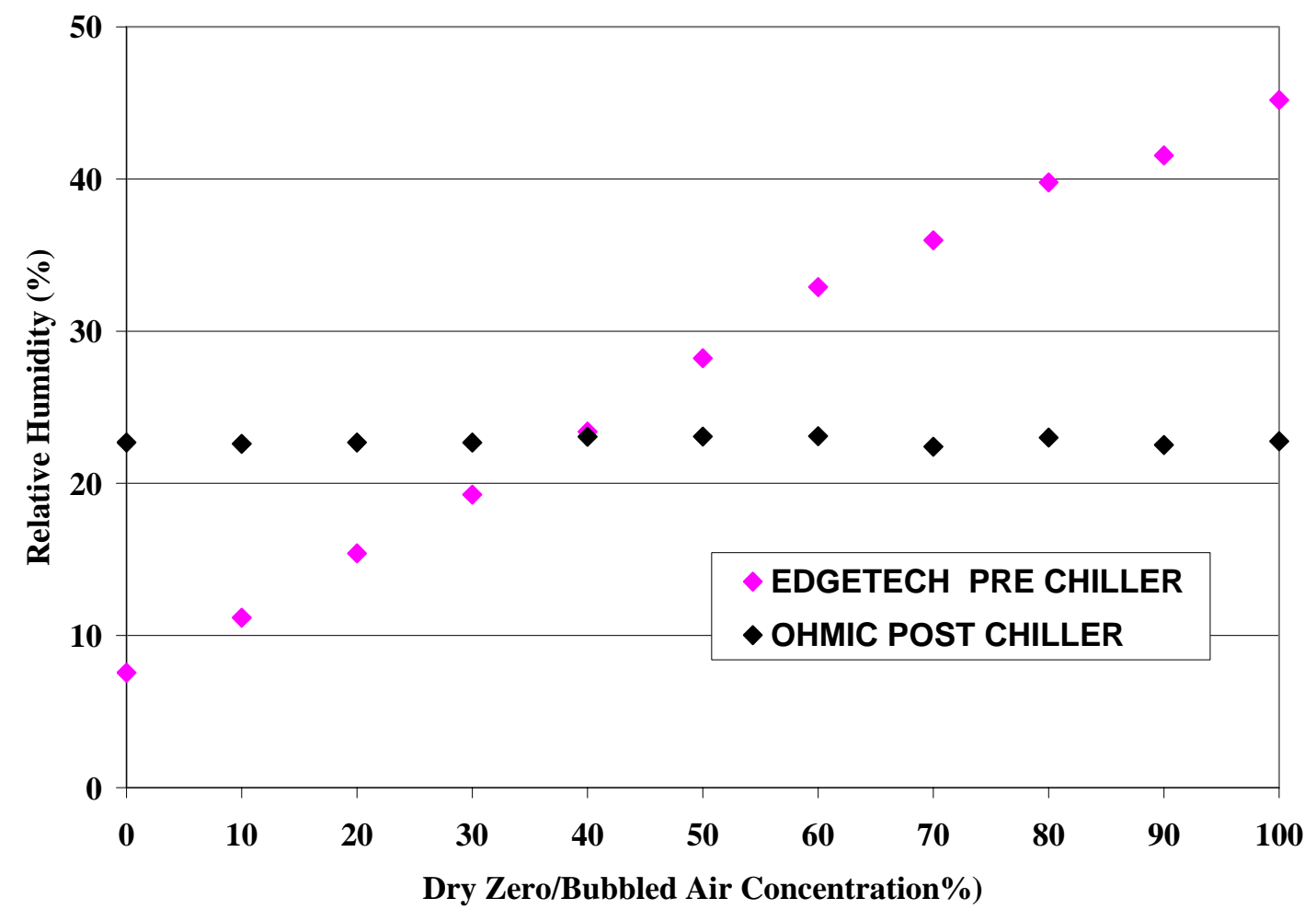

It can be concluded from Figure 14 that both pre and post chiller dry bulb temperature measure by EdgeTech DewPrime II and Ohmic hygrometers respectively, follows strictly an approximate steady behavior and only show a difference of $1^{\circ} \mathrm{F}$ between pre and post chiller dry bulb measurement. 
Fig. 14, Dry Bulb Temperature Comparison Between EdgeTech DewPrime II Pre Chiller Ohmic AMM-15 Post Chiller

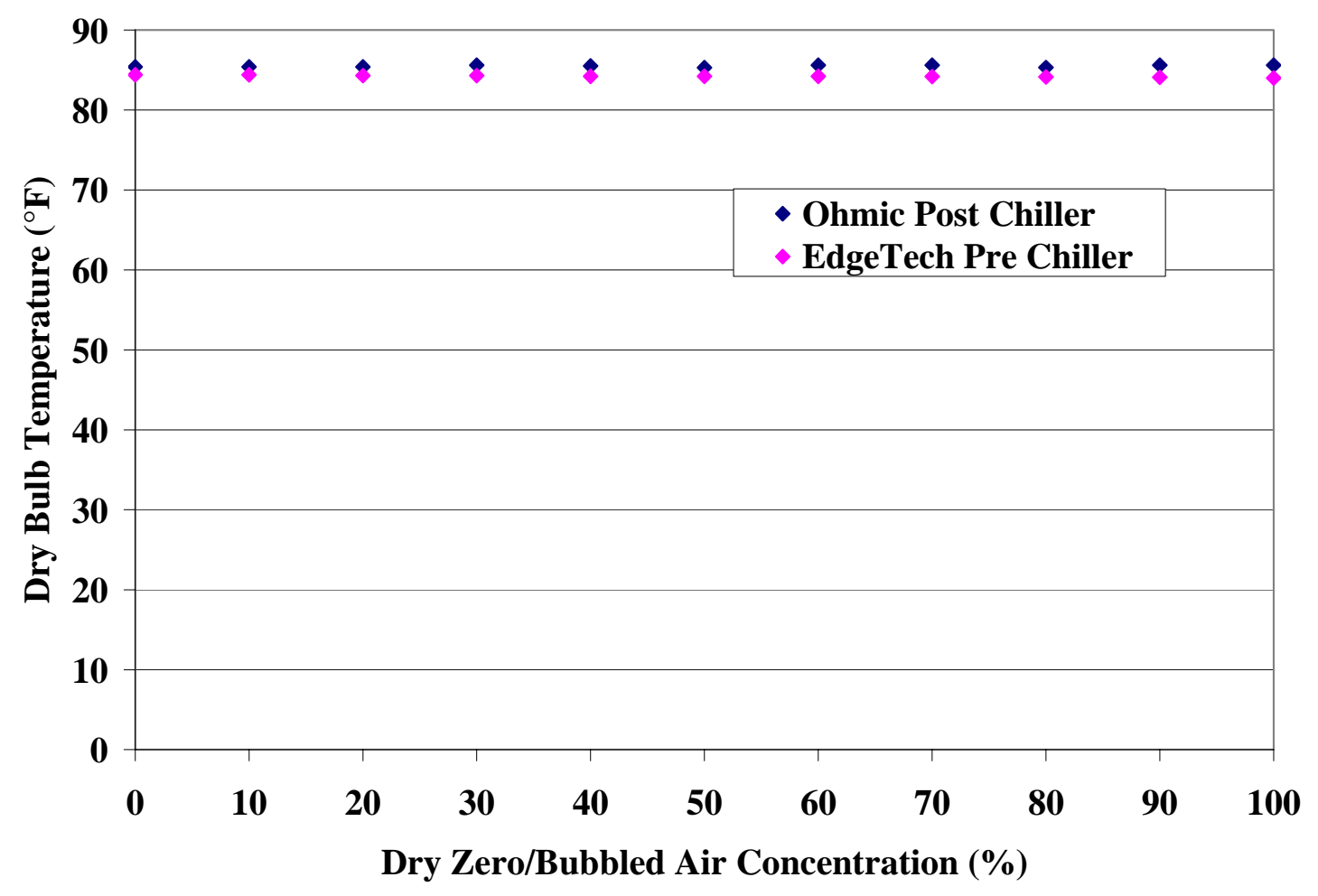

\subsubsection{Test Setup\#3\&4 Ambient Air, Dry Zero Air and Dry Zero/Bubbled Air Ran Through Chiller with EdgeTech DewPrime II Pre and Ohmic AMM-15 Post chiller}

At the beginning of the third test ambient air in the dilution tunnel ran through the chiller and the data was recorded through EdgeTech and Ohmic AMM-15 hygrometers installed at the inlet and outlet of the Domnic Hunter CRD5-100, a chiller unit installed in the emission bench at WVU EERC. Following the ambient air run through the chiller, dry zero air and then dry air through the water bubbler flooded the probe in the dilution tunnel and was pulled by the $\mathrm{CO} / \mathrm{CO}_{2}$ pump into the chiller unit in the emission bench. The fourth setup followed the same procedure as in the third test except the switching of two hygrometers between pre and post chiller operation, thus making a comparison of the accuracy and repeatability of the data obtained from the two hygrometers. Figure 15 
shows the schematic diagram of the third setup. Initially, only ambient air present in the dilution tunnel was pulled by the $\mathrm{CO} / \mathrm{CO}_{2}$ pump installed in the emission bench at WVU EERC and delivered it to Domnic Hunter CRD5-100 (chiller) and both EdgeTech and Ohmic hygrometers installed at pre and post chiller operation, using quarter inch outer diameter teflon tubing and quick disconnect arrangement. The second case was done with dry bottled zero air connected to dilution tunnel using quarter inch outer diameter teflon tubing and quick disconnect arrangement. The rest of the configuration followed the same arrangement as in case of ambient air run through the chiller. The third case was accomplished with dry bottled zero air passing through a water bubbler and connected to the dilution tunnel using quarter inch outer diameter teflon tubing and quick disconnect arrangement. The rest of the configuration followed the same arrangement as in last two cases. Both EdgeTech and Ohmic hygrometers were connected to the computer through serial ports to record the response from both hygrometers. The fourth setup followed exactly the same arrangement as in third set up except switching the position of two hygrometers. 


\section{Fig. 15 Test Setup\#3\&4 Ambient Air, Dry Zero Air and Dry Zero/Bubbled Air Ran Through Chiller with EdgeTech DewPrime II Pre and Ohmic AMM-15 Post chiller}

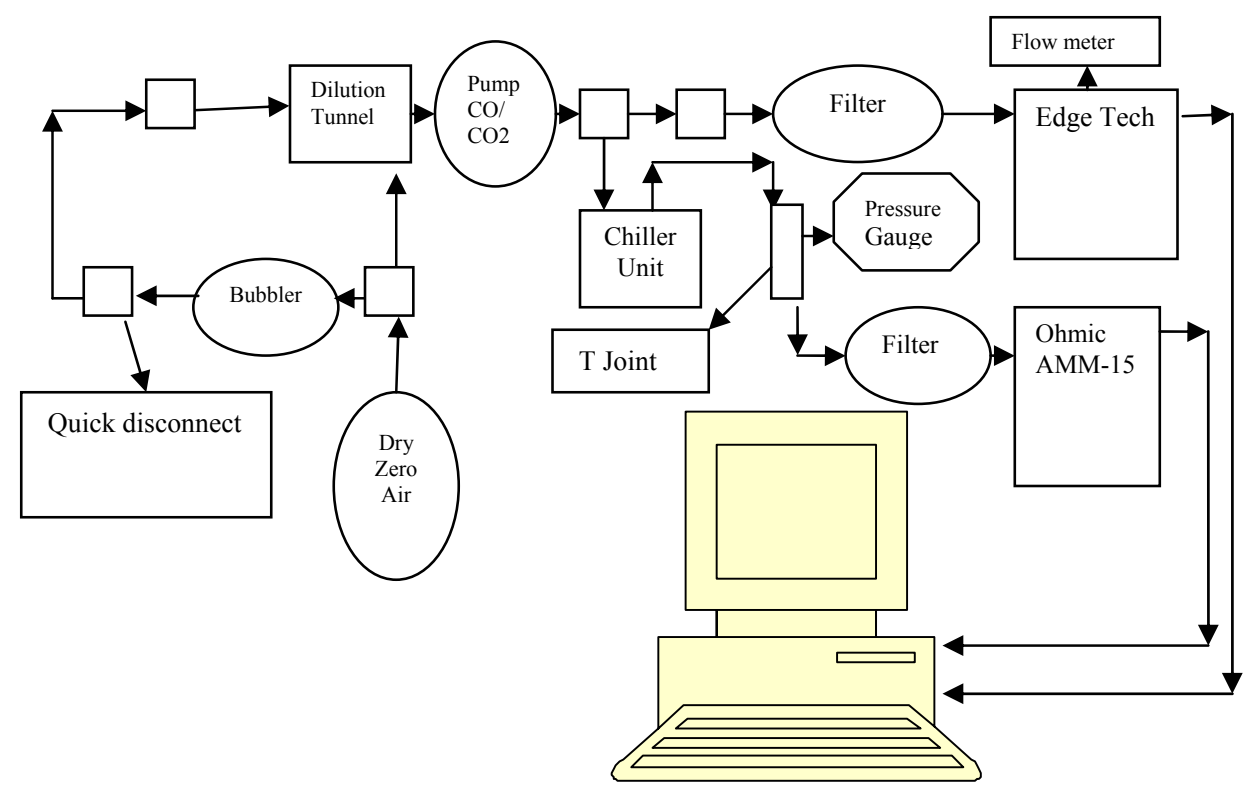

From Table 8 and 9, it can be concluded that post chiller dew point temperature, dry bulb temperature and relative humidity measurement made by the EdgeTech DewPrime II and Ohmic AMM-15 hygrometers, regardless of the pre chiller conditions, follow an approximate fixed post chiller pattern. The post chiller dew point, dry bulb temperature and relative humidity don't show much variation and maintain a certain value regardless of pre chiller ambient air, dry zero air or dry zero/bubbled air. Particularly for dry zero air the measured post chiller parameters by EdgeTech DewPrime II and Ohmic AMM-15 hygrometers always show higher values than the pre chiller dew point, dry bulb and relative humidity. These higher post chiller values for dry zero air suggest that dry zero air was humidified due to moisture from the chiller. 
Table 8 Test Setup\#3 Ambient Air, Dry Zero Air and Dry Zero/Bubbled Air Ran Through Domnic Hunter CRD5-100 (Chiller) with EdgeTech DewPrime II Pre and Ohmic AMM-15 Post Chiller

\begin{tabular}{|l|c|c|c|}
\hline $\begin{array}{c}\text { EdgeTech Pre Domnic Hunter/Ohmic } \\
\text { Post Domnic hunter (Chiller) }\end{array}$ & $\begin{array}{c}\text { Ambient } \\
\text { Air }\end{array}$ & $\begin{array}{c}\text { Dry Zero } \\
\text { Air }\end{array}$ & $\begin{array}{c}\text { Dry Bubbled } \\
\text { Air }\end{array}$ \\
\hline Pre Chiller Dew Point Temperature $\left({ }^{\circ} \mathrm{F}\right)$ & 54.55 & -5.40 & 61.58 \\
\hline Post Chiller Dew Point Temperature $\left({ }^{\circ} \mathrm{F}\right)$ & 43.07 & 43.45 & 43.64 \\
\hline Pre Chiller Dry Bulb Temperature $\left({ }^{\circ} \mathrm{F}\right)$ & 83.30 & 83.30 & 83.22 \\
\hline Post Chiller Dry Bulb Temperature $\left({ }^{\circ} \mathrm{F}\right)$ & 85.60 & 85.60 & 85.60 \\
\hline Pre Chiller Relative Humidity (\%) & 37.24 & 3.000 & 48.07 \\
\hline Post Chiller Relative Humidity (\%) & 22.60 & 22.94 & 23.10 \\
\hline
\end{tabular}

Table 9 Test Setup\#4 Ambient Air, Dry Zero Air and Dry Zero/Bubbled Air Ran Through Domnic Hunter CRD5-100 (Chiller) with Ohmic AMM-15 Pre and EdgeTech DewPrime II Post chiller.

\begin{tabular}{|l|c|c|c|}
\hline $\begin{array}{c}\text { Ohmic Pre Domnic Hunter/EdgeTech Post } \\
\text { Domnic Hunter (Chiller) }\end{array}$ & $\begin{array}{c}\text { Ambient } \\
\text { Air }\end{array}$ & $\begin{array}{c}\text { Dry Zero } \\
\text { Air }\end{array}$ & $\begin{array}{c}\text { Dry Bubbled } \\
\text { Air }\end{array}$ \\
\hline Pre Chiller Dew Point Temperature $\left({ }^{\circ} \mathrm{F}\right)$ & 59.90 & -4.73 & 59.83 \\
\hline Post Chiller Dew Point Temperature $\left({ }^{\circ} \mathrm{F}\right)$ & 41.80 & 39.97 & 41.86 \\
\hline Pre Chiller Dry Bulb Temperature $\left({ }^{\circ} \mathrm{F}\right)$ & 85.60 & 85.40 & 85.20 \\
\hline Post Chiller Dry Bulb Temperature $\left({ }^{\circ} \mathrm{F}\right)$ & 85.60 & 85.60 & 85.60 \\
\hline Pre Chiller Relative Humidity $(\%)$ & 42.09 & 2.910 & 42.52 \\
\hline Post Chiller Relative Humidity $(\%)$ & 23.10 & 21.72 & 23.73 \\
\hline
\end{tabular}




\subsubsection{Test Setup \# 5, 6, 7\& 8 Dry Zero and Dry Zero/Bubbled Air Ran Through ECP 1000/2000}

Two different sampling systems at WVU ERL were evaluated and include the gas dryer units ECP 1000 and ECP 2000. The technical specification and design of these gas dryers have been described earlier. To check the effectiveness of these two dryer units two different experimental setups were devised. In the fifth setup, dry zero air was run through the dryer unit ECP 1000 and the EdgeTech DewPrime II and Ohmic AMM-15 hygrometers were placed, respectively, at pre and post chiller operation to record the dew point, dry bulb and the relative humidity through a data acquisition program. The same test was repeated by switching the two hygrometers between pre and post chiller operation. In the sixth setup, bubbled dry zero air was passed through the dryer units and the humidity was measured with the EdgeTech DewPrime II and Ohmic AMM-15 hygrometers at the pre and post chiller, respectively. The same test was repeated again by switching the two hygrometers between pre and post chiller positions and thus data obtained from both of the hygrometers was used to make a comparison of the accuracy of the two meters and also this data was used to interpret the drying effectiveness of the two chiller units. The seventh and eighth set up devised for testing the dryer ECP 2000 followed the same procedure and instrumental arrangement as in the case of ECP 1000 .

Figure 16 is the schematic diagram of the fifth setup. Quarter inch outer diameter teflon tubing, T-joint and quick disconnect arrangement was used to connect all components included in the fifth setup. Both EdgeTech and Ohmic hygrometers were

connected to the computer through serial ports to record the response from both hygrometers. 
Figure 16 Test Setup\# 5 Dry Zero Air Ran Through ECP 1000 with EdgeTech DewPrime II Pre and Ohmic AMM-15 Post Chiller

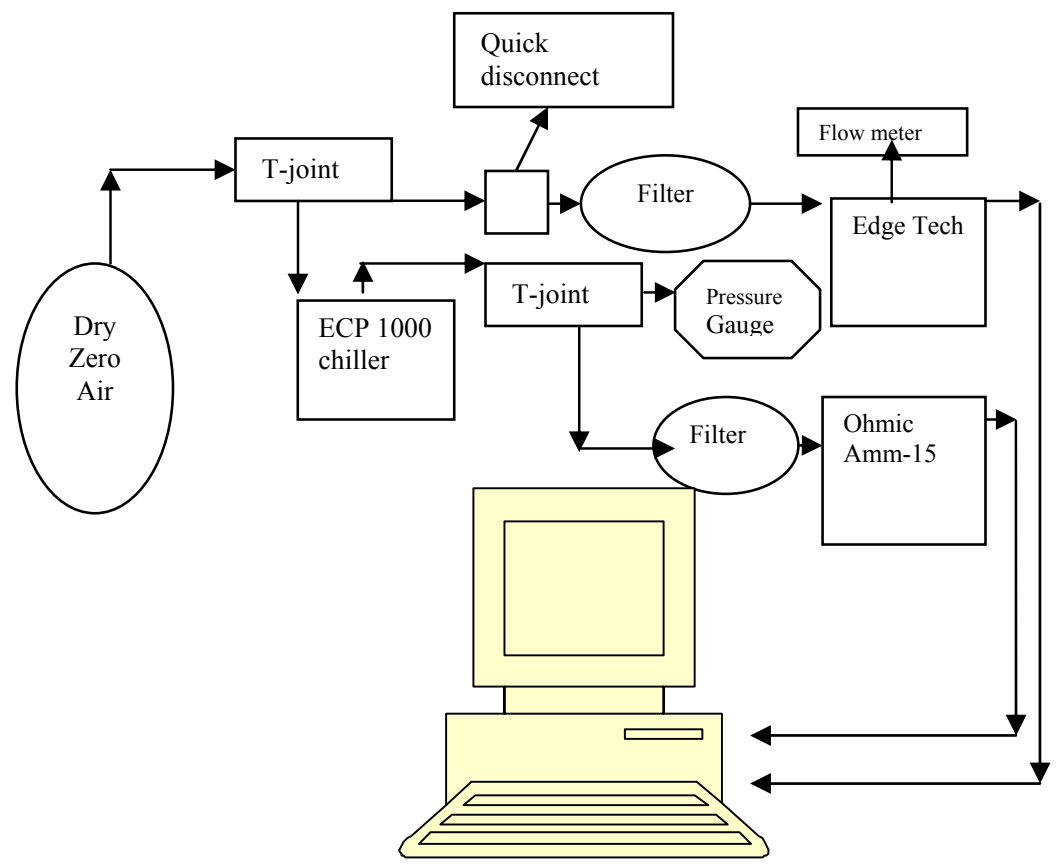

Figure 17 is the schematic diagram of sixth test setup. Quarter inch outer diameter teflon tubing, T-joint and quick disconnect arrangement was used to connect all components included in the sixth setup as shown in Figure 16. Both EdgeTech and Ohmic hygrometers were connected to the computer through serial ports to record the response from both hygrometers.

Figure 17, Test Setup\# 6 Dry Zero/Bubbled Air Ran Through ECP 1000 with EdgeTech DewPrime II Pre and Ohmic AMM-15 Post Chiller

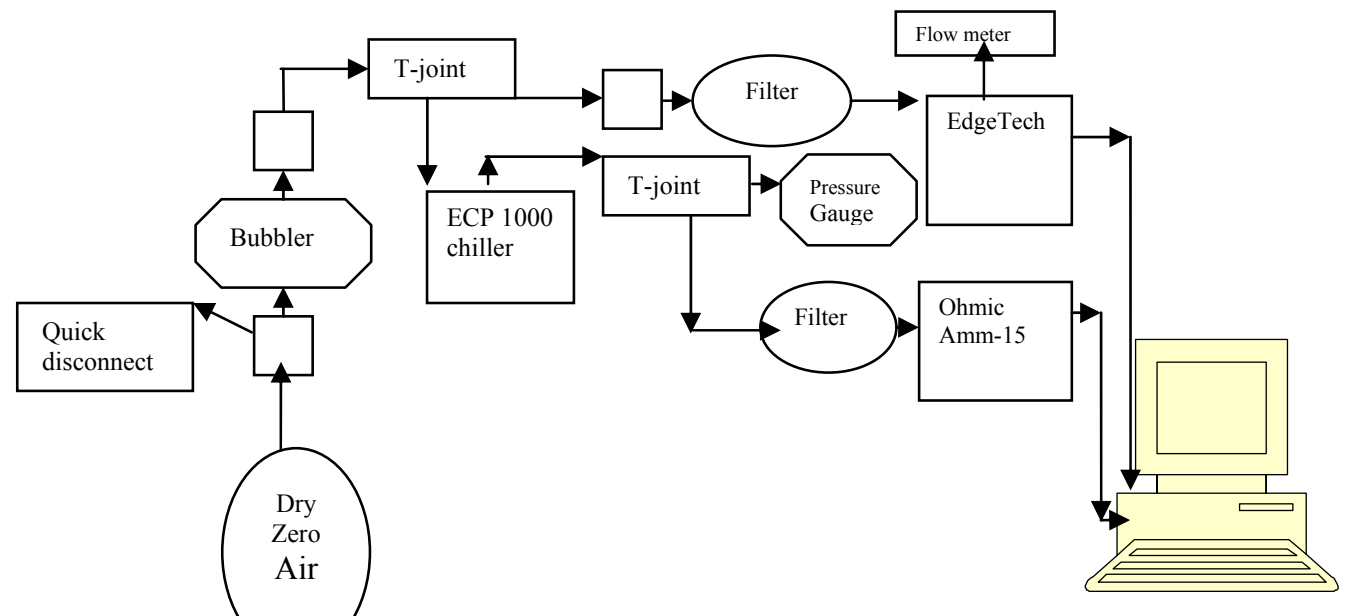


From Table 10, it is obvious that for dry zero air post chiller dew point and relative humidity measured by both EdgeTech DewPrime II and Ohmic AMM-15 have significantly higher values in comparison to pre chiller dew point and relative humidity. This behavior of gas dryer ECP1000 suggests that dry zero air, while running through the dryer unit, picked up some moisture from the chiller unit.

Table 10 Test Setup\#5 Dry Zero Air Ran Through Gas Dryer ECP 1000

\begin{tabular}{|c|c|c|c|}
\hline $\begin{array}{c}\text { Types of Hygrometers } \\
\text { Used at Pre and Post } \\
\text { Chiller }\end{array}$ & $\begin{array}{c}\text { Dew Point } \\
\text { Temperature }\left({ }^{\circ} \mathrm{F}\right)\end{array}$ & $\begin{array}{c}\text { Dry Bulb } \\
\text { Temperature }\left({ }^{\circ} \mathrm{F}\right)\end{array}$ & $\begin{array}{c}\text { Relative } \\
\text { Humidity (\%) }\end{array}$ \\
\hline EdgeTech Pre Chiller & -10.42 & 70.23 & 3.590 \\
\hline Ohmic Post Chiller & 36.18 & 73.91 & 25.32 \\
\hline Ohmic Pre Chiller & -17.30 & 73.66 & 2.280 \\
\hline EdgeTech Post Chiller & 34.52 & 70.50 & 26.53 \\
\hline
\end{tabular}

From Table 11, it can be inferred that for dry zero/bubbled air, the pre and post dew point, dry bulb and relative humidity measured by both of the hygrometers show a close agreement and are within the accuracy limit of both of the EdgeTech and Ohmic hygrometers.

Table 11 Test setup\#6: Dry zero/Bubbled air ran through gas dryer ECP 1000

\begin{tabular}{|c|c|c|c|}
\hline $\begin{array}{c}\text { Types of Hygrometers } \\
\text { Used at Pre and Post } \\
\text { Chiller }\end{array}$ & $\begin{array}{c}\text { Dew Point } \\
\text { Temperature } \\
\left({ }^{\circ} \mathrm{F}\right)\end{array}$ & $\begin{array}{c}\text { Dry Bulb } \\
\text { Temperature } \\
\left({ }^{\circ} \mathrm{F}\right)\end{array}$ & $\begin{array}{c}\text { Relative } \\
\text { Humidity } \\
(\%)\end{array}$ \\
\hline EdgeTech Pre Chiller & 64.84 & 70.84 & 81.41 \\
\hline Ohmic Post Chiller & 35.53 & 72.95 & 25.48 \\
\hline Ohmic Pre Chiller & 67.77 & 72.69 & 84.59 \\
\hline EdgeTech Post Chiller & 34.44 & 70.38 & 26.57 \\
\hline
\end{tabular}


From Table 12, it can be concluded that in comparison to gas dryer EC1000, the gas dryer ECP 2000 performed better in reducing post chiller dew point and relative humidity. Still, the post chiller dew point and relative humidity being higher than their pre chiller values indicated that dry zero air, while passing through the dryer unit, picked some moisture and resulted higher post dew point and relative humidity measurements from both of the hygrometers.

Table 12 Test Setup\#7 Dry Zero Air Ran Through Gas Dryer ECP 2000

\begin{tabular}{|c|c|c|c|}
\hline $\begin{array}{c}\text { Types of Hygrometers Used at } \\
\text { Pre and Post Chiller }\end{array}$ & $\begin{array}{c}\text { Dew Point } \\
\text { Temperature } \\
\left({ }^{\circ} \mathrm{F}\right)\end{array}$ & $\begin{array}{c}\text { Dry Bulb } \\
\text { Temperature } \\
\left({ }^{\circ} \mathrm{F}\right)\end{array}$ & $\begin{array}{c}\text { Relative } \\
\text { Humidity } \\
(\%)\end{array}$ \\
\hline EdgeTech Pre Chiller & -10.81 & 72.48 & 3.31 \\
\hline Ohmic Post Chiller & 31.79 & 73.87 & 21.27 \\
\hline Ohmic Pre Chiller & -35.63 & 75.05 & .81 \\
\hline EdgeTech Post Chiller & 4.201 & 73.61 & 6.89 \\
\hline
\end{tabular}

Table 13 indicates that the pre and post chiller dew point, dry bulb and relative humidity measurements accomplished by EdgeTech and Ohmic hygrometers showed a close agreement and were found within in the accuracy limit of both of the hygrometers. The pre and post dew point and relative humidity showed a significant difference between each other and this is an indication that this gas dryer unit is performing well under the designed parameters. ECP 1000/2000 is designed to have a maximum outlet dew point ranging from $41^{\circ} \mathrm{F}$ to $43^{\circ} \mathrm{F}$. Having a look at the post dew points of $43.40^{\circ} \mathrm{F}$ and $44.34^{\circ} \mathrm{F}$. Table 14 indicates that the pre and post chiller dew point, dry bulb and relative humidity measurements accomplished by EdgeTech and Ohmic hygrometers showed a close agreement and were found within in the accuracy limit of both of the 
hygrometers. The pre and post dew points and relative humidity showed a significant difference between each other and this is an indication that this gas dryer unit is performing well under the designed parameters. ECP 1000/2000 is designed to have a maximum outlet dew point ranging from $41^{\circ} \mathrm{F}$ to $43^{\circ} \mathrm{F}$. Having a look at the post dew points of $43.40^{\circ} \mathrm{F}$ and $44.34^{\circ} \mathrm{F}$ measured by Ohmic and EdgeTech hygrometers, gives an indication that the gas dryer unit ECP 2000 is closely following the design specifications.

Table 13 Test Setup\#8 Dry Zero /Bubbled Air Ran Through Gas Dryer ECP 2000

\begin{tabular}{|c|c|c|c|}
\hline $\begin{array}{c}\text { Types of Hygrometers } \\
\text { Used at Pre and Post } \\
\text { Chiller }\end{array}$ & $\begin{array}{c}\text { Dew Point } \\
\text { Temperature } \\
\left({ }^{\circ} \mathrm{F}\right)\end{array}$ & $\begin{array}{c}\text { Dry Bulb } \\
\text { Temperature } \\
\left({ }^{\circ} \mathrm{F}\right)\end{array}$ & $\begin{array}{c}\text { Relative } \\
\text { Humidity } \\
(\%)\end{array}$ \\
\hline EdgeTech Pre Chiller & 67.81 & 75.76 & 76.43 \\
\hline Ohmic Post Chiller & 43.40 & 77.43 & 29.84 \\
\hline Ohmic Pre Chiller & 72.29 & 77.20 & 84.89 \\
\hline EdgeTech Post Chiller & 44.34 & 75.26 & 33.17 \\
\hline
\end{tabular}

\subsubsection{Test Setup\# 9, 10.11 and 12 Dry Zero and Dry Zero/Bubbled Air Ran Through MEMS and Micro MEMS Chiller Units}

The gas dryer units in the Mobile Emission Measurement System (MEMS) and Micro Mobile Emission Measurement System were investigated for their operational effectiveness. Four different experimental setups were devised. In the ninth test setup, dry zero air passing through a flooded probe was run through the dryer unit and EdgeTech DewPrime II and Ohmic AMM-15 hygrometers were placed at pre and post chiller operation respectively, recording the dew point, dry bulb and the relative humidity through a data acquisition program. The same set up was repeated by switching the two hygrometers between pre and post chiller operation. Using flooded probe, the tenth setup was accomplished by passing bubbled dry zero air through the dryer units and placing the 
EdgeTech DewPrime II and Ohmic AMM-15 hygrometers at the pre and post chiller respectively. The same setup was repeated again by switching the two hygrometers between pre and post chiller positions to obtain data from both hygrometers to make a comparison of the accuracy of the two meters and to interpret the drying effectiveness of the two chiller units. The eleventh and twelfth setup devised for testing the Micro MEMS chiller followed the same procedure and instrumental arrangement as in case of MEMS chiller testing. Figure 18 is the schematic diagram of ninth test setup. Quarter inch outer diameter teflon tubing, T-joints and quick disconnect arrangement was used to connect all components included in the sixth setup and also shown in Figure 18. Both EdgeTech and Ohmic hygrometers were connected to the computer through serial ports to record the response from both hygrometers.

\section{Figure 18 Test Setup\#9 Dry Zero Air Ran Through MEMS Chiller with EdgeTech DewPrime II Pre and Ohmic AMM-15 Post Chiller}

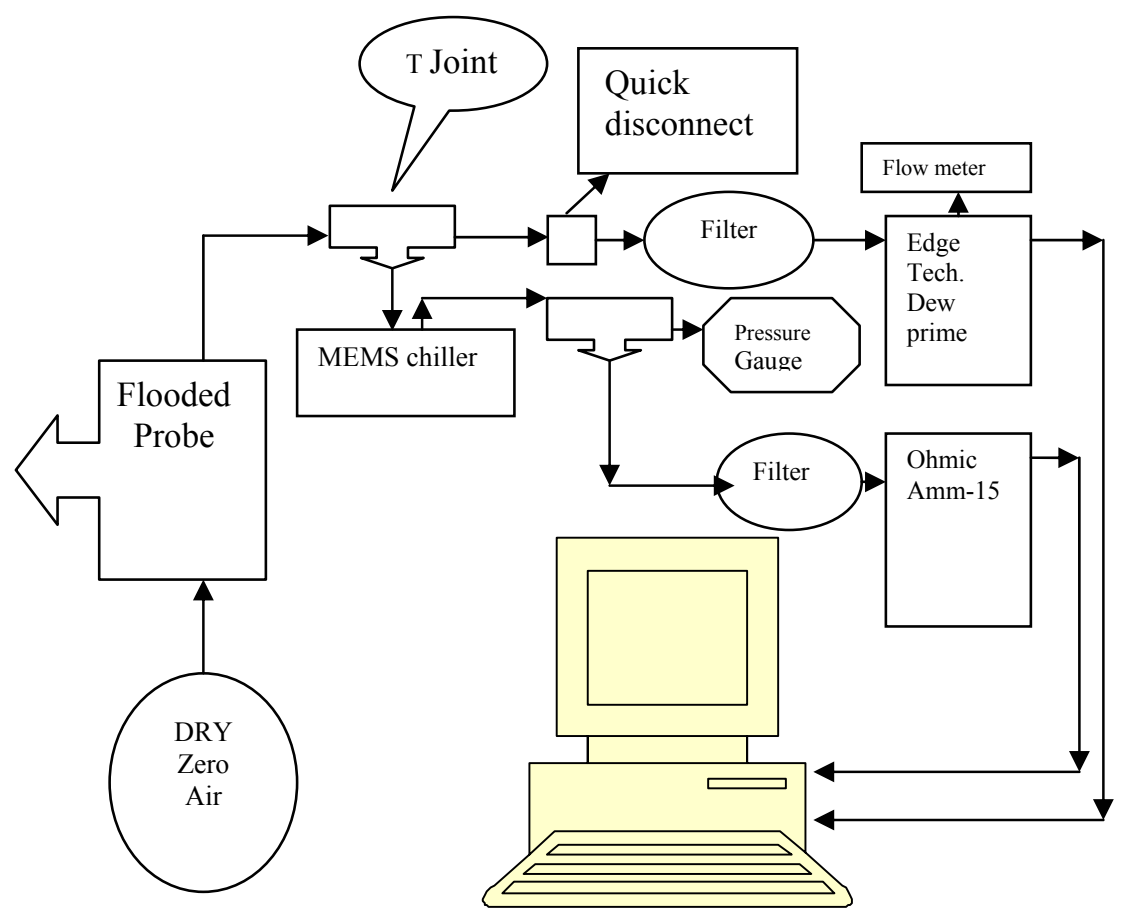


Figure 19 is the schematic diagram of tenth test setup. Quarter inch outer diameter teflon tubing, T-joints and quick disconnect arrangement was used to connect all components included in the sixth setup and also shown in Figure 18. Both EdgeTech and Ohmic hygrometers were connected to the computer through serial ports to record the response from both hygrometers

\section{Figure 19Test setup\#10 Dry Zero/Bubbled Air Ran Through MEMS Chiller with EdgeTech DewPrime II Pre and Ohmic AMM-15 Post Chiller}

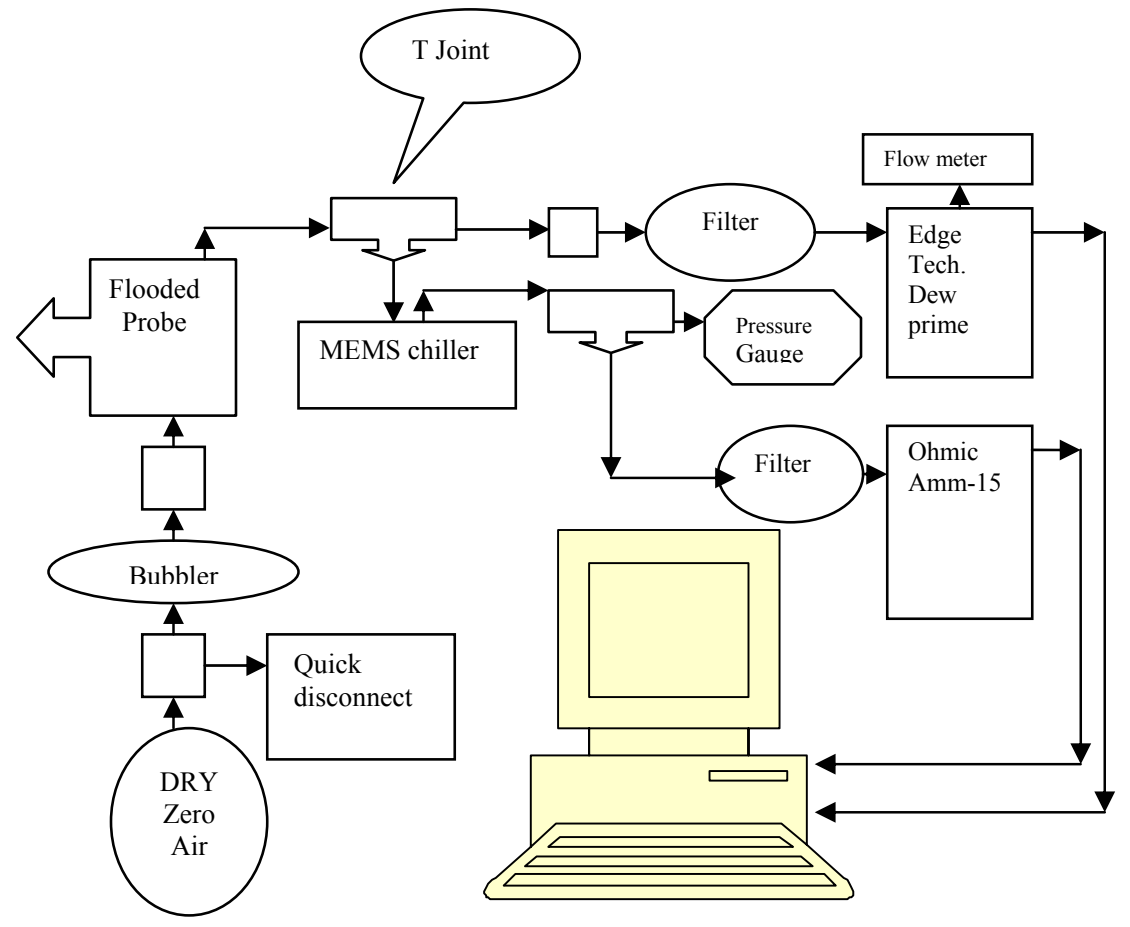

From Table 14 it can be concluded that, in comparison to other chiller units, the MEMS chiller unit performed very well in reducing the pre chiller dry zero air dew point and relative humidity. But, still the post chiller dew point and relative humidity being higher than those of pre chiller values indicated towards some moisture picked up by dry zero air while passing through the chiller unit. 
Table 14 Test Setup\#9 Dry Zero Air Ran Through MEMS Chiller Unit

\begin{tabular}{|c|c|c|c|}
\hline $\begin{array}{c}\text { Types of Hygrometers } \\
\text { Used at Pre and Post } \\
\text { Chiller }\end{array}$ & $\begin{array}{c}\text { Dew Point } \\
\text { Temperature } \\
\left({ }^{\circ} \mathrm{F}\right)\end{array}$ & $\begin{array}{c}\text { Dry Bulb } \\
\text { Temperature } \\
\left({ }^{\circ} \mathrm{F}\right)\end{array}$ & $\begin{array}{c}\text { Relative } \\
\text { Humidity } \\
(\%)\end{array}$ \\
\hline EdgeTech Pre Chiller & 0.150 & 86.2 & 3.60 \\
\hline Ohmic Post Chiller & 3.66 & 88.3 & 3.94 \\
\hline Ohmic Pre Chiller & -14.2 & 88.6 & 1.64 \\
\hline EdgeTech Post Chiller & 0.140 & 86.2 & 3.57 \\
\hline
\end{tabular}

Table 15 indicates that the pre and post chiller dew point, dry bulb and relative humidity measurements measured by EdgeTech DewPrime II and Ohmic AMM-15 hygrometers and then switching them between pre and post chiller positions, show a close agreement on their comparison with each other and were found within in the accuracy limit of both of the hygrometers. The pre and post dew points and relative humidity showed a significant difference between each other and this is an indication that this gas dryer unit is performing well under the designed specifications.

Table 15 Test Setup \#10 Dry Zero/Bubbled Air Ran Through MEMS Chiller Unit

\begin{tabular}{|c|c|c|c|}
\hline $\begin{array}{c}\text { Types of Hygrometers } \\
\text { Used at Pre and Post } \\
\text { Chiller }\end{array}$ & $\begin{array}{c}\text { Dew Point } \\
\text { Temperature } \\
\left({ }^{\circ} \mathrm{F}\right)\end{array}$ & $\begin{array}{c}\text { Dry Bulb } \\
\text { Temperature } \\
\left({ }^{\circ} \mathrm{F}\right)\end{array}$ & $\begin{array}{c}\text { Relative } \\
\text { Humidity } \\
(\%)\end{array}$ \\
\hline EdgeTech Pre Chiller & 66.39 & 85.80 & 52.43 \\
\hline Ohmic Post Chiller & 37.25 & 87.43 & 17.01 \\
\hline Ohmic Pre Chiller & 68.56 & 87.70 & 53.27 \\
\hline EdgeTech Post Chiller & 33.48 & 86.08 & 15.25 \\
\hline
\end{tabular}

From Table 16, it is obvious that for dry zero air post chiller dew point and relative humidity measured by both the EdgeTech DewPrime II and Ohmic AMM-15 hygrometers have significantly higher values in comparison to pre chiller dew point and 
relative humidity. This behavior of Micro MEMS chiller unit suggests that dry zero air while running through the chiller unit picked some moisture from the chiller unit.

Table 16 Test Setup\#11 Dry Zero Air Ran Through Micro MEMS Chiller Unit

\begin{tabular}{|c|c|c|c|}
\hline $\begin{array}{c}\text { Types of Hygrometers } \\
\text { Used at Pre and Post } \\
\text { Chiller }\end{array}$ & $\begin{array}{c}\text { Dew Point } \\
\text { Temperature } \\
\left({ }^{\circ} \mathrm{F}\right)\end{array}$ & $\begin{array}{c}\text { Dry Bulb } \\
\text { Temperature } \\
\left({ }^{\circ} \mathrm{F}\right)\end{array}$ & $\begin{array}{c}\text { Relative } \\
\text { Humidity } \\
(\%)\end{array}$ \\
\hline EdgeTech Pre Chiller & -1.87 & 83.56 & 3.520 \\
\hline Ohmic Post Chiller & 49.34 & 86.90 & 27.49 \\
\hline Ohmic Pre Chiller & -10.48 & 84.96 & 2.22 \\
\hline EdgeTech Post Chiller & 61.48 & 85.52 & 52.73 \\
\hline
\end{tabular}

Table 17 indicates that the pre and post chiller dew point, dry bulb and relative humidity measurements accomplished by EdgeTech DewPrime II and Ohmic AMM-15 hygrometers and then switching them between pre and post chiller positions, show a close agreement on their comparison with each other and were found within in the accuracy limit of both of the hygrometers. Pre and post dew points and relative humidity showed a significant difference between each other and this is an indication that gas dryer unit is performing well under the designed specifications.

\section{Table 17 Test Setup \#12 Dry Zero/Bubbled Air Ran Through Micro MEMS Chiller Unit}

\begin{tabular}{|c|c|c|c|}
\hline $\begin{array}{c}\text { Types of Hygrometers } \\
\text { Used at Pre and Post } \\
\text { Chiller }\end{array}$ & $\begin{array}{c}\text { Dew Point } \\
\text { Temperature } \\
\left({ }^{\circ} \mathrm{F}\right)\end{array}$ & $\begin{array}{c}\text { Dry Bulb } \\
\text { Temperature } \\
\left({ }^{\circ} \mathrm{F}\right)\end{array}$ & $\begin{array}{c}\text { Relative } \\
\text { Humidity } \\
(\%)\end{array}$ \\
\hline EdgeTech Pre Chiller & 67.23 & 83.70 & 57.73 \\
\hline Ohmic Post Chiller & 45.04 & 85.40 & 24.53 \\
\hline Ohmic Pre Chiller & 68.18 & 85.10 & 57.11 \\
\hline EdgeTech Post Chiller & 41.32 & 83.95 & 22.23 \\
\hline
\end{tabular}




\subsubsection{Test Setup\# 13 and 14 Dry Zero and Dry Zero/Bubbled Air Ran Through SEMTECH-D Chiller Unit}

The gas dryer unit in the SEMTECH-D mobile emission measurement system was investigated for its operational effectiveness. Two different experimental setups were devised. In the thirteenth setup, dry zero air was run through the dryer unit and the EdgeTech DewPrime II and Ohmic AMM-15 hygrometers were placed at pre and post chiller operation respectively, recording the dew point, dry bulb and the relative humidity through a data acquisition program. The same set up was repeated by switching the two hygrometers between pre and post chiller operation. The fourteenth set up was accomplished by passing bubbled dry zero air through the dryer unit and placing the EdgeTech DewPrime II and Ohmic AMM-15 hygrometers at the pre and post chiller, respectively. The same setup was repeated again by switching the two hygrometers between pre and post chiller positions and thus data obtained from both of the hygrometers was used to make a comparison of the accuracy of the two meters and same data was used to interpret the drying effectiveness of the chiller unit.

As shown in Table 18, SEMTECH-D chiller proved to be most effective chiller when tested with dry zero air. In first case with EdgeTech DewPrime II at pre and Ohmic AMM-15 at pos chiller operation, SEMTECH-D reduced the pre chiller dew Point from 6 ${ }^{\circ} \mathrm{F}$ to -11.4 and relative humidity from $3.30 \%$ to $2.41 \%$. In the second case with Ohmic AMM-15 at pre and EdgeTech DewPrime II at post chiller position, post chiller dew point and relative humidity were observed to be higher than their pre chiller values. These higher post chiller values might be due to the fact that EdgeTech DewPrime II could not be provided with an additional external cooling of the chilled mirror needed to show accurate readings. 
Table 18 Test set up\#13 Dry zero air ran through SEMTECH-D chiller unit

\begin{tabular}{|c|c|c|c|}
\hline $\begin{array}{c}\text { Types of Hygrometers } \\
\text { Used at Pre and Post } \\
\text { Chiller }\end{array}$ & $\begin{array}{c}\text { Dew Point } \\
\text { Temperature } \\
\left({ }^{\circ} \mathrm{F}\right)\end{array}$ & $\begin{array}{c}\text { Dry Bulb } \\
\text { Temperature } \\
\left({ }^{\circ} \mathrm{F}\right)\end{array}$ & $\begin{array}{c}\text { Relative } \\
\text { Humidity } \\
(\%)\end{array}$ \\
\hline EdgeTech Pre Chiller & -6.00 & 79.2 & 3.30 \\
\hline Ohmic Post Chiller & -11.4 & 81.0 & 2.41 \\
\hline Ohmic Pre Chiller & -22.1 & 81.5 & 1.37 \\
\hline EdgeTech Post Chiller & -3.90 & 80.6 & 3.50 \\
\hline
\end{tabular}

As shown in table 19 , post chiller dew point of $44.3^{\circ} \mathrm{F}$ and $42.3^{\circ} \mathrm{F}$, and relative humidity of $25 \%$ and $24.8 \%$, in both cases of dry zero/bubbled air running through SEMTECH-D chiller, indicate that this chiller performed effectively in reducing the humidity level. Also, the post chiller dew points and relative humidity measured from both hygrometers were found within the accuracy limits of two hygrometers. Dry bulb temperatures recorded by Ohmic AMM-15 regardless of pre or post chiller position were observed to be higher than EdgeTech DewPrime II. This might be caused due to the heating of the temperature sensor embedded inside the Ohmic hygrometer.

Table 19 Test set up\#14 Dry zero /bubbled air ran through SEMTECH-D chiller unit

\begin{tabular}{|c|c|c|c|}
\hline $\begin{array}{c}\text { Types of Hygrometers } \\
\text { Used at Pre and Post } \\
\text { Chiller }\end{array}$ & $\begin{array}{c}\text { Dew Point } \\
\text { Temperature } \\
\left({ }^{\circ} \mathrm{F}\right)\end{array}$ & $\begin{array}{c}\text { Dry Bulb } \\
\text { Temperature } \\
\left({ }^{\circ} \mathrm{F}\right)\end{array}$ & $\begin{array}{c}\text { Relative } \\
\text { Humidity } \\
(\%)\end{array}$ \\
\hline EdgeTech Pre Chiller & 76.2 & 81.9 & 82.9 \\
\hline Ohmic Post Chiller & 44.3 & 83.9 & 25.0 \\
\hline Ohmic Pre Chiller & 80.0 & 83.8 & 88.4 \\
\hline EdgeTech Post Chiller & 42.3 & 81.6 & 24.8 \\
\hline
\end{tabular}




\section{Conclusions and Recommendations}

\subsection{Conclusions}

On the basis of experimental results obtained from six chiller units, it can be concluded from Table 20 that for every chiller unit except for the SEMTECH-D tested with dry zero air, showed higher post chiller dew points and relative humidity then their pre chiller values. The higher post chiller humidity suggested that dry zero air always picks up some moisture whenever it was run through Domnic Hunter CRD5-100, ECP 1000.ECP 2000, MEMS chiller, Micro MEMS chiller unit respectively. SEMTECH-D, being the most efficient chiller, when tested with dry zero air, reduced the dew point to between $-6^{\circ} \mathrm{F}$ to $-11^{\circ} \mathrm{F}$. It is also concluded from Table 20 that generally pre and post chiller dew point and relative humidity measurements, recorded by EdgeTech in comparison to Ohmic hygrometer, are neither in close agreements nor in the accuracy limits of both instruments when measuring low dew points. The reason for this mismatch might be due to the fact that EdgeTech is not very accurate at lower humidity levels without provision of external coolant needed by the chilled mirror to accurately measure the dew points and relative humidity. It is also observed from Table 20 that dry bulb temperature measurement by Ohmic hygrometer in comparison to EdgeTech, regardless of pre or post chiller operation, has a higher value. It is speculated that ambient air temperature and or Ohmic AMM-15 sensor location may have also caused a difference in these readings. The Ohmic AMM-15 sensor was embedded in the instrument and electrical heating from the instrument's electronics may have caused a higher reading than the EdgeTech DewPrime II hygrometer. The Edge Tech has an accuracy of $\pm 0.6^{\circ} \mathrm{F}$ for dew point, dry bulb and $0.5 \%$ for relative humidity, whilst Ohmic dew point meter 
has an accuracy of $\pm 4^{\circ} \mathrm{F}$ for temperature ranging from 20 to $-40^{\circ} \mathrm{F}$ and an accuracy of \pm $2^{\circ} \mathrm{F}$ for temperature ranging from 20 to $80^{\circ} \mathrm{F}$. The dry bulb temperature accuracy for Ohmic hygrometer is $\pm 1 \mathrm{~F}$. Looking towards the accuracy limits of both of these meters it can be followed from Table 21 that pre and post chiller dew points recorded by the EdgeTech and Ohmic hygrometers showed a close agreement on their comparison and were found closely within the accuracy limit of both instruments. Similar to the case of zero air passing through chillers, dry bulb temperature readings from Ohmic hygrometer regardless of pre or post chiller operation were found higher than the EdgeTech. As shown in Figure 20 and also from Table 21, it can also be concluded that whenever dry zero bubbled air was run through chillers, all of the chiller units except ECP 1000 and MEMS thermoelectric chiller, post chiller dew points were observed to be higher than $40^{\circ} \mathrm{F}$. Only ECP 1000 and MEMS chiller units were observed to have post dew points between $35^{\circ} \mathrm{F}$ to $40^{\circ} \mathrm{F}$. Also it an be concluded from the Table 21 that among all of the six chillers tested with dry zero bubbled air, ECP 1000 showed the highest performance by reducing the pre chiller dew point to a post chiller value which corresponds to dew point reduction of $45.20 \%$. MEMS and SEMTECH-D chiller were also observed to have good performance showing a dew point reduction of $43.89 \%$ and $41.86 \%$, respectively. Whenever the dry zero air was bubbled and run through the chillers, the pre and post chiller recorded parameters showed significant differences between each other, suggesting that all of the chillers installed in the emission measurement systems at WVU are performing well under their required specifications and design characteristics. Among all of the chiller and dryer units investigated for their performance, ECP 1000, MEMS chiller and SEMTECH-D chiller units showed high performance by reducing the pre 
chiller dry zero bubbled air dew point temperature to $45.2 \%, 43.89 \%$ and $41.86 \%$ respectively. 
Table 20 Pre and Post Dew Point, Dry Bulb Temperature and Relative Humidity Comparison with Dry Zero Air Running Through the Chillers

\begin{tabular}{|c|c|c|c|c|c|c|c|c|c|c|c|c|}
\hline \multirow{3}{*}{$\begin{array}{c}\text { Type of } \\
\text { Chiller Unit }\end{array}$} & \multicolumn{3}{|c|}{$\begin{array}{c}\text { EdgeTech Pre Chiller } \\
\text { with Dry Zero Air }\end{array}$} & \multicolumn{3}{|c|}{$\begin{array}{l}\text { Ohmic Post Chiller } \\
\text { with Dry Zero Air }\end{array}$} & \multicolumn{3}{|c|}{$\begin{array}{c}\text { Ohmic Pre Chiller with } \\
\text { Dry Zero air }\end{array}$} & \multicolumn{3}{|c|}{$\begin{array}{l}\text { Edge Tech Post Chiller } \\
\text { with Dry Zero Air }\end{array}$} \\
\hline & \begin{tabular}{|c|} 
Dew \\
Point \\
Temp.
\end{tabular} & $\begin{array}{c}\text { Dry } \\
\text { Bulb } \\
\text { Temp. }\end{array}$ & $\begin{array}{l}\text { Relative } \\
\text { Humidity }\end{array}$ & \begin{tabular}{|c|} 
Dew \\
Point \\
Temp.
\end{tabular} & \begin{tabular}{|c|} 
Dry \\
Bulb \\
Temp.
\end{tabular} & $\begin{array}{c}\text { Relative } \\
\text { Humidity }\end{array}$ & \begin{tabular}{|l|} 
Dew \\
Point \\
Temp.
\end{tabular} & $\begin{array}{l}\text { Dry } \\
\text { Bulb } \\
\text { Temp. }\end{array}$ & $\begin{array}{l}\text { Relative } \\
\text { Humidity }\end{array}$ & \begin{tabular}{|c|} 
Dew \\
Point \\
Temp.
\end{tabular} & $\begin{array}{c}\text { Dry } \\
\text { Bulb } \\
\text { Temp. }\end{array}$ & $\begin{array}{l}\text { Relative } \\
\text { Humidity }\end{array}$ \\
\hline & ${ }^{\circ} \mathbf{F}$ & ${ }^{\circ} \mathrm{F}$ & $\%$ & ${ }^{\circ} \mathbf{F}$ & ${ }^{\circ} \mathrm{F}$ & $\%$ & ${ }^{\circ} \mathbf{F}$ & ${ }^{\circ} \mathrm{F}$ & $\%$ & ${ }^{\circ} \mathbf{F}$ & ${ }^{\circ} \mathrm{F}$ & $\%$ \\
\hline $\begin{array}{l}\text { Domnic } \\
\text { Hunter }\end{array}$ & -5.4 & 83.30 & 3.0 & 43.45 & 85.60 & 22.90 & -4.730 & 85.40 & 2.91 & 39.97 & 85.60 & 21.72 \\
\hline ECP 1000 & -10.42 & 70.20 & 3.59 & 36.18 & 73.90 & 25.32 & -17.30 & 73.70 & 2.28 & 34.52 & 70.50 & 26.53 \\
\hline ECP 2000 & -10.81 & 72.50 & 3.31 & 31.79 & 73.90 & 21.27 & -35.63 & 75.10 & 0.81 & 4.20 & 73.61 & 6.89 \\
\hline $\begin{array}{l}\text { Mems } \\
\text { Chiller }\end{array}$ & 0.15 & 86.20 & 3.60 & 3.660 & 88.30 & 3.94 & -14.20 & 88.60 & 1.64 & 0.14 & 86.20 & 3.57 \\
\hline $\begin{array}{l}\text { Micro } \\
\text { Mems } \\
\text { Chiller }\end{array}$ & -1.87 & 83.60 & 3.52 & 49.34 & 86.90 & 27.49 & -10.48 & 85.00 & 2.22 & 61.48 & 85.52 & 52.73 \\
\hline $\begin{array}{l}\text { SEMTECH- } \\
\text { D chiller }\end{array}$ & -6.0 & 79.20 & 3.30 & -11.40 & 81.00 & 2.41 & -22.10 & 81.50 & 1.37 & -3.90 & 80.60 & 3.50 \\
\hline
\end{tabular}


Table 21 Pre and Post Dew Point, Dry Bulb and Relative Humidity Comparison with Dry Zero/Bubbled Air Running Through the Chillers.

\begin{tabular}{|c|c|c|c|c|c|c|c|c|c|c|c|c|}
\hline \multirow{3}{*}{$\begin{array}{c}\text { Type of Chiller } \\
\text { Unit }\end{array}$} & \multicolumn{3}{|c|}{$\begin{array}{c}\text { Edge Tech Pre Chiller } \\
\text { with Dry Zero and } \\
\text { Bubbled Air }\end{array}$} & \multicolumn{3}{|c|}{$\begin{array}{c}\text { Ohmic Post Chiller } \\
\text { with Dry Zero and } \\
\text { Bubbled Air } \\
\end{array}$} & \multicolumn{3}{|c|}{$\begin{array}{c}\text { Ohmic Pre Chiller } \\
\text { with Dry Zero and } \\
\text { Bubbled Air } \\
\end{array}$} & \multicolumn{3}{|c|}{$\begin{array}{c}\text { Edge Tech Post Chiller } \\
\text { with Dry Zero and } \\
\text { Bubbled Air } \\
\end{array}$} \\
\hline & $\begin{array}{l}\text { Dew } \\
\text { Point } \\
\text { Temp. }\end{array}$ & $\begin{array}{c}\text { Dry } \\
\text { Bulb } \\
\text { Temp. }\end{array}$ & $\begin{array}{l}\text { Relative } \\
\text { Humidity }\end{array}$ & $\begin{array}{l}\text { Dew } \\
\text { Point } \\
\text { Temp. }\end{array}$ & $\begin{array}{l}\text { Dry } \\
\text { Bulb } \\
\text { Temp }\end{array}$ & $\begin{array}{l}\text { Relative } \\
\text { Humidity }\end{array}$ & $\begin{array}{l}\text { Dew } \\
\text { Point } \\
\text { Temp. }\end{array}$ & $\begin{array}{l}\text { Dry } \\
\text { Bulb } \\
\text { Temp. }\end{array}$ & $\begin{array}{l}\text { Relative } \\
\text { Humidity }\end{array}$ & $\begin{array}{l}\text { Dew } \\
\text { Point } \\
\text { Temp. }\end{array}$ & $\begin{array}{l}\text { Dry } \\
\text { Bulb } \\
\text { Temp }\end{array}$ & $\begin{array}{l}\text { Relative } \\
\text { Humidity }\end{array}$ \\
\hline & ${ }^{\circ} \mathbf{F}$ & ${ }^{\circ} \mathrm{F}$ & $\%$ & ${ }^{\circ} \mathbf{F}$ & ${ }^{\circ} \mathrm{F}$ & $\%$ & ${ }^{\circ} \mathbf{F}$ & ${ }^{\circ} \mathrm{F}$ & $\%$ & ${ }^{\circ} \mathbf{F}$ & ${ }^{\circ} \mathrm{F}$ & $\%$ \\
\hline Domnic Hunter & 61.58 & 83.20 & 48.07 & 43.64 & 85.60 & 23.1 & 59.83 & 85.20 & 42.52 & 41.9 & 85.6 & 23.73 \\
\hline ECP 1000 & 64.84 & 70.80 & 81.41 & 35.53 & 72.95 & 25.48 & 67.77 & 72.69 & 84.59 & 34.4 & 70.4 & 26.57 \\
\hline ECP 2000 & 67.81 & 75.80 & 76.43 & 43.40 & 77.43 & 29.84 & 72.29 & 77.20 & 84.89 & 44.3 & 75.3 & 33.17 \\
\hline Mems Chiller & 66.39 & 85.80 & 52.43 & 37.25 & 87.43 & 17.01 & 68.56 & 87.7 & 53.27 & 33.5 & 86.1 & 15.25 \\
\hline $\begin{array}{l}\text { Micro Mems } \\
\text { Chiller }\end{array}$ & 67.23 & 83.70 & 57.74 & 45.04 & 85.40 & 24.53 & 68.18 & 85.1 & 57.11 & 41.3 & 84 & 22.23 \\
\hline $\begin{array}{l}\text { SEMTECH-D } \\
\text { chiller }\end{array}$ & 76.20 & 81.90 & 82.90 & 44.30 & 83.90 & 25.02 & 80.00 & 83.8 & 88.43 & 42.3 & 81.6 & 24.8 \\
\hline
\end{tabular}


Figure 20 Pre and Post Dew Point Comparison with Dry Zero/Bubbled Air running Through Chillers

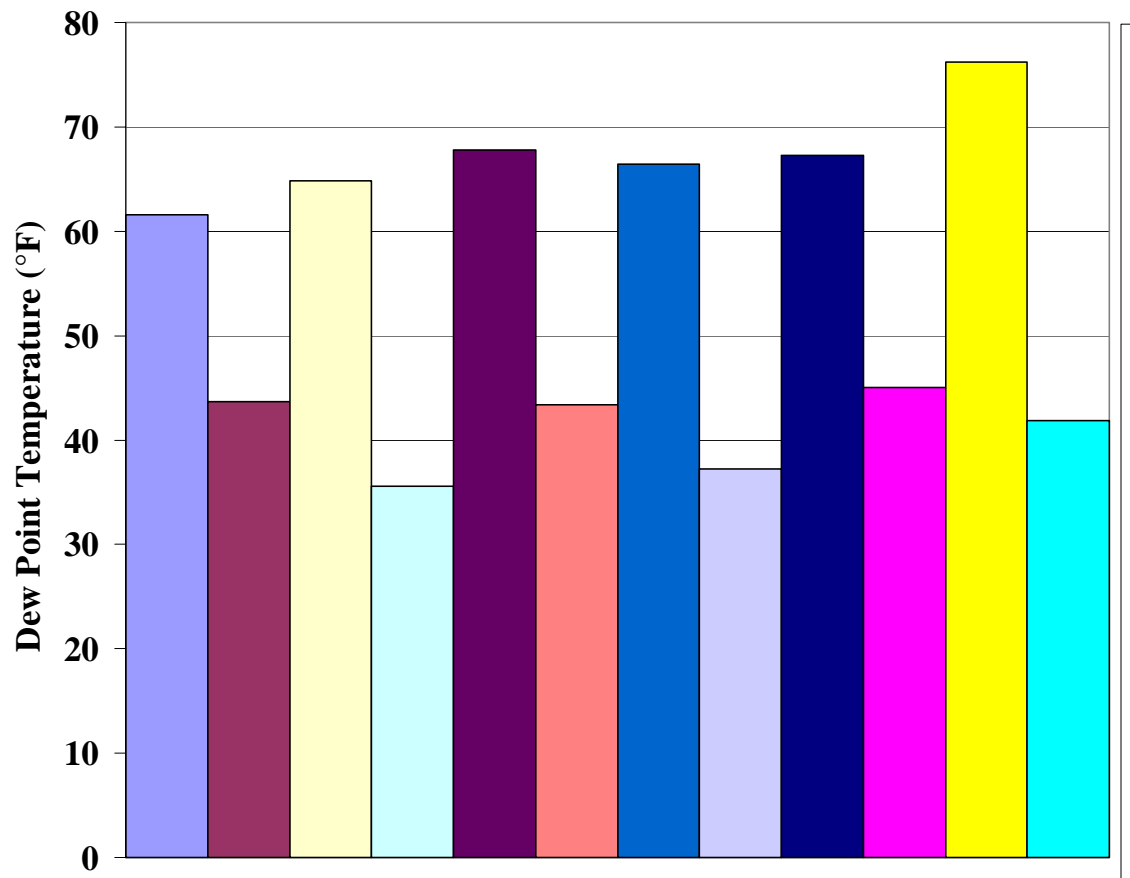

EdgeTEch Pre

Domnic Hunter

$\square$ Ohmic Post Domnic

HUnter

$\square$ EdgeTech Pre ECP

1000

$\square$ Ohmic Post ECP 1000

EdgeTech Pre ECP

2000

$\square$ Ohmic Post ECP 2000

EdgeTech Pre MEMS

Chiller

$\square$ Ohmic Post MEMS

Chiller

EdgeTech Pre Micro

MEMS Chiller

$\square$ Ohmic Post Micro

MEMS Chiller

$\square$ EdgeTech Pre

SEMTECH Chiller

$\square$ Ohmic Post

SEMTECH Chiller

Table 22 Dew Point Reductions for Dry Zero and Bubbled Air Passing Through Chillers

\begin{tabular}{|c|c|c|c|}
\hline \multirow[t]{2}{*}{$\begin{array}{c}\text { Types of } \\
\text { Chiller Units }\end{array}$} & $\begin{array}{c}\text { EdgeTech } \\
\text { Pre Chiller } \\
\text { with Dry } \\
\text { Zero/Bubbled } \\
\text { Air }\end{array}$ & $\begin{array}{c}\text { Ohmic Post } \\
\text { Chiller with } \\
\text { Dry } \\
\text { Zero/Bubbled } \\
\text { Air }\end{array}$ & $\begin{array}{c}\text { Dew } \\
\text { Point } \\
\text { Reduction }\end{array}$ \\
\hline & $\begin{array}{l}\text { Dew point } \\
\text { temp }\left({ }^{\circ} \mathrm{F}\right)\end{array}$ & $\begin{array}{l}\text { Dew point } \\
\text { temp }\left({ }^{\circ} \mathrm{F}\right)\end{array}$ & $\%$ \\
\hline $\begin{array}{l}\text { Domnic } \\
\text { Hunter }\end{array}$ & 61.58 & 43.64 & 29.13 \\
\hline ECP 1000 & 64.84 & 35.53 & 45.20 \\
\hline ECP 2000 & 67.81 & 43.40 & 36.00 \\
\hline MEMS Chiller & 66.39 & 37.25 & 43.89 \\
\hline $\begin{array}{l}\text { Micro MEMS } \\
\text { Chiller }\end{array}$ & 67.23 & 45.04 & 33.01 \\
\hline $\begin{array}{l}\text { SEMTECH-D } \\
\text { chiller }\end{array}$ & 76.20 & 44.30 & 41.86 \\
\hline
\end{tabular}




\subsection{Recommendations}

The future efforts suggested by the results of this study focus on humidity measurements during actual emissions testing. Ohmic AMM-15 in comparison to EdgeTech DewPrime II found to be lighter in wait, smaller in size, portable, less expensive, and accurate at both low and high levels of humidity. A better option could be having two portable Ohmic AMM-15 installed at pre and post chiller operation and record the data during actual emissions testing. 


\section{References}

1. Emissions Standards: USA - Heavy Duty Truck and Bus Engines, www.dieselnet.com, EcoPoint Inc., May 2005.

2. Frey, H. C., Unal, A., Rouphall, N. M., and Colyar, J. D., "On-Road Measurement of Vehicle Tailpipe Emissions Using a Portable Instrument," Journal of the Air \& Waste Management Association, Volume 53, 992-1002, August, 2003.

3. Gautam, M., Clark, N. N., Thompson, G. J., Carder, D. K., and Lyons, D. W. (2000), "Evaluation of Mobile Monitoring Technologies for Heavy-Duty Diesel- Powered Emissions," Phase I Report, Submitted to the Settling Heavy-Duty Diesel Engine Manufacturers by West Virginia University, Morgantown, WV, March 2000.

4. Scarbro, C., "An Investigation of Rover's Capabilities to Accurately Measure the In-use Activity and Emissions of Late-Model Diesel and Gasoline Trucks," Proceedings of the 10th CRC On-Road Vehicle Emissions Workshop, San Diego, CA; Coordinating Research Council: Atlanta, GA, 2000.

5. Reading, A., "Technical Advances in Portable Emission Measurement Systems," Proceedings of the Government/Industry Meeting, Washington D.C., May 12-14, 2003.

6. Nakamura, H., Kihara, H., Adachi, M., and Ishida, K., "Development of a Wet-Based NDIR and Its Application to On-Board Emission Measurement System," SAE Technical Paper No. 2002-01-0612, 2002.

7. Kihara, N., Tsukamoto, T., Matsumoto, K., Ishida, K., Kon, M., and Murase, T., "Real-Time, On-Board Measurement of Mass Emission of NOx, Consumption, Road Load, and Engine Output for Diesel Vehicles," SAE Technical Paper No. 2000-01$1141,2000$.

8. Branstetter, R., Burrahm, R., and Dietzmann, H., "Relationship of Underground Diesel Engine Maintenance to Emissions," Final Report for 1978 to 1983 to the U.S. Bureau of Mines, Department of Interior Contract H0292009, 1983.

9. Chan, L., Carlson, D. H., and Johnson, J. H., "Evaluation and Application of a Portable Tailpipe Emissions Measurement Apparatus for Field Use," SAE Technical Paper No. 921647, 1992.

10. Spears, M. W., "An Emissions-Assisted Maintenance Procedure for Diesel-Powered Equipment," University of Minnesota, Center for Diesel Research, Minneapolis, MN, 1997.

11. Englund, M. S., "Field Compatible NOx Emission Measurement Technique," SAE Technical Paper No. 820647, 1982. 
12. Human, D. M. and Ullman, T. L., "Development of an I/M Short Emissions Test for Buses," SAE Technical Paper No. 920727, 1992.

13. Kelly, N. A. and Groblicki, P. J., "Real-world Emissions from a Modern Production Vehicle Driven in Los Angeles," Journal of the Air \& Waste Management Association, Volume 43, 1351-1357, July, 1993.

14. Butler, J. W., Gierczak, C. A., Jesion, G., Stedman, D. H., and Lesko, J. M., “OnRoad NOx Emissions Intercomparison of On-Board Measurements and Remote Sensing," Final Report, Coordinating Research Council, Inc., Atlanta, GA, CRC Report No. VE-11-6, 1994.

15. Bentz, A. P. and Weaver, E., "Marine Diesel Exhaust Emissions Measured By Portable Instruments,” SAE Technical Paper No. 941784, 1994.

16. Vojtisek-Lom, M. and Cobb, J. T., "Measuring On-Road Heavy-Duty Vehicle Emissions using a Portable On-Board System," Proceedings of the Ninth CRC OnRoad Vehicle Workshop, April 19-21, San Diego, CA, 1999.

17. Vojtisek-Lom, M. and Cobb, J. T., "On-Road Light-Duty Vehicle Mass Emission Measurements using a Novel Inexpensive On-Board Portable System," Proceedings of the Ninth CRC On-Road Vehicle Workshop, April 20-22, San Diego, CA, 1998.

18. Bruneel, H., "Heavy Duty Testing Cycles Development: a New Methodology," SAE Technical Paper No. 2000-01-1860, 2000.

19. "Construction Equipment Retrofit Project," Northeast States for Coordinated Air Use Management, Boston, MA, 1998.

20. Butler, J. W., Korniski, T. J., Reading, A. R., and Kotenko, T. L., "Dynamometer Quality Data On-board Vehicles for Real-World Emission Measurements," Proceedings of the Ninth CRC On-Road Vehicle Workshop, April 19-21, San Diego, CA, 1999.

21. Jetter, J., Maeshiro, S., Hatcho, S., and Klebba, R., "Development of an On-Board Analyzer for Use on Advanced Low Emission Vehicles," SAE Technical Paper No. 2000-01-1140, 2000.

22. Pankratz, D., Johnson, K.C, Smith, M.R, Welch, W.A., and Norbeck, J.M, “Develop On-Road System for Emissions Measurement from Heavy-Duty Trucks," Final Report submitted to South Coast Air Quality Management District, Diamond Bar, CA, May 31, 2001. 
23. Miller, J. W., Cocker, D., Johnson, K.C., Park, C. S., Welch, W. A., and Norbeck, J. M., "Use of a Mobile Laboratory to Measure HDD Real World Emissions from a Number of Standard and Non-Standard Cycles," Proceeding of the 12th CRC OnRoad Vehicle Emissions Workshop, San Diego, CA, April 15-17, 2002.

24. Thompson, G., Gautam, M., Clark, N., Carder, D. K., Riddle, W., Shade, B., and Lyons, D., "Measurement of In-Use, On-Board Emissions From Heavy-Duty Diesel Vehicles: Mobile Emissions Measurement System," SAE Technical Paper No. 200101-3643, 2001.

25. Czachura, B., Brandon, L., and May, A., "Demonstration of the "Simple, Portable, On-Vehicle Testing. (SPOT) System on a Class 8 Vehicle," Proceedings of the 11th On- road Vehicle Emissions Workshop, San Diego, CA, 2001.

26. Jimenez, J. L., Mcrae, G. J., Nelson, D. D., Zahniser, M. S., and Kolb, C. E., “ Final Report: Remote Sensing of $\mathrm{NO}$ and $\mathrm{NO}_{2}$ Emissions from Heavy-Duty Diesel Trucks Using Tunable Diode Lasers," National Center for Environmental Research, EPA Grant No. R824794, 1998.

27. Jahnke, J. A., Continuous Emission Monitoring, Van Nostrand Reinhold, New York, 1993.

28. Bata, R., Clark, N. N., Lyons, D. W., Palmer, G. M., Long, T. R., Howell, A., Loth, J., Rapp, B.L. and Wang, W., "The First Transportable Heavy Duty vehicle Emissions Testing Laboratory," 1991 SAE Transactions: Journal of Commercial Vehicles, Volume 100, 37-43, November, 1991.

29. Gautam, M., Clark, N. N., Thompson, G. J., and Lyons, D. W., "Assessment of Mobile Monitoring Technologies for Heavy-Duty Vehicle Emissions," Department of Mechanical and Aerospace Engineering, West Virginia University, Morgantown, WV, 1999.

30. Instruction Manual - MEXA-120 NOx Analyzer, Horiba, Ltd. First edition, Version 1.0, September, 1998, Kyoto, Japan.

31. Nitric Oxide Sensor - Operating Instructions, City Technology Ltd., Portsmouth, UK, 1999.

32. Instruction Manual-EdgeTech DewPrime II Hygrometer, Model 2000 Series DewPrime Dew Point Hygrometers, Mahtomedi, Minnesota, 2004.

33. Instruction Manual-Ohmic AMM-15 Hygrometer, Ohmic Instrument Corporation, September, 2003, Easton, Maryland.

34. Instruction Manual -Electric Gas Cooler Series ECP, Analysentechnik mit System, Version ECP 1000/2000/3000, July 2002, Ratingen, Germany. 
35. User Manual-CRD5-100 (60 Hz) Refrigeration Dryer, Domnic Hunter Ltd. Issue 2, June 2002.

36. Hearne, J. S., "School Bus Idling and Mobile Diesel Emissions Testing: Effect of Fuel Type and Development of a Mobile Test Cycle," M.S Thesis, Department of Mechanical Engineering, Rowan University, Glassboro, NJ, 2003 